\title{
Modular Total Synthesis of Farnesyl Analogues of Cell Wall Precursors Lipid I and II Containing the Staphylococcus aureus Pentaglycine Bridge Modification
}

Lukas M. Wingen ${ }^{\mathrm{a}}$, Marvin Rausch ${ }^{\mathrm{b}, \mathrm{c}}$, Tanja Schneider $^{\mathrm{b}}$, and Dirk Menche ${ }^{\mathrm{a} *}$

aKekulé Institute of Organic Chemistry and Biochemistry, University of Bonn, 53121 Bonn, Germany, bInstitute for Pharmaceutical Microbiology, University Clinic Bonn, University of Bonn, 53115 Bonn, Germany. ' German Center for Infection Research (DZIF), partner site Bonn-Cologne, 53127 Bonn, Germany.

dirk.menche@uni-bonn.de 


\section{Table of Contents}

1. Optimized Synthesis of Carbohydrate Fragment $6 \quad$ S3

2. Copies of NMR Spectra S5 


\section{Optimized Synthesis of Carbohydrate Fragment 6}

Scheme S1. Synthesis of the carbohydrate building block 6

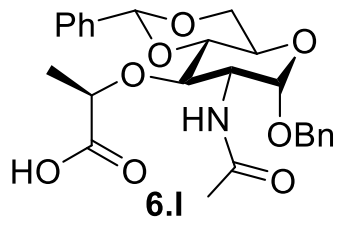<smiles>OCC(Cl)(Cl)Cl</smiles>

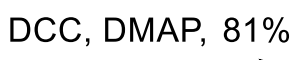

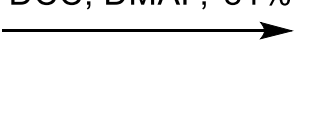

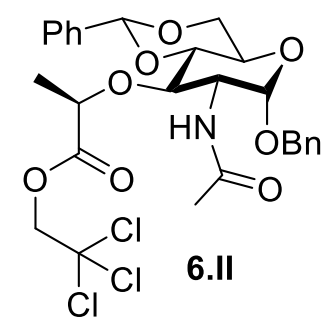

1. $10 \% \mathrm{Pd}-\mathrm{C}, \mathrm{H}_{2}$

2. Benzaldehyde dimethylacetal, $p-\mathrm{TsOH}$ 96\% (2 steps)

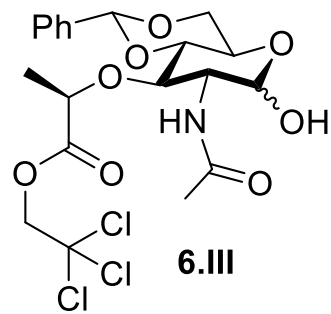

1. $1 \mathrm{H}$-tetrazole, ${ }^{i} \mathrm{Pr}_{2} \mathrm{NP}(\mathrm{OBn})_{2}$

2. $m \mathrm{CPBA}$ $79 \%$ (2 steps)

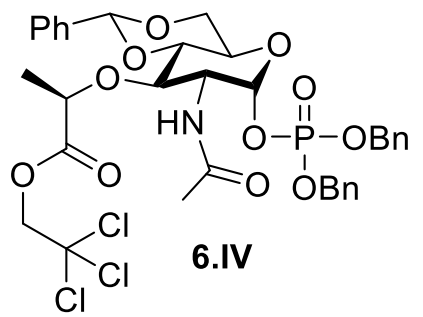

$\mathrm{Zn}, \mathrm{AcOH}$ $97 \%$

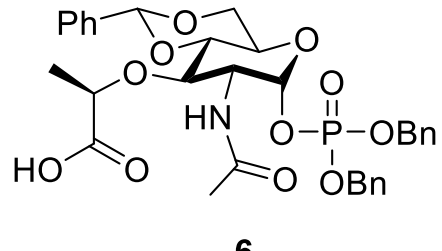

6

Carbohydrate 6: To a solution of acid $6.1(1.00 \mathrm{~g}, 2.12 \mathrm{mmol})$ and 4-(dimethylamino)-pyridin (DMAP) $(25.9 \mathrm{mg}, 212 \mu \mathrm{mol})$ in THF $(16 \mathrm{~mL})$ was added 2,2,2-trichloroethanol $(0.48 \mathrm{~mL}$, $4.24 \mathrm{mmol}$ ) followed by $N, N^{\prime}$-dicyclohexylcarbodiimide (656 mg, $3.18 \mathrm{mmol}$ ). After stirring for $5 \mathrm{~h}$ at $\mathrm{rt}$ the mixture was filtered through a cotton plug and the precipitate was washed with EtOAc $(2 \times 20 \mathrm{~mL})$. The solvent was removed under reduced pressure and the crude product was purified by flash chromatography $\left(15 \% \mathrm{EtOAc} / \mathrm{CH}_{2} \mathrm{Cl}_{2}\right)$ to yield 6. .I $(1.03 \mathrm{~g}, 1.71 \mathrm{mmol}, 81 \%)$ as a colorless solid.

To a solution of protected carbohydrate 6.11 (500 mg, $829 \mu \mathrm{mol})$ in EtOAc $(40 \mathrm{~mL})$ was added $\mathrm{Pd}-\mathrm{C}(650 \mathrm{mg}, 10 \% \mathrm{Pd})$. The reaction vessel was filled with hydrogen. After stirring for $20 \mathrm{~min}$ at $r$ the suspension was filtered through celite and the precipitate was washed with methanol $(2 \times 20 \mathrm{~mL})$. The solvent was removed under reduced pressure and acetonitrile $(30 \mathrm{~mL})$ was added followed by benzaldehyde dimethyl acetal (187 $\mu \mathrm{L}, 1.24 \mathrm{mmol})$ and a solution of $p$ $\mathrm{TsOH}$ in acetonitrile ( $1 \mathrm{~mL}$ of a $232 \mathrm{mM}$ solution, $232 \mu \mathrm{mol}$ ) dried over $3 \AA$ MS. After stirring for $4 \mathrm{~h}$ at $\mathrm{rt}$ the reaction was neutralized with $\mathrm{NEt}_{3}$ and the solvent was removed under reduced pressure. The crude product was purified by flash chromatography $190 \%$ EtOAc/cyclohexane) to yield 6.III (409 mg, $798 \mu \mathrm{mol}, 96 \%$ ) as a colorless solid and as a mixture of $\alpha$ and $\beta$ anomers (ratio $\alpha: \beta=4: 1$ ). The mixture was used for the next reactions without separation. 
Alcohol 6.III (100 mg, $195 \mu \mathrm{mol})$ was dissolved in dry $\mathrm{CH}_{2} \mathrm{Cl}_{2}(5 \mathrm{~mL})$ and a $0.45 \mathrm{M}$ solution of $1 \mathrm{H}$-tetrazole in acetonitrile $(1.63 \mathrm{~mL}, 731 \mu \mathrm{mol})$ was added. The reaction was cooled to $-40{ }^{\circ} \mathrm{C}$ and dibenzyl( $N, N$-diisopropyl)phosphoramidite $(164 \mu \mathrm{L}, 488 \mu \mathrm{mol})$ was added. After $1 \mathrm{~h}$ warming to $r t$ the reaction was stirred for another hour. Then, $m$ CPBA (101 mg, $585 \mu \mathrm{mol})$ was added at $-60{ }^{\circ} \mathrm{C}$ and the reaction was stirred for $30 \mathrm{~min}$ at $0{ }^{\circ} \mathrm{C}$ followed by $30 \mathrm{~min}$ stirring at rt. The mixture was diluted with $5 \mathrm{~mL} \mathrm{CH} \mathrm{Cl}_{2}$ and washed two times with aq. $\mathrm{Na}_{2} \mathrm{SO}_{3}(10 \mathrm{~mL}$, $10 \%)$, two times with aq. sat. $\mathrm{NaHCO}_{3}(10 \mathrm{~mL})$ and two times with water $(10 \mathrm{~mL})$. After drying over $\mathrm{MgSO}_{4}$ the mixture was filtered, concentrated and purified by flash chromatography (65\% EtOAc/cyclohexane) to yield 6.IV (101 mg, 79\%, $585 \mu \mathrm{mol})$ as a colorless solid.

Carbohydrate 6.IV (160 mg, $207 \mu \mathrm{mol}$ ) was dissolved in a mixture of 90\% $\mathrm{AcOH} /$ water $(15 \mathrm{~mL})$ and zinc powder (120 mg, $1.84 \mathrm{mmol}$ ) was added. The suspension was stirred vigorously for $3 \mathrm{~h}$ at $\mathrm{rt}$. After filtering and washing with $\mathrm{MeOH}$ the solvent was removed under reduced pressure and the crude product was purified by flash chromatography $(0.1 \% \mathrm{AcOH} / 10 \%$ $\left.\mathrm{MeOH} / \mathrm{CH}_{2} \mathrm{Cl}_{2}\right)$ to yield carbohydrate $6(129 \mathrm{mg}, 201 \mu \mathrm{mol} 97 \%)$ as a colorless solid. The spectroscopic data were in agreement with those previously reported. ${ }^{1}$

(1) Ha, S.; Chang, E.; Lo, M.; Men, H.; Park, P.; Ge, M.; Walker, S. The Kinetic Characterization of Escherichia coli MurG Using Synthetic Substrate Analogues. J. Am. Chem. Soc. 1999, 121, 8415-8426. 


\section{Copies of NMR Spectra}



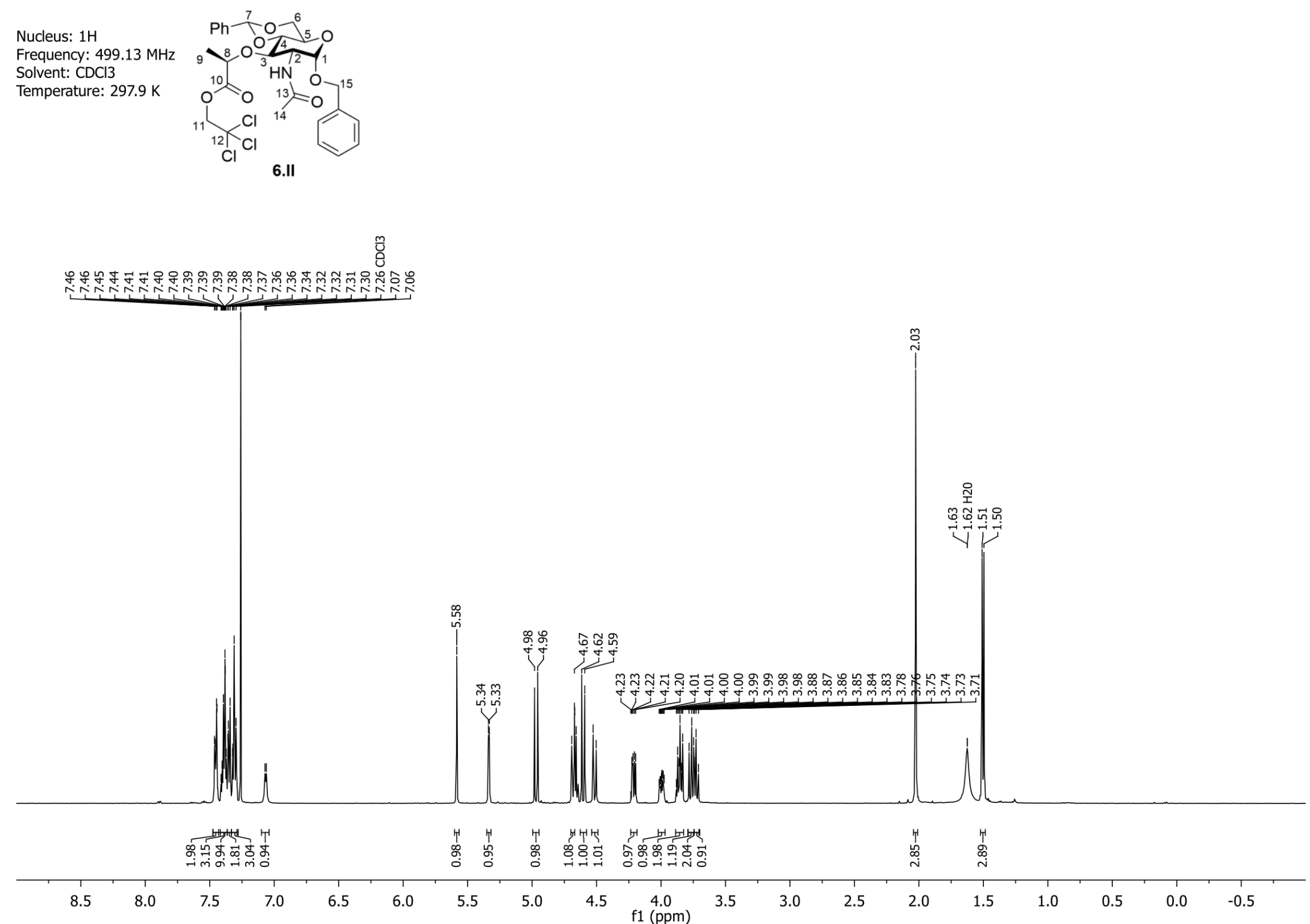

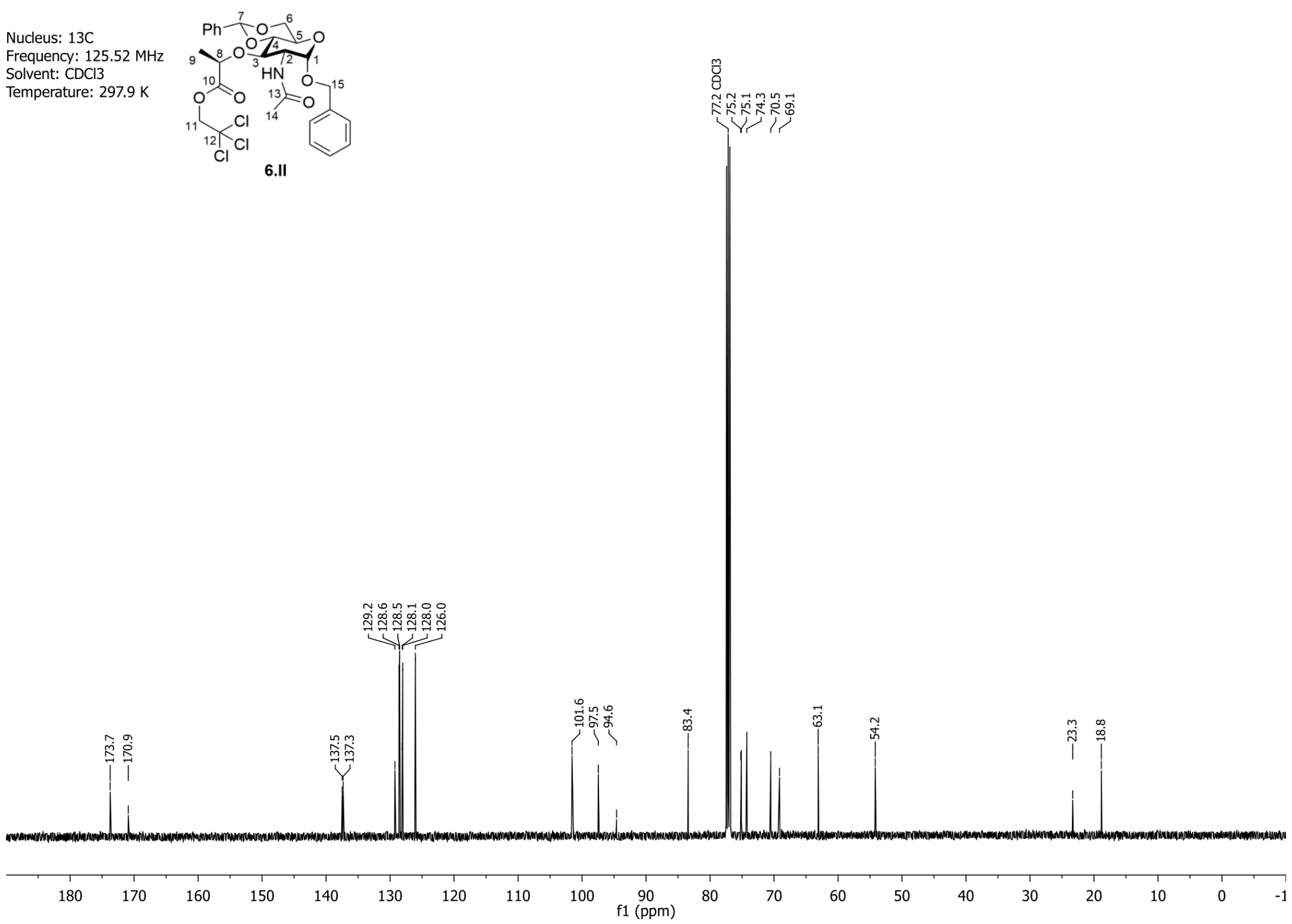

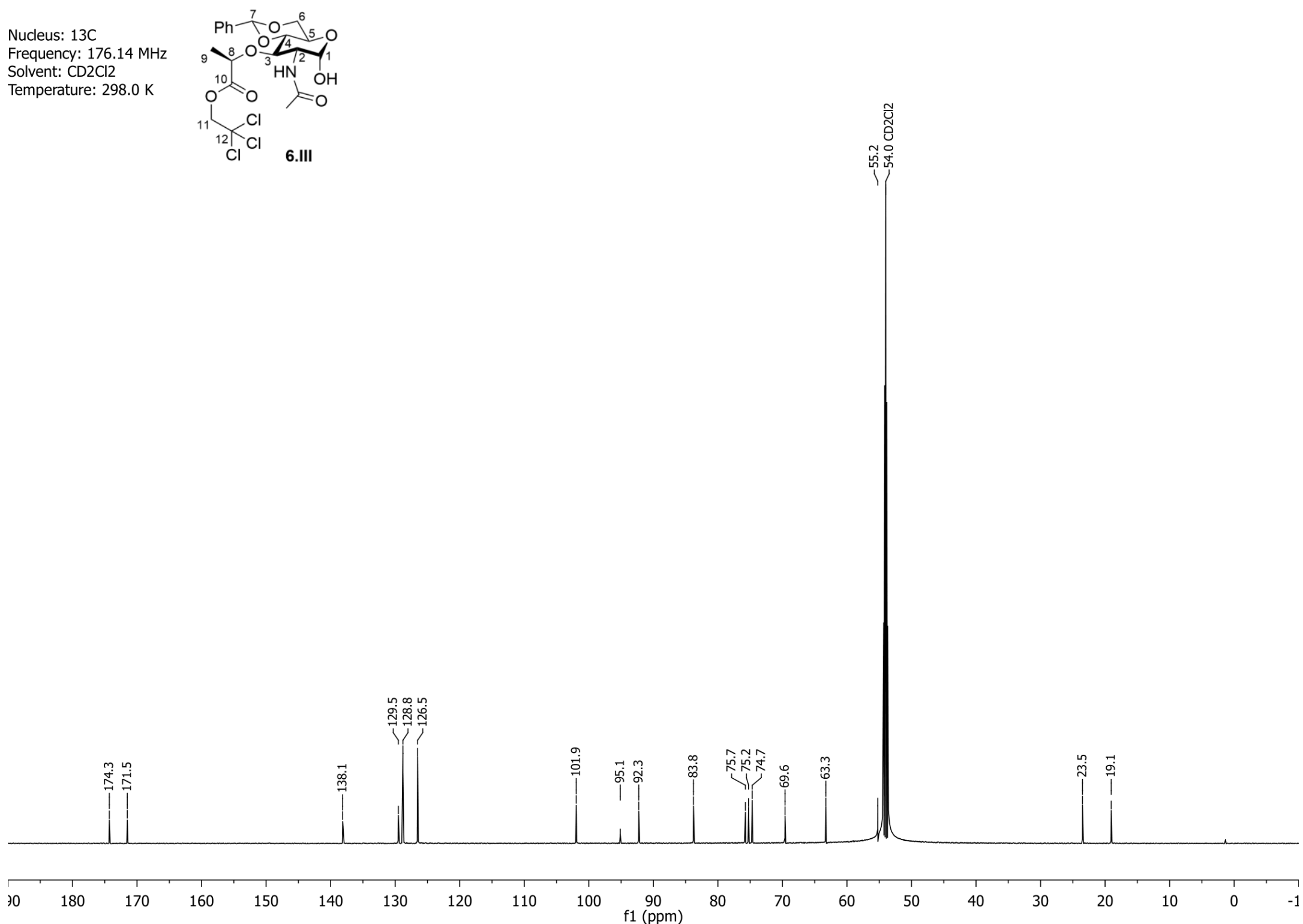

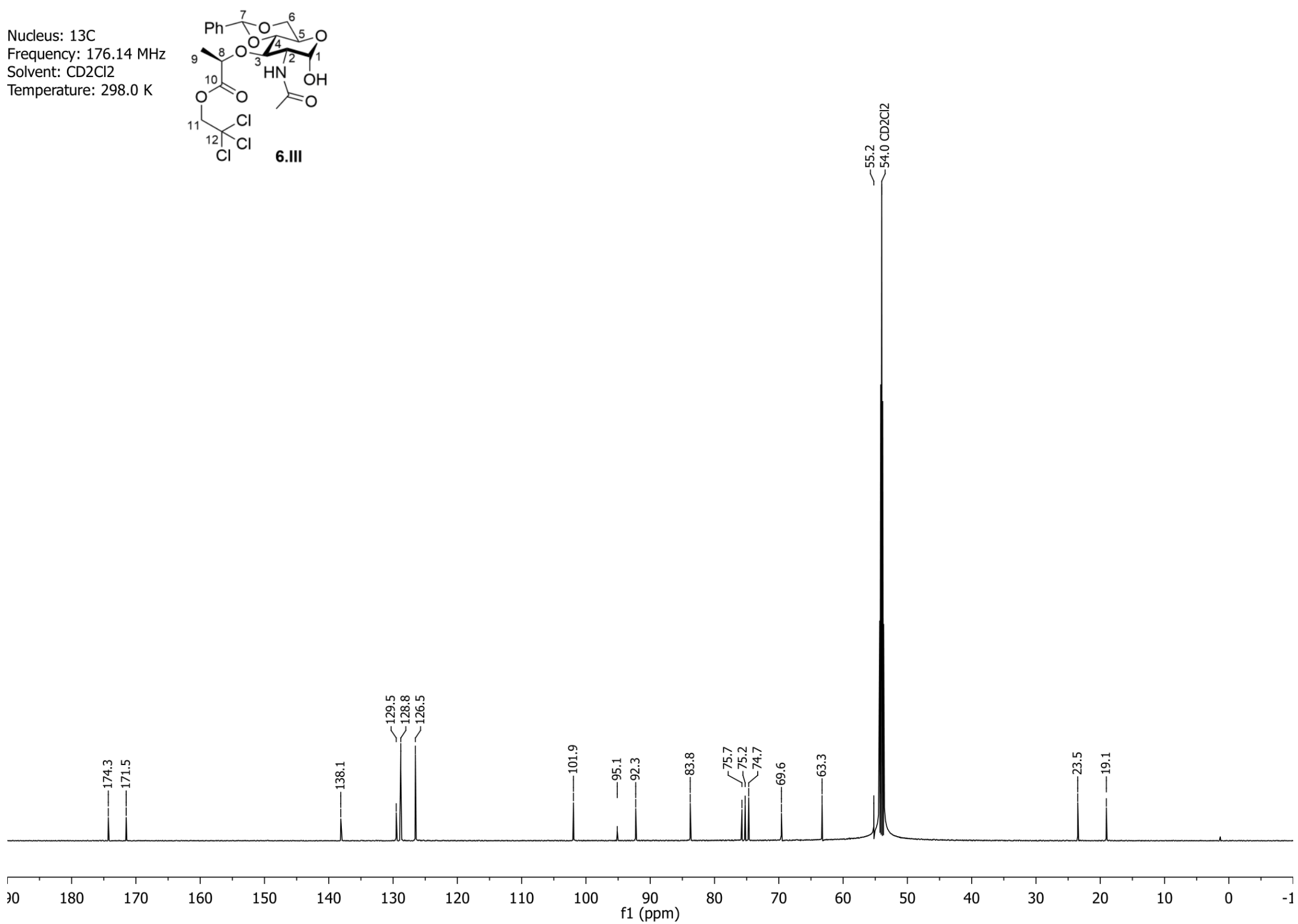


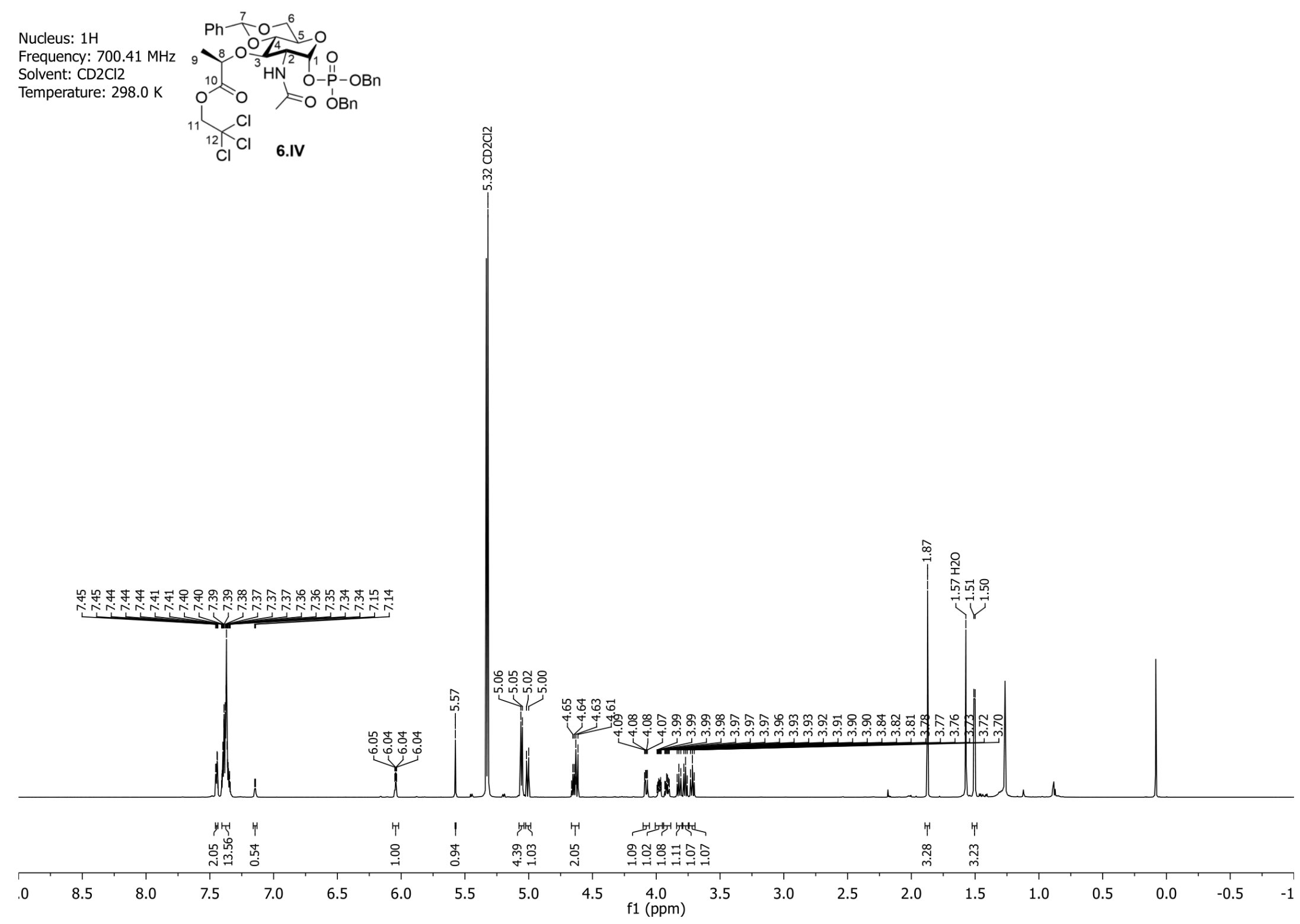



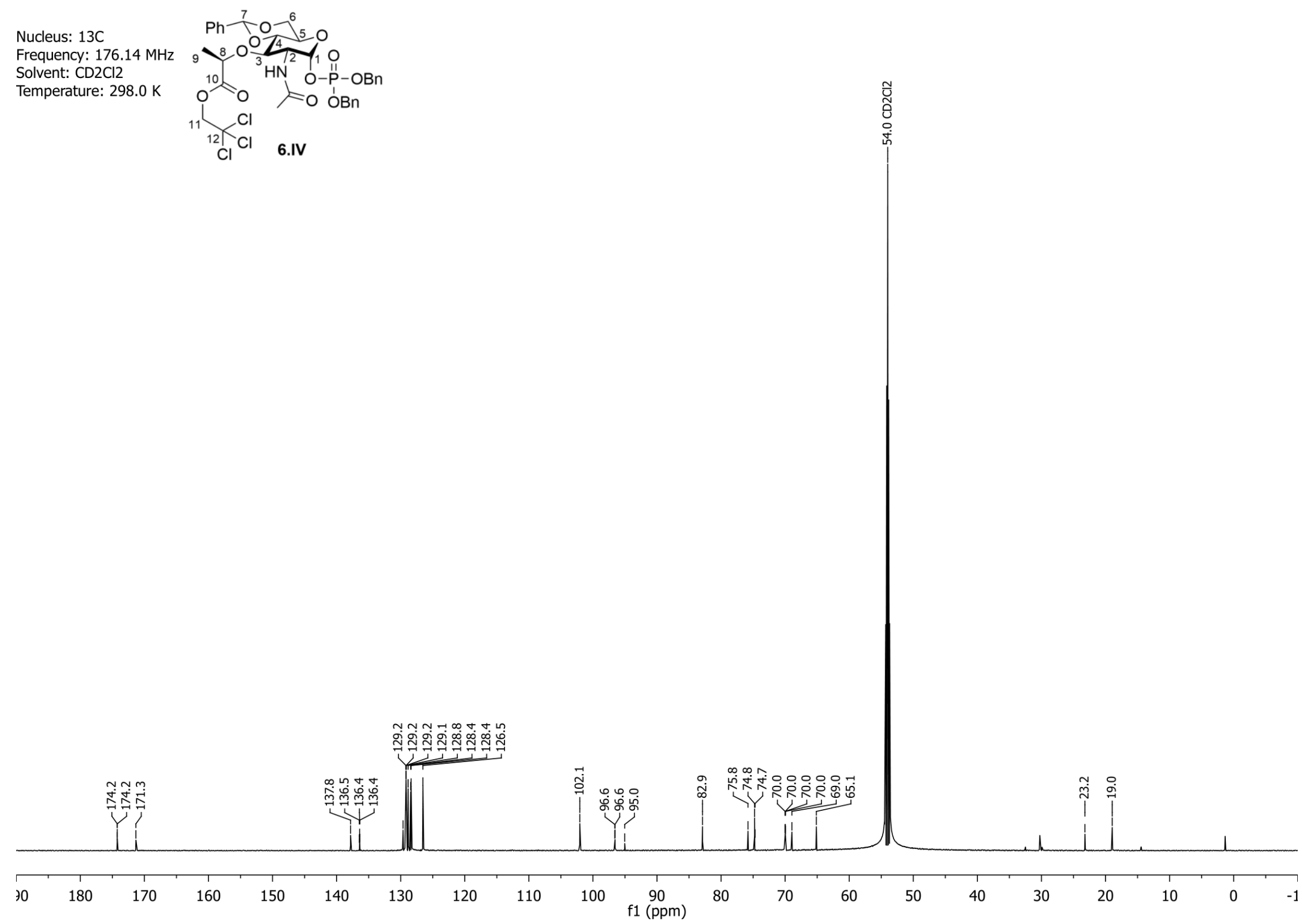
$\begin{array}{llll}\text { Nucleus: } 31 \mathrm{P} & \\ \text { Frequency: } 283.52 \mathrm{MHz} \\ \text { Solvent: } \mathrm{CD} 2 \mathrm{Cl} 2 \\ \text { Temperature: } 298.0 \mathrm{~K}\end{array}$

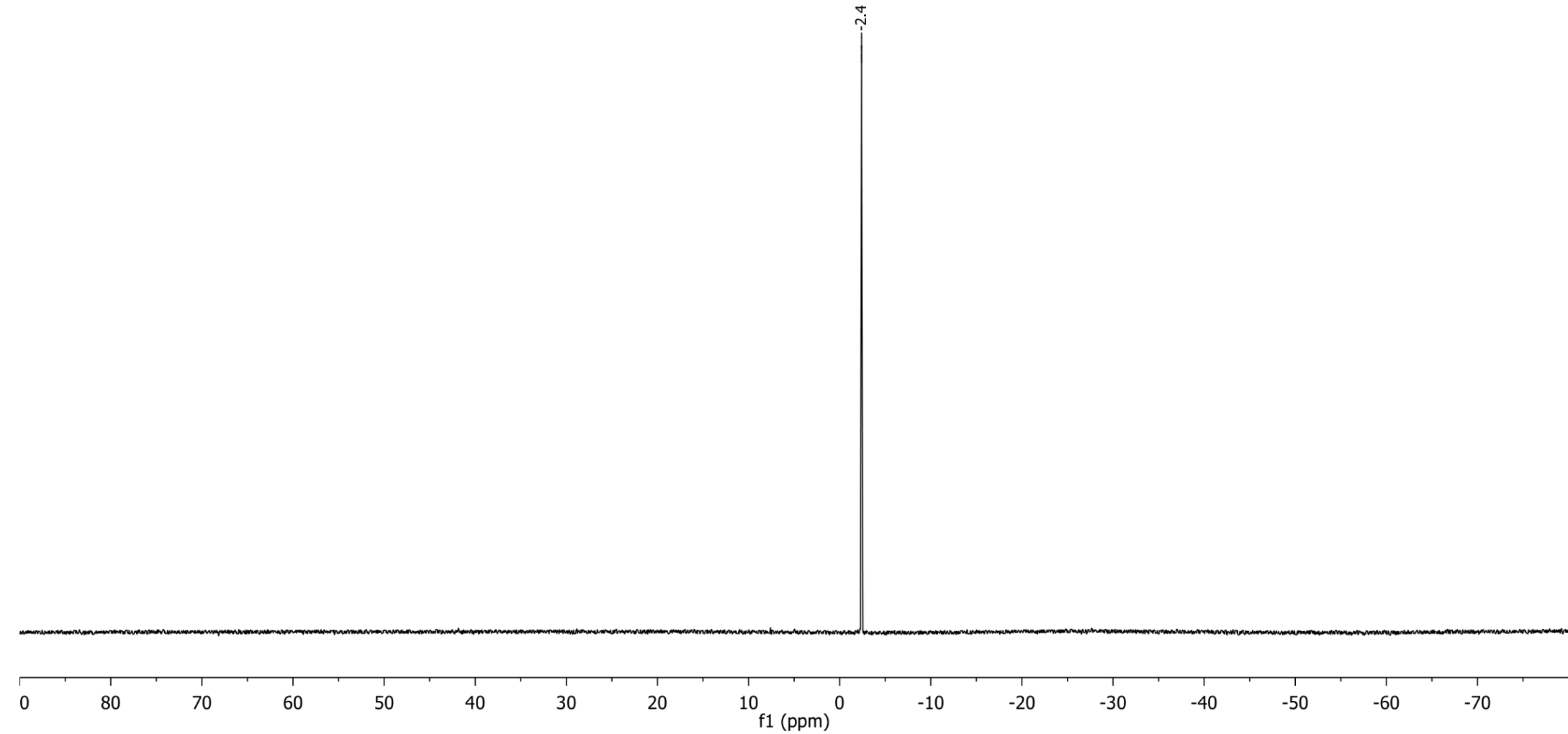



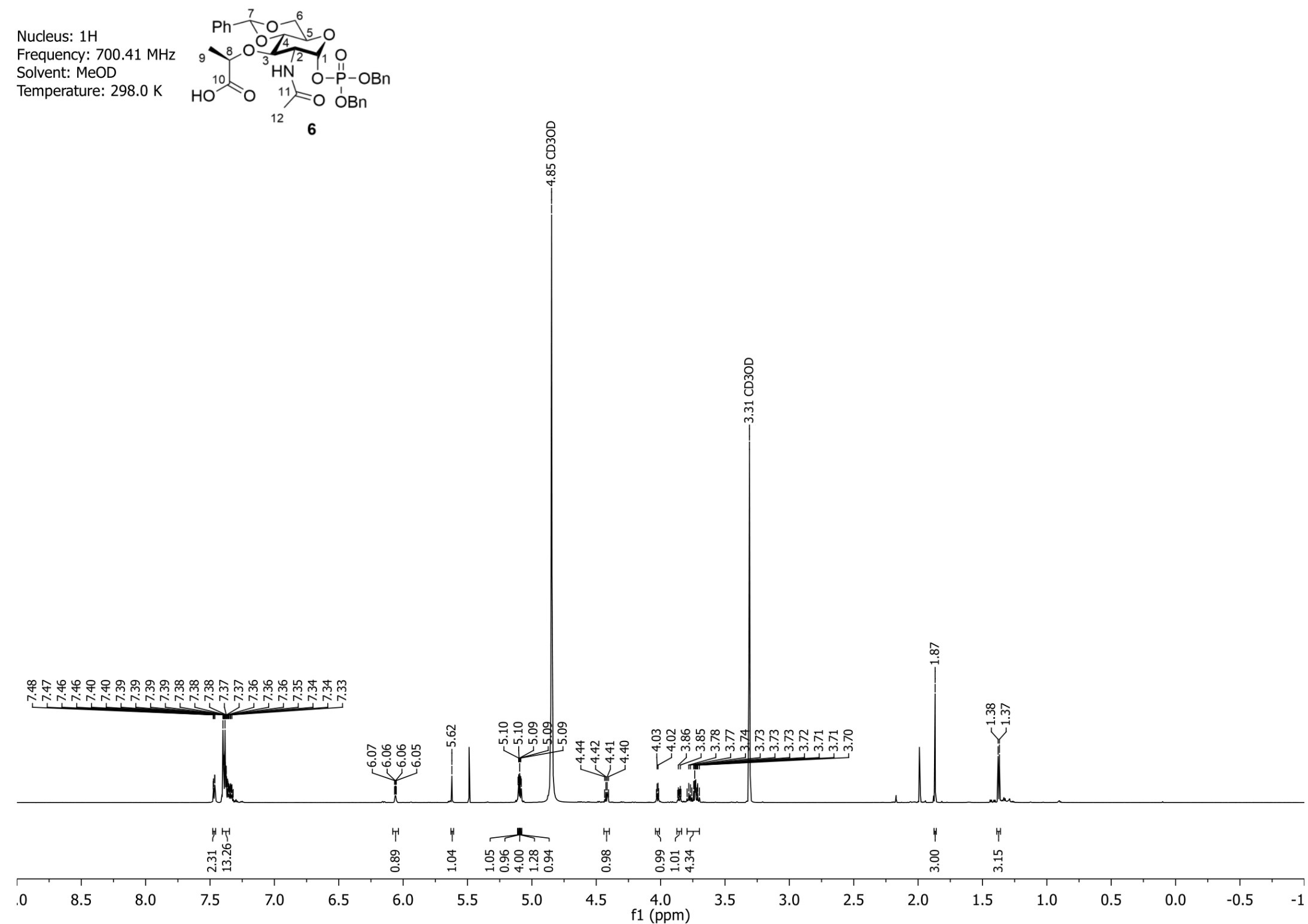

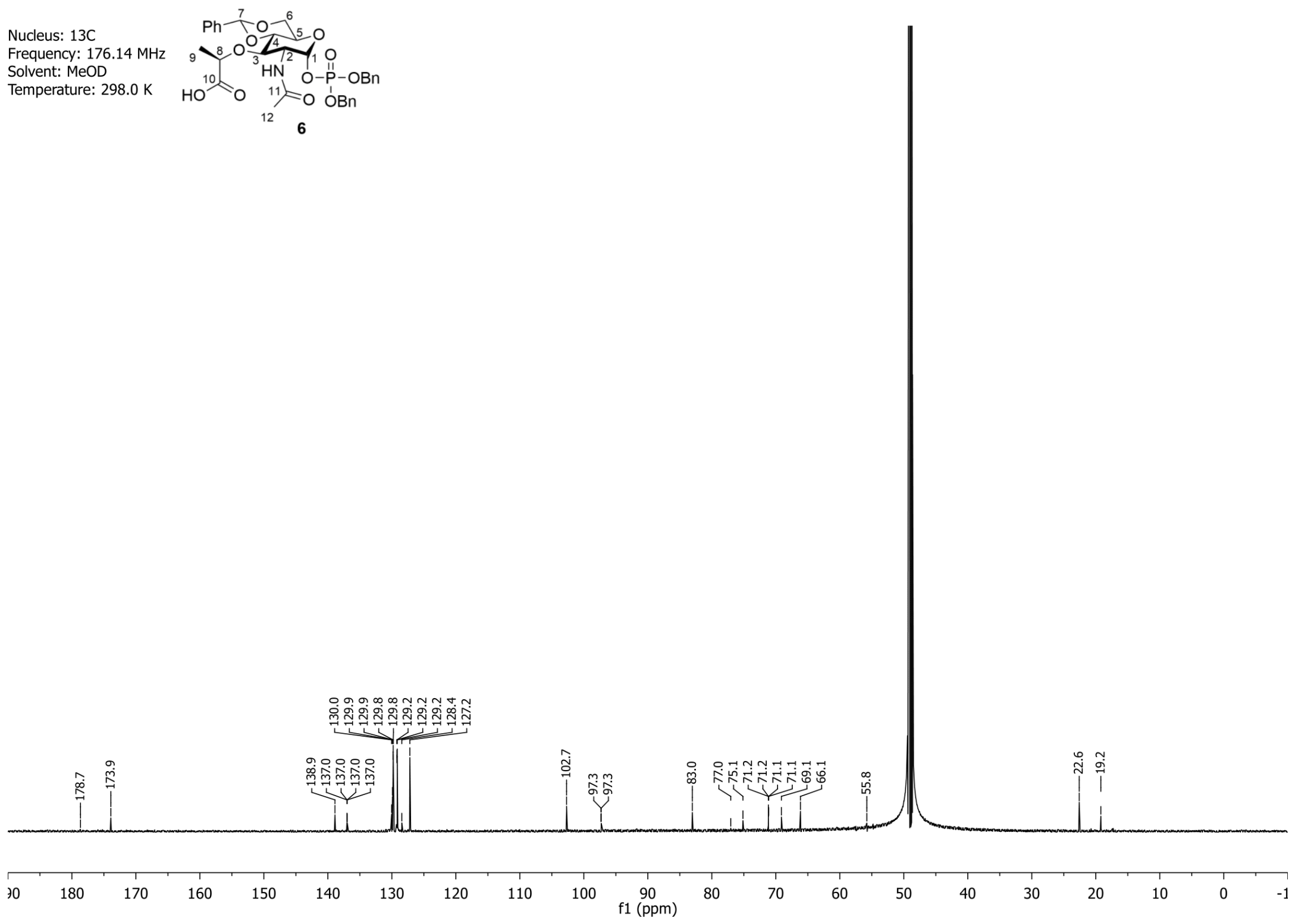

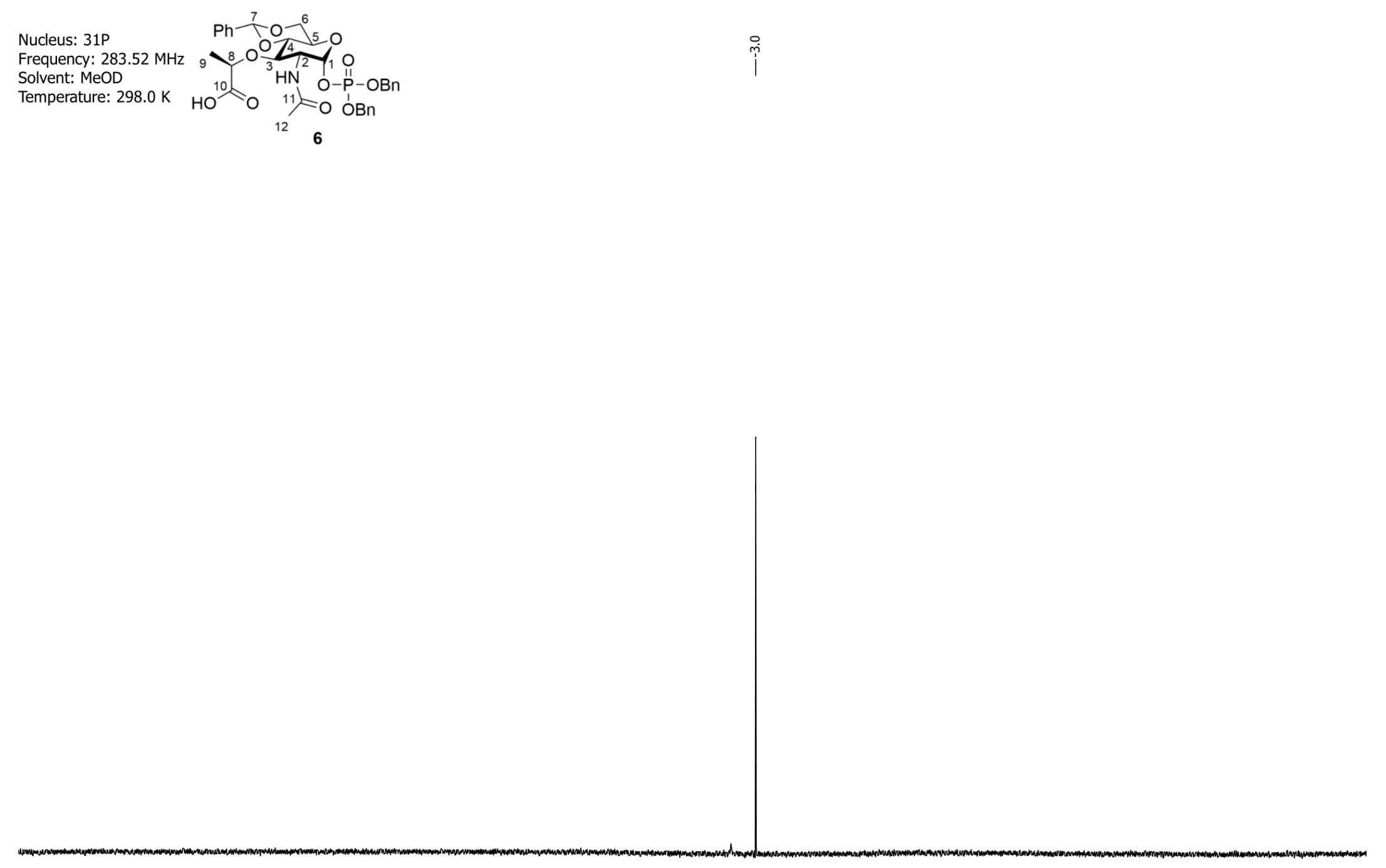

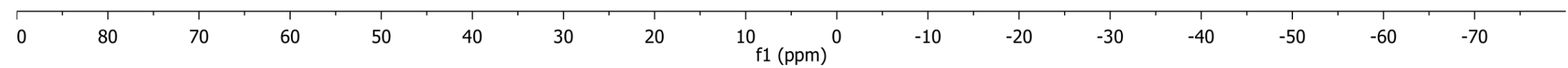




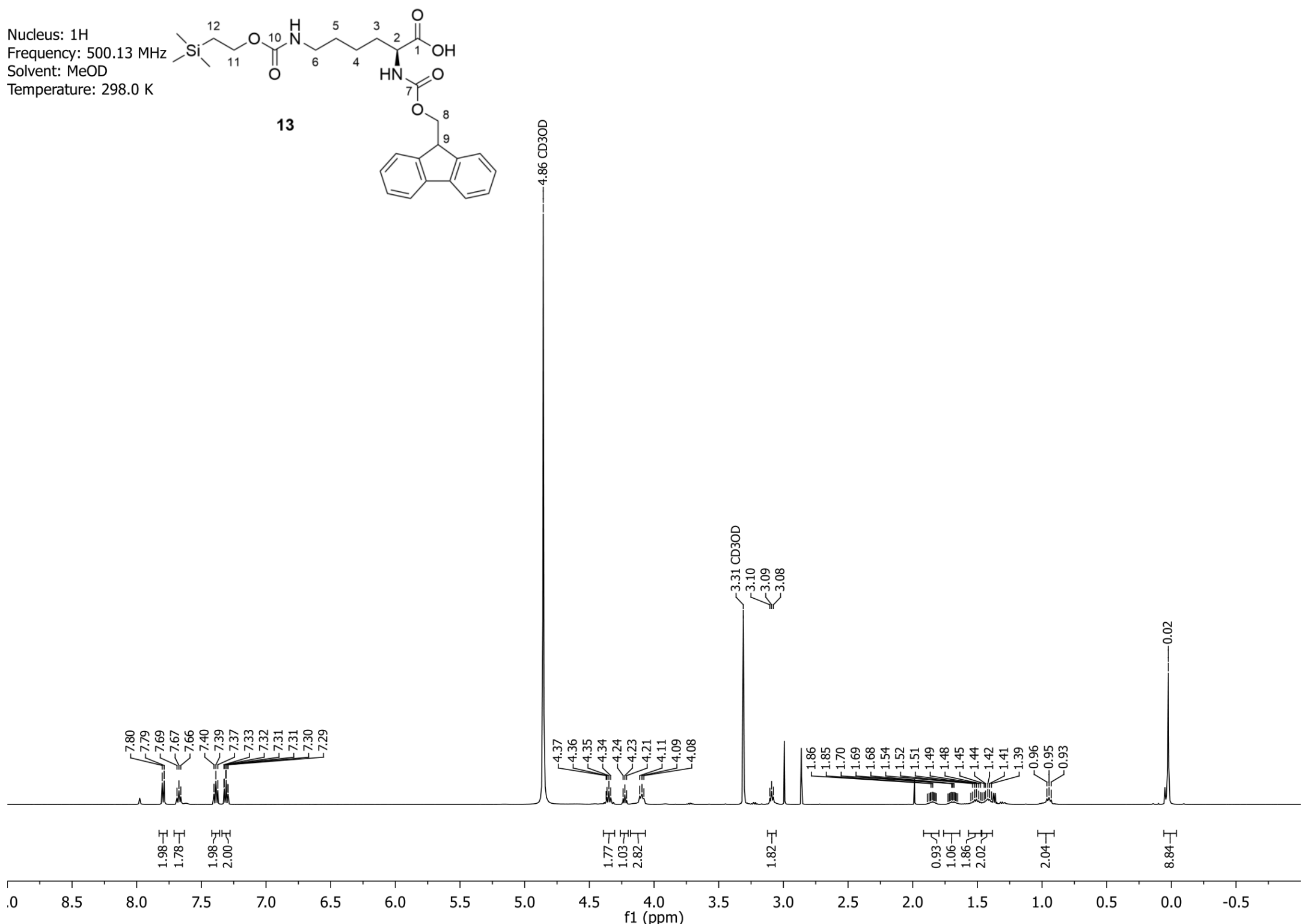




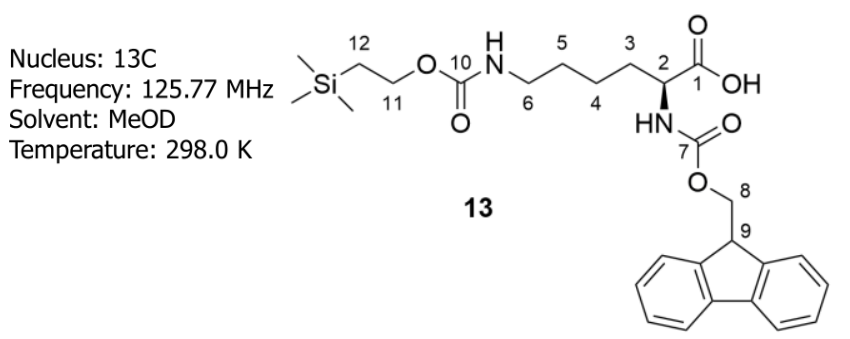

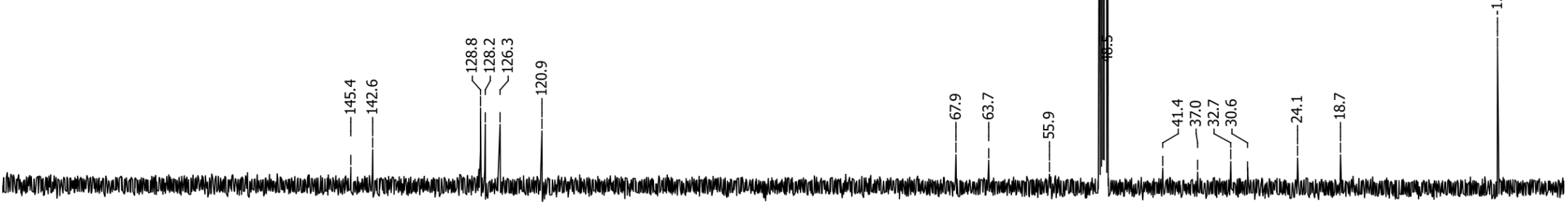

\begin{tabular}{|c|c|c|c|c|c|c|c|c|c|c|c|c|c|c|c|c|c|c|}
\hline$x$ & 180 & 170 & 160 & 150 & 140 & 130 & 120 & 110 & 100 & $\begin{array}{c}90 \\
\mathrm{f} 1(\mathrm{ppm})\end{array}$ & 80 & 70 & 60 & 50 & 40 & 30 & 20 & 10 \\
\hline
\end{tabular}



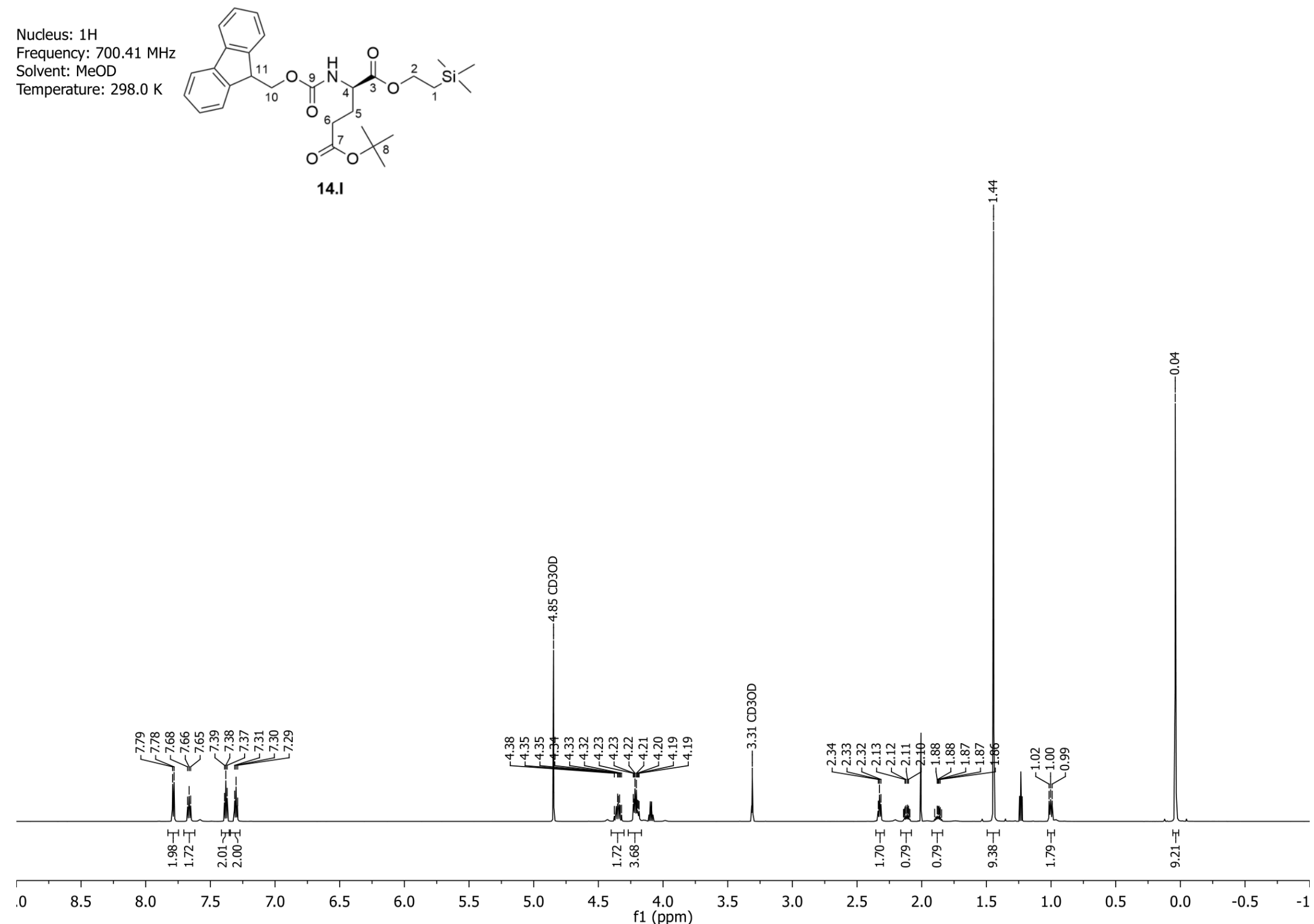

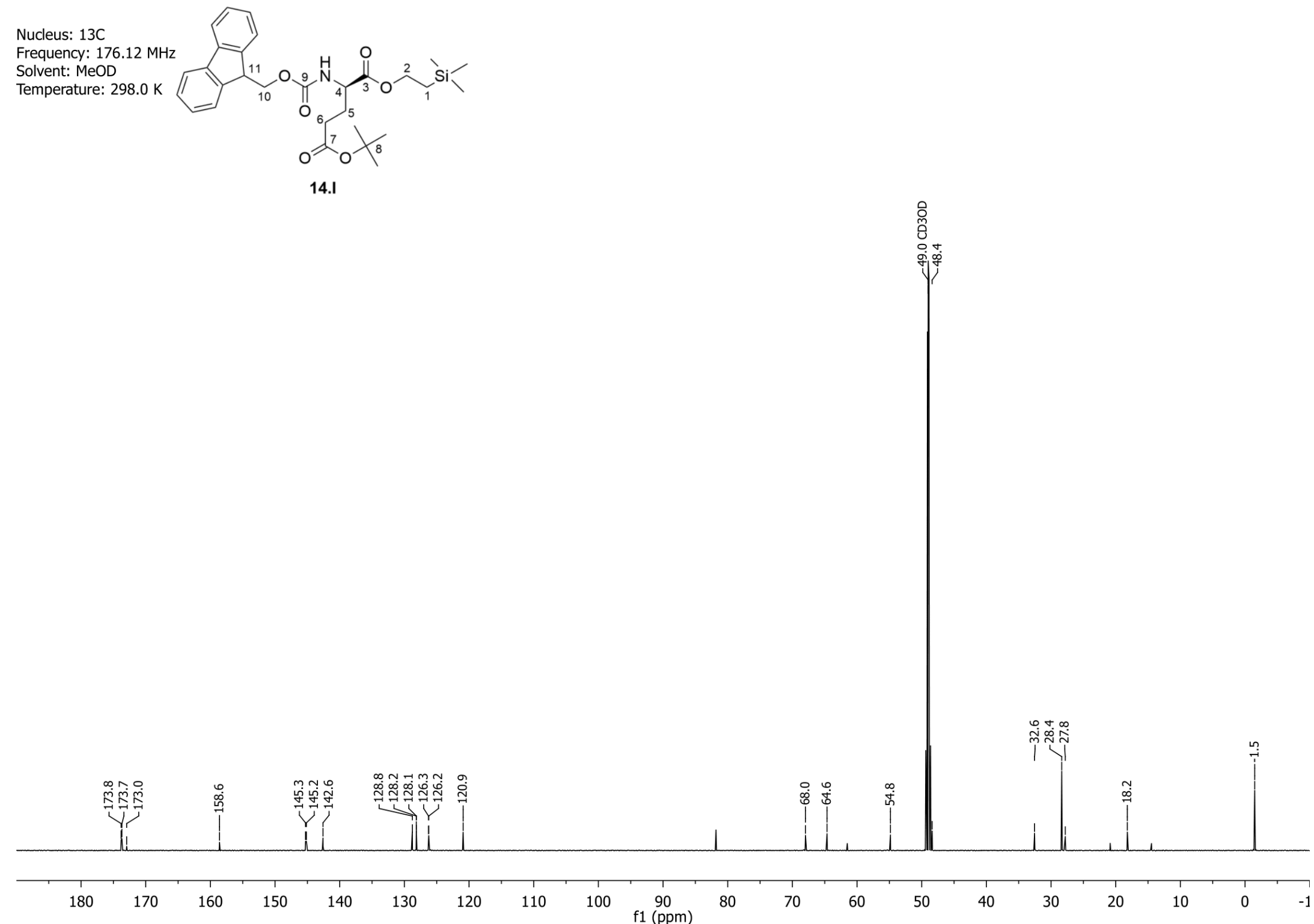

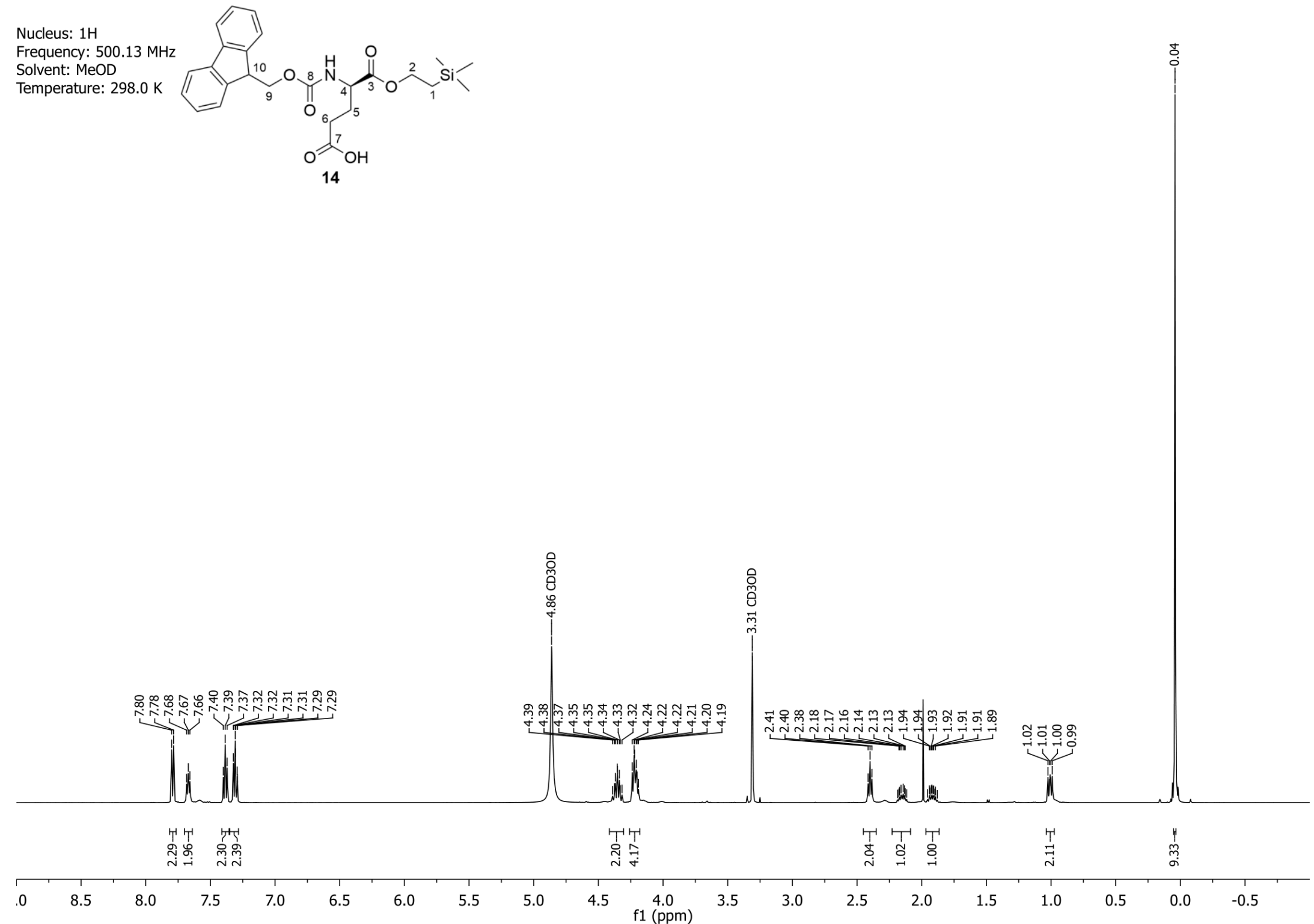

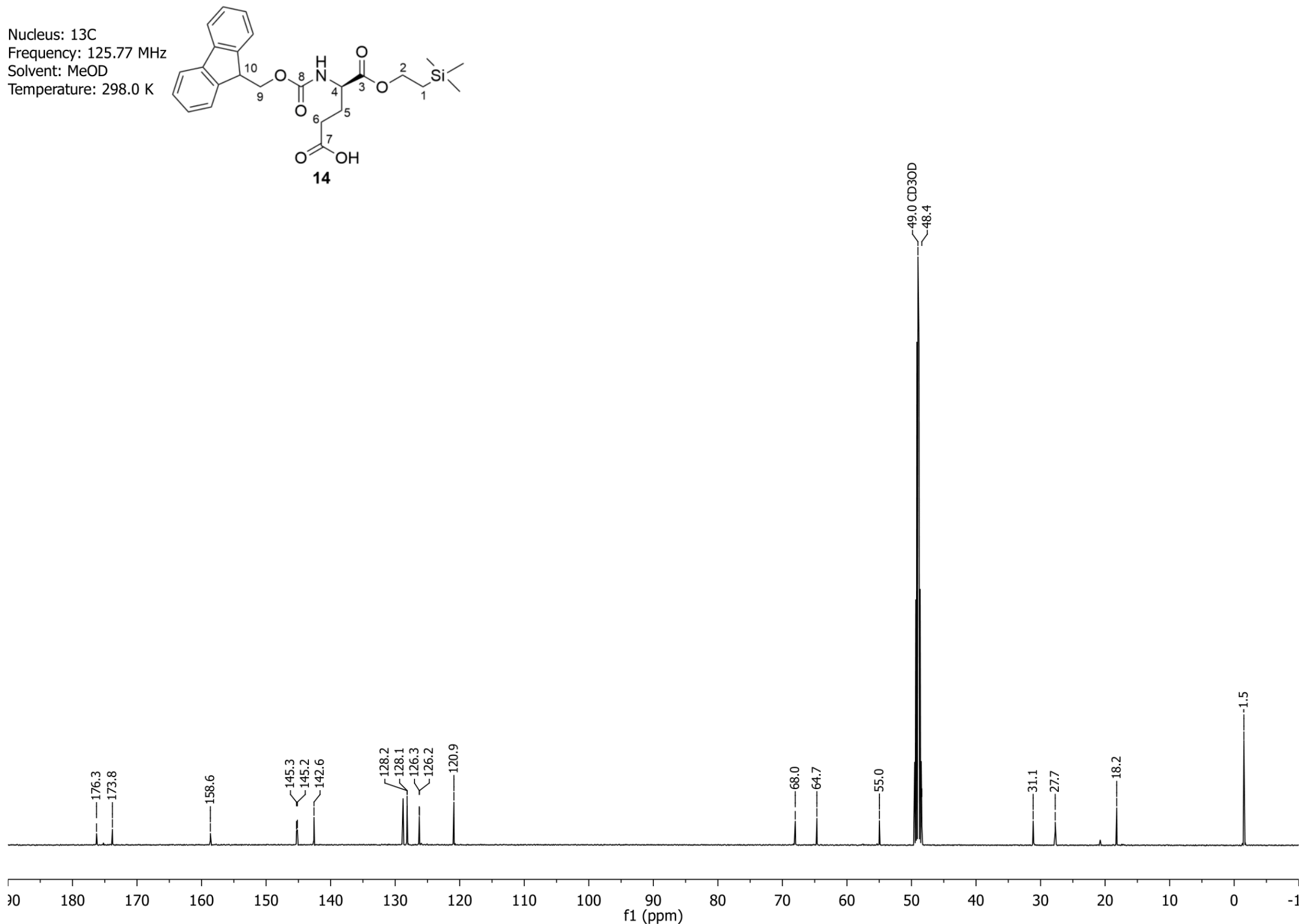

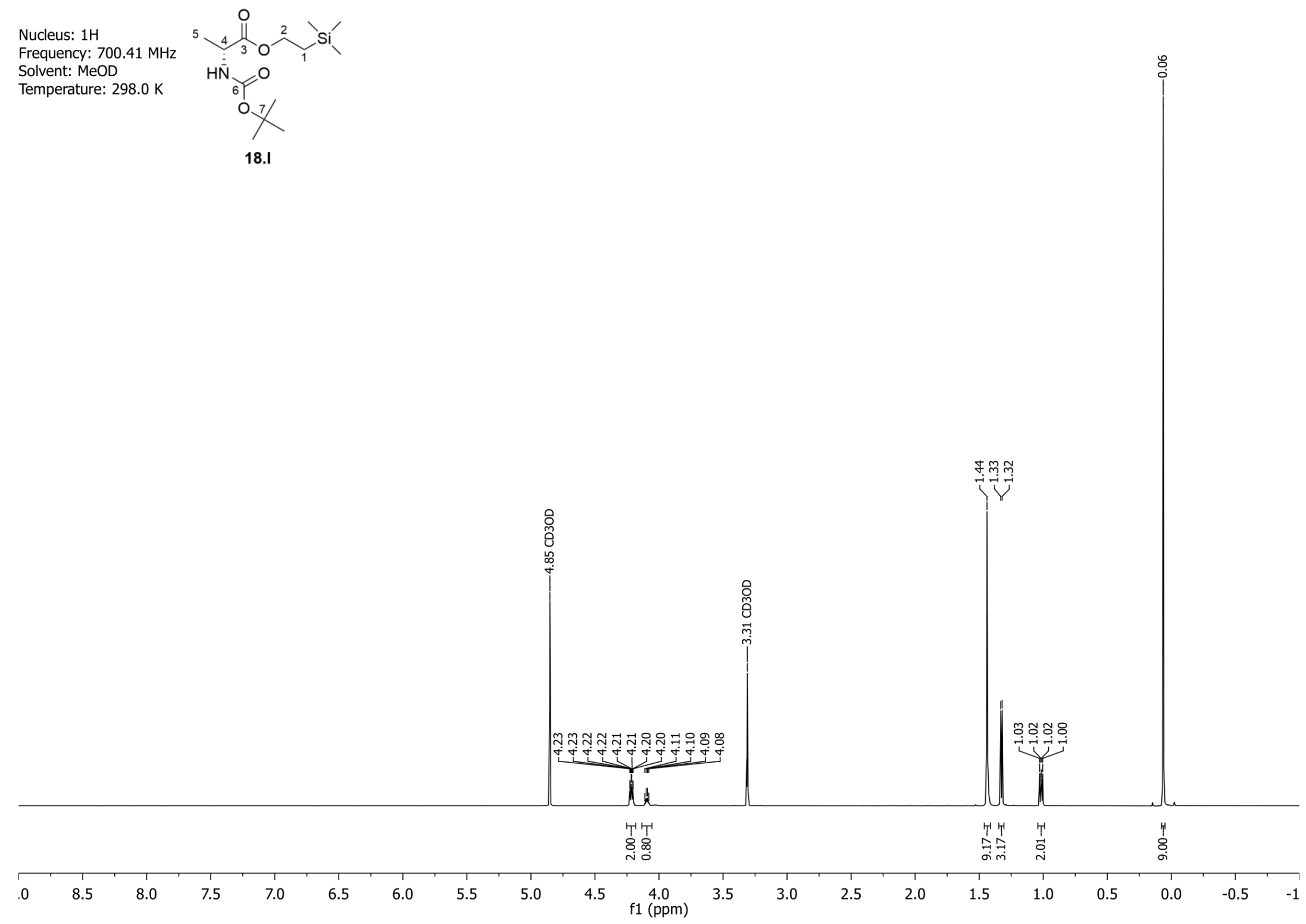


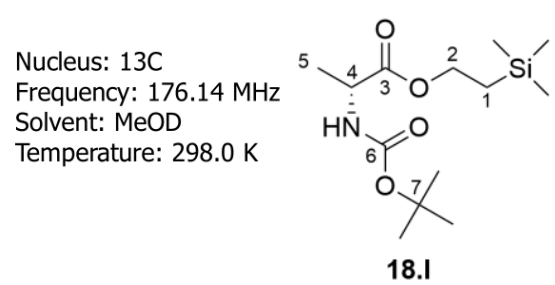

18.1

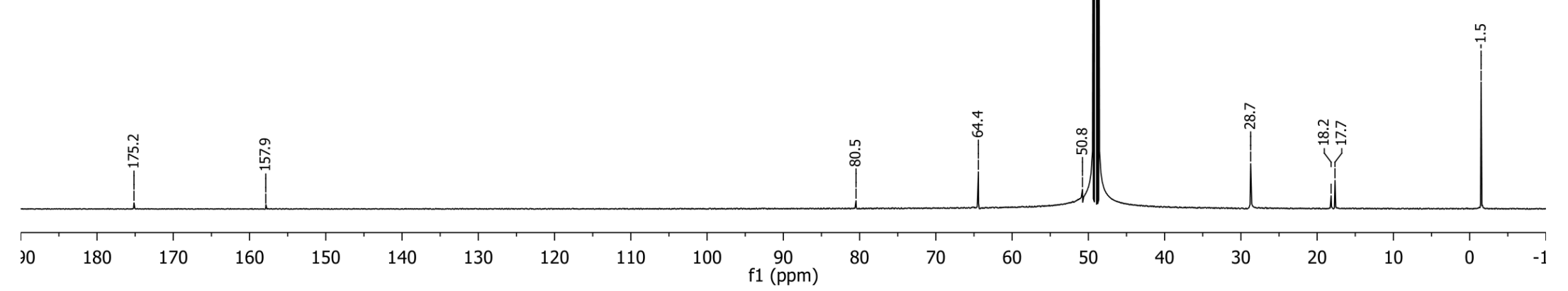




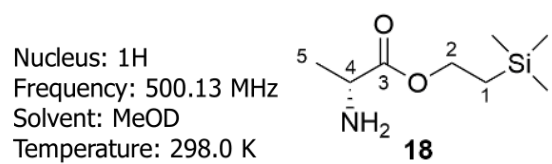

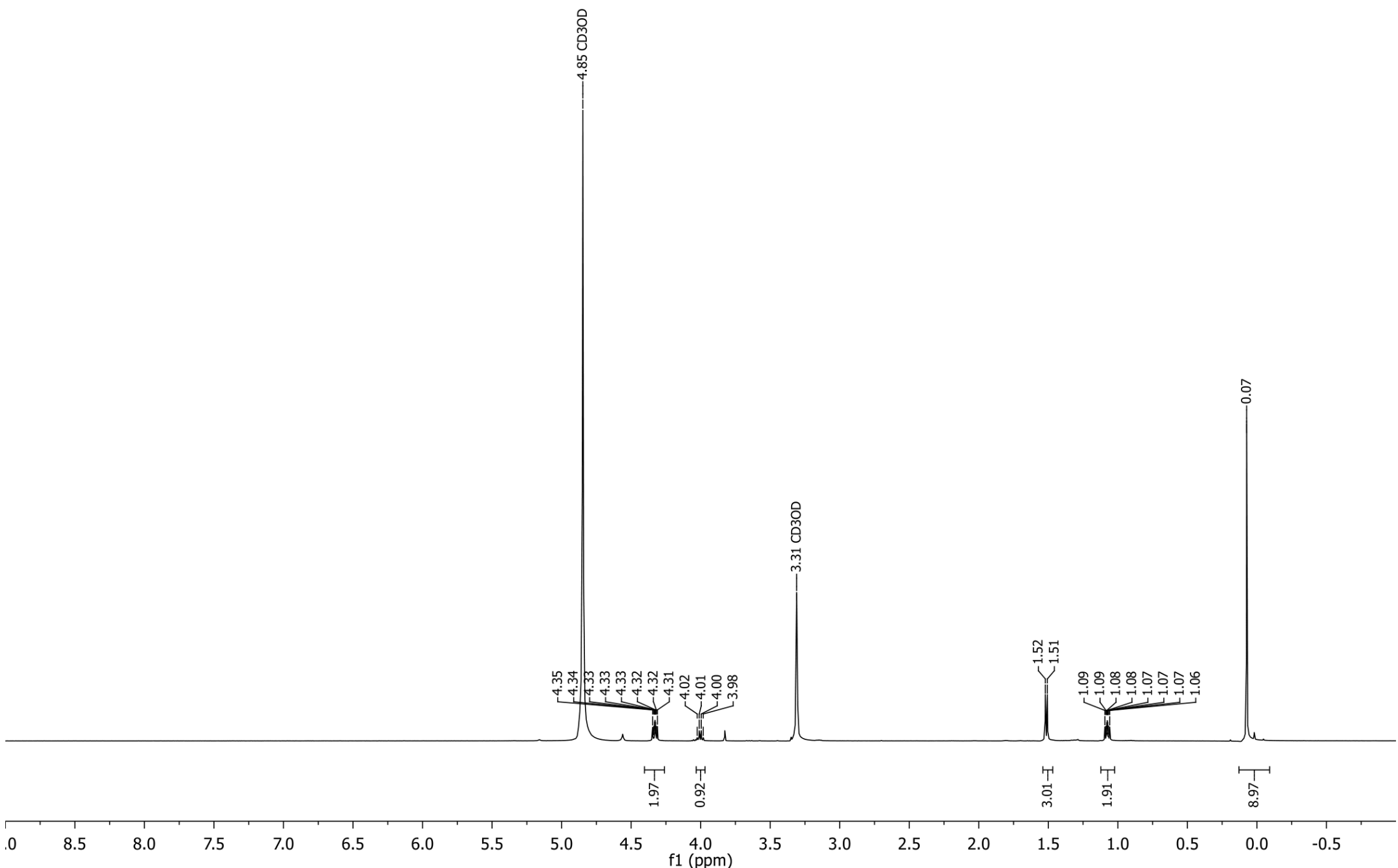




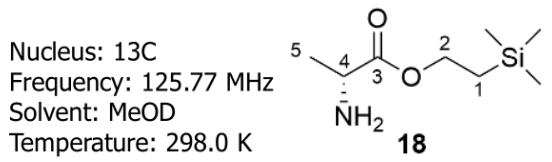

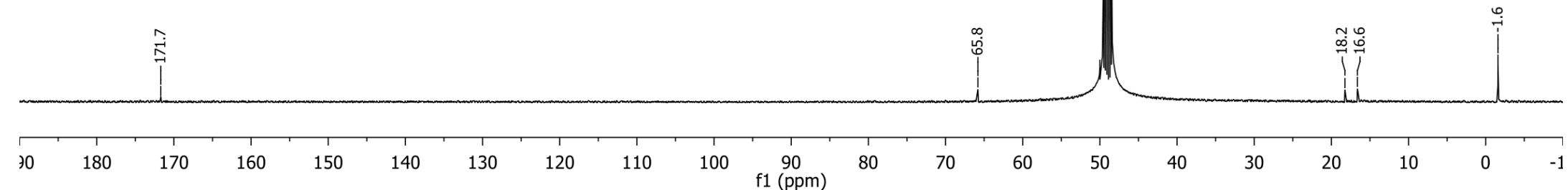


Nucleus: $1 \mathrm{H}$

Frequency: $700.41 \mathrm{MHz}$

Solvent: DMSO

Temperature: $298.0 \mathrm{~K}$

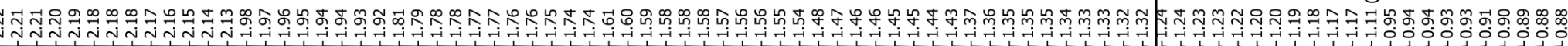
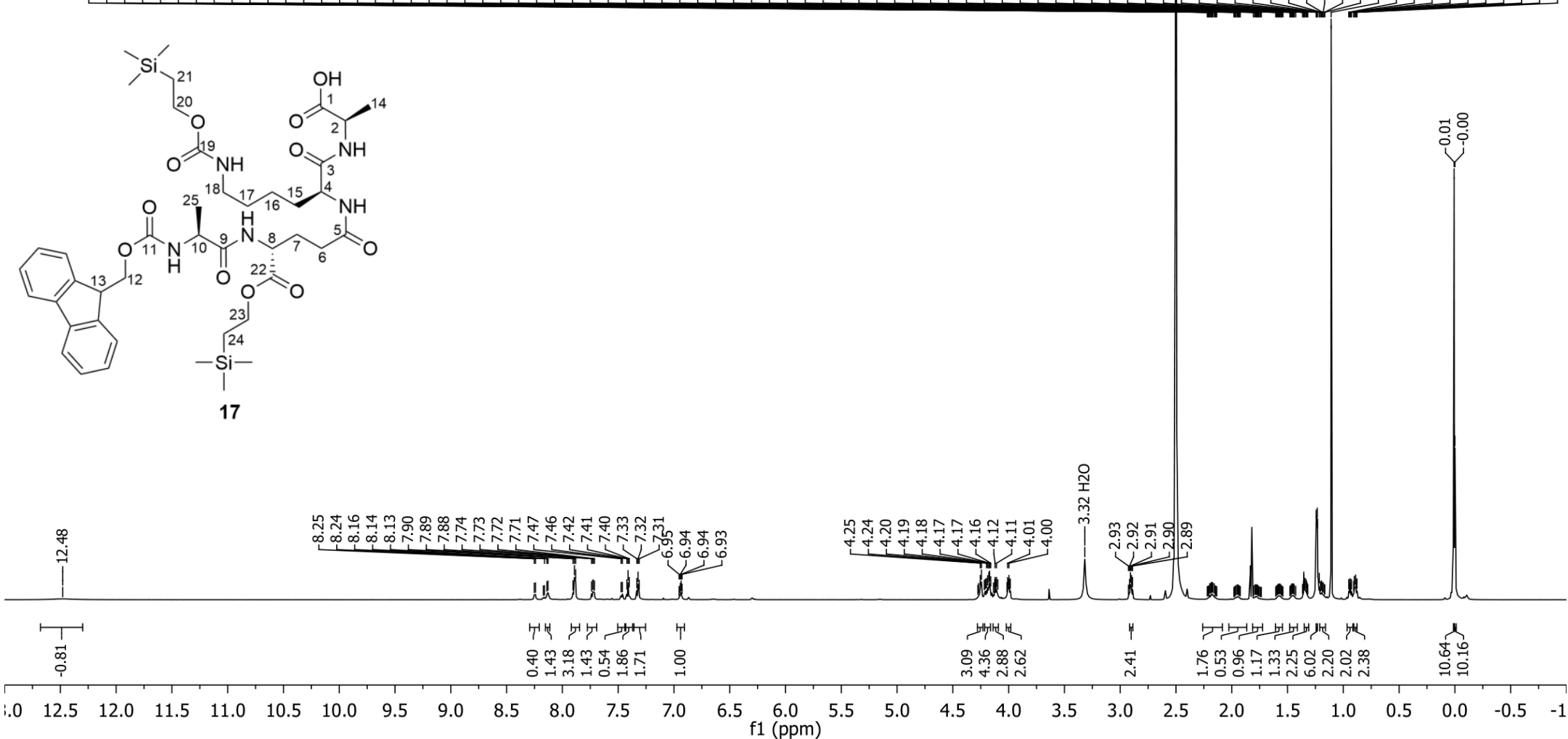

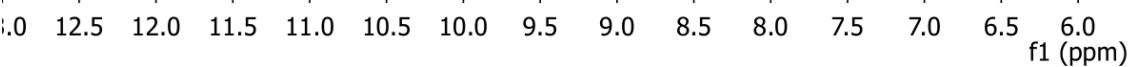



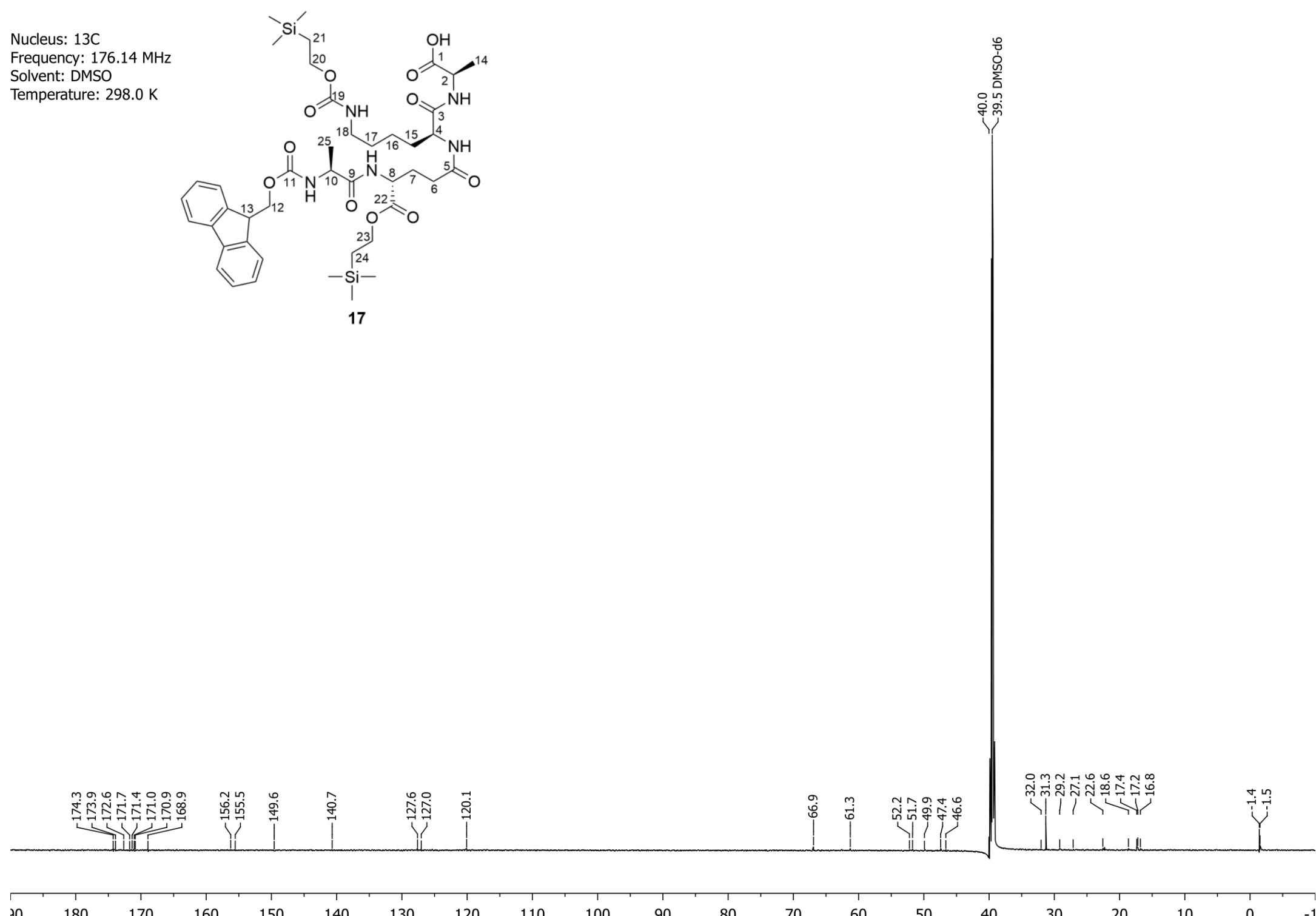

160

150

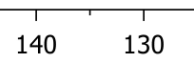

120

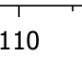

100

$\stackrel{90}{\mathrm{f} 1(\mathrm{ppm})}$ 


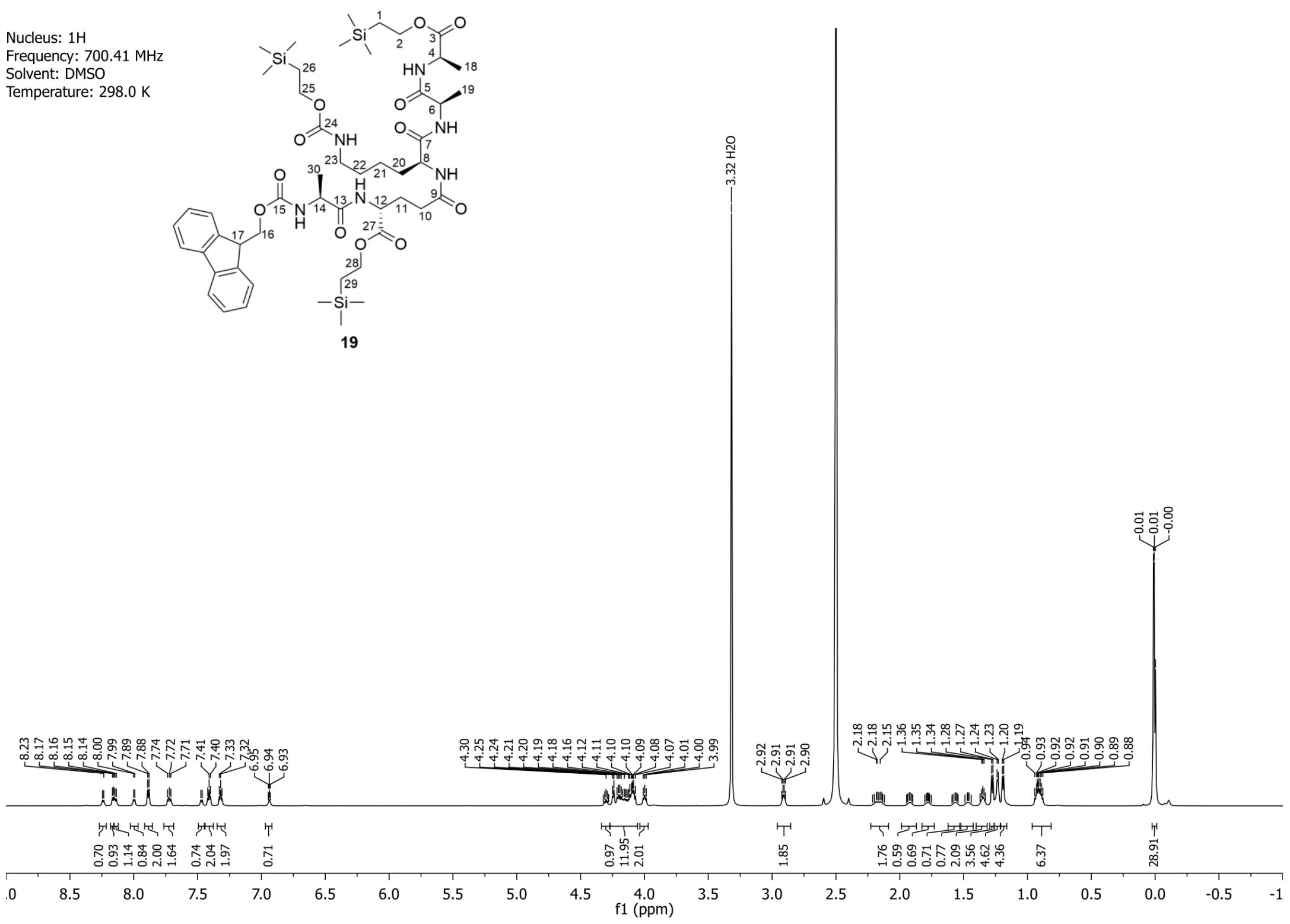



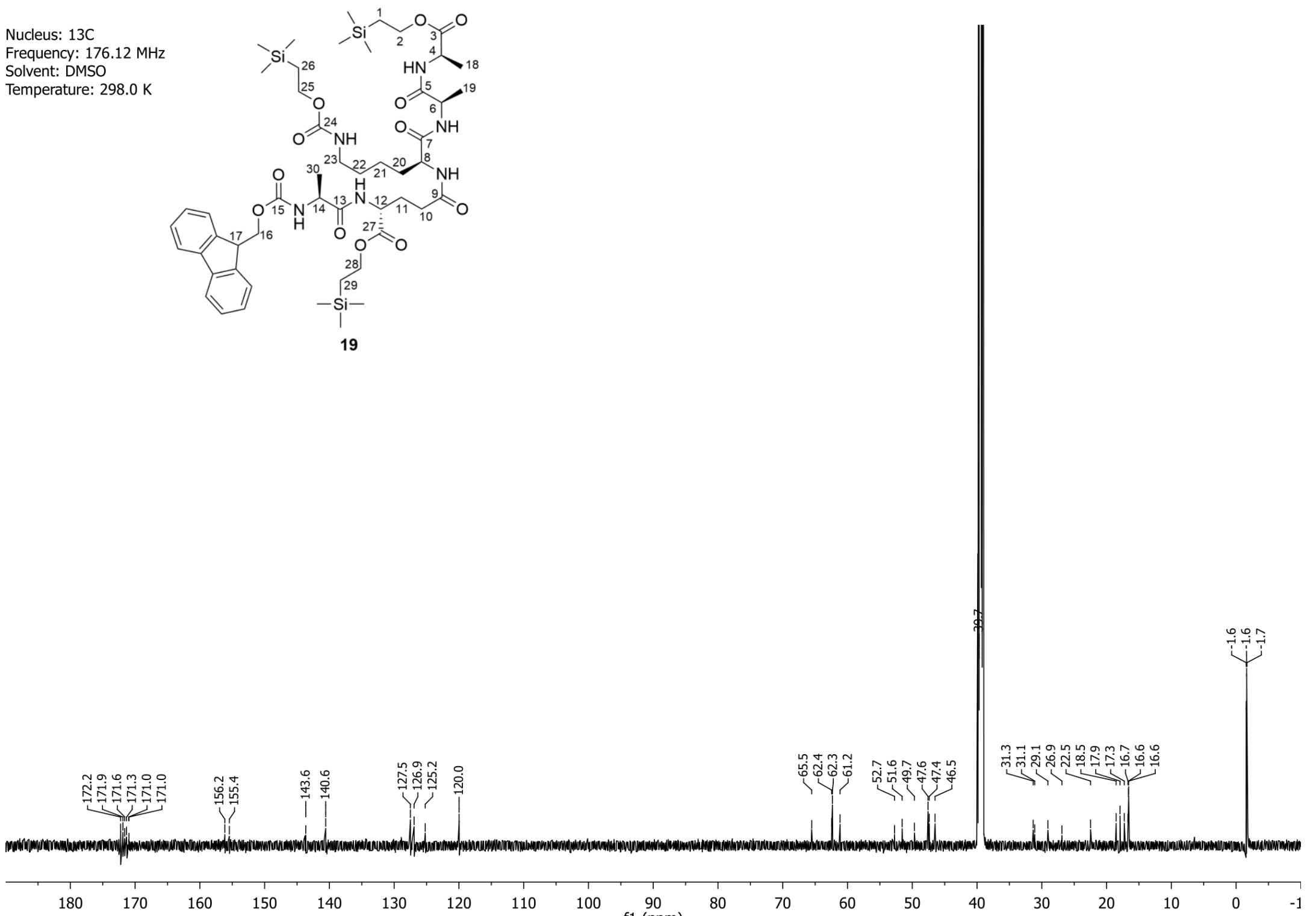


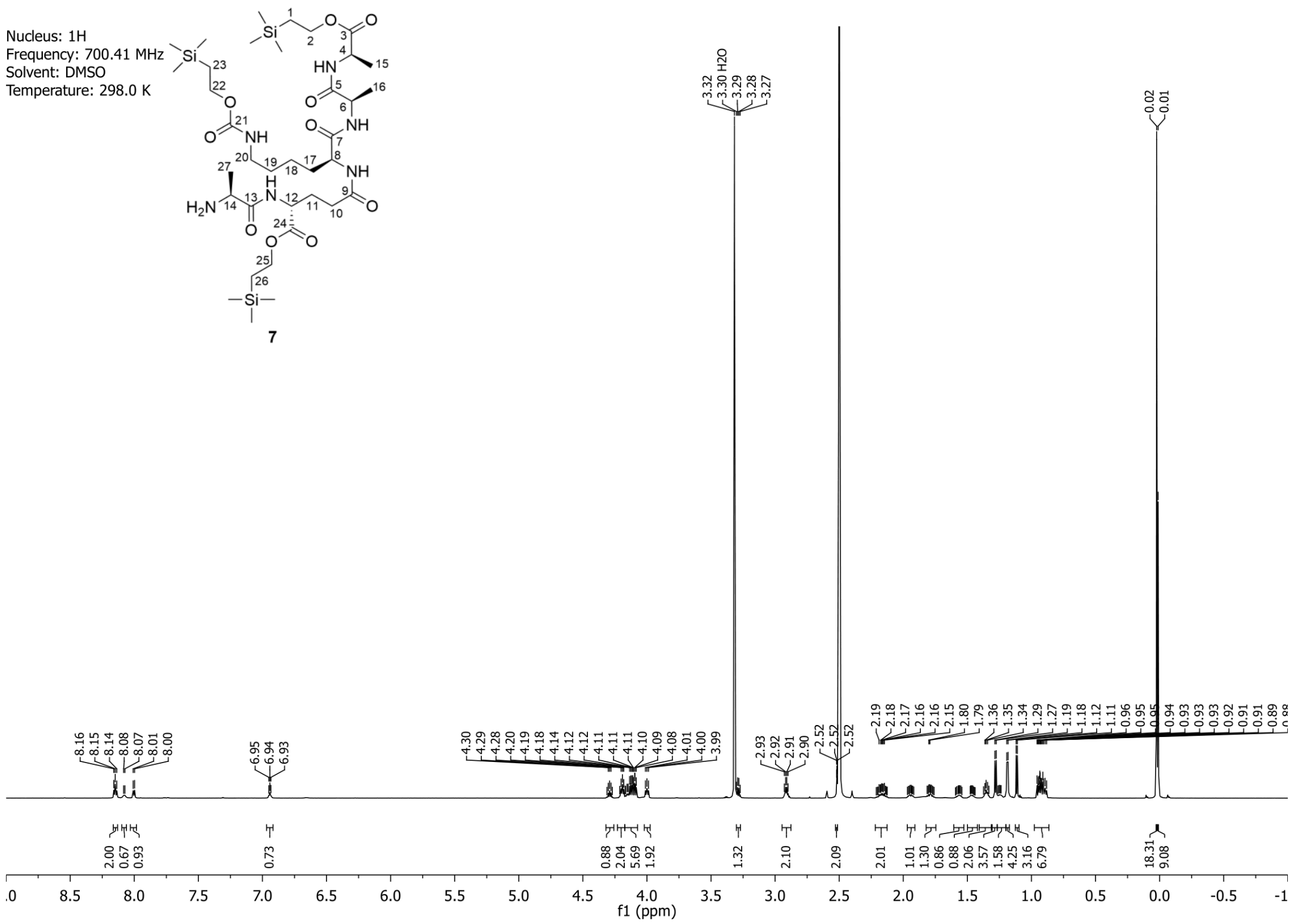



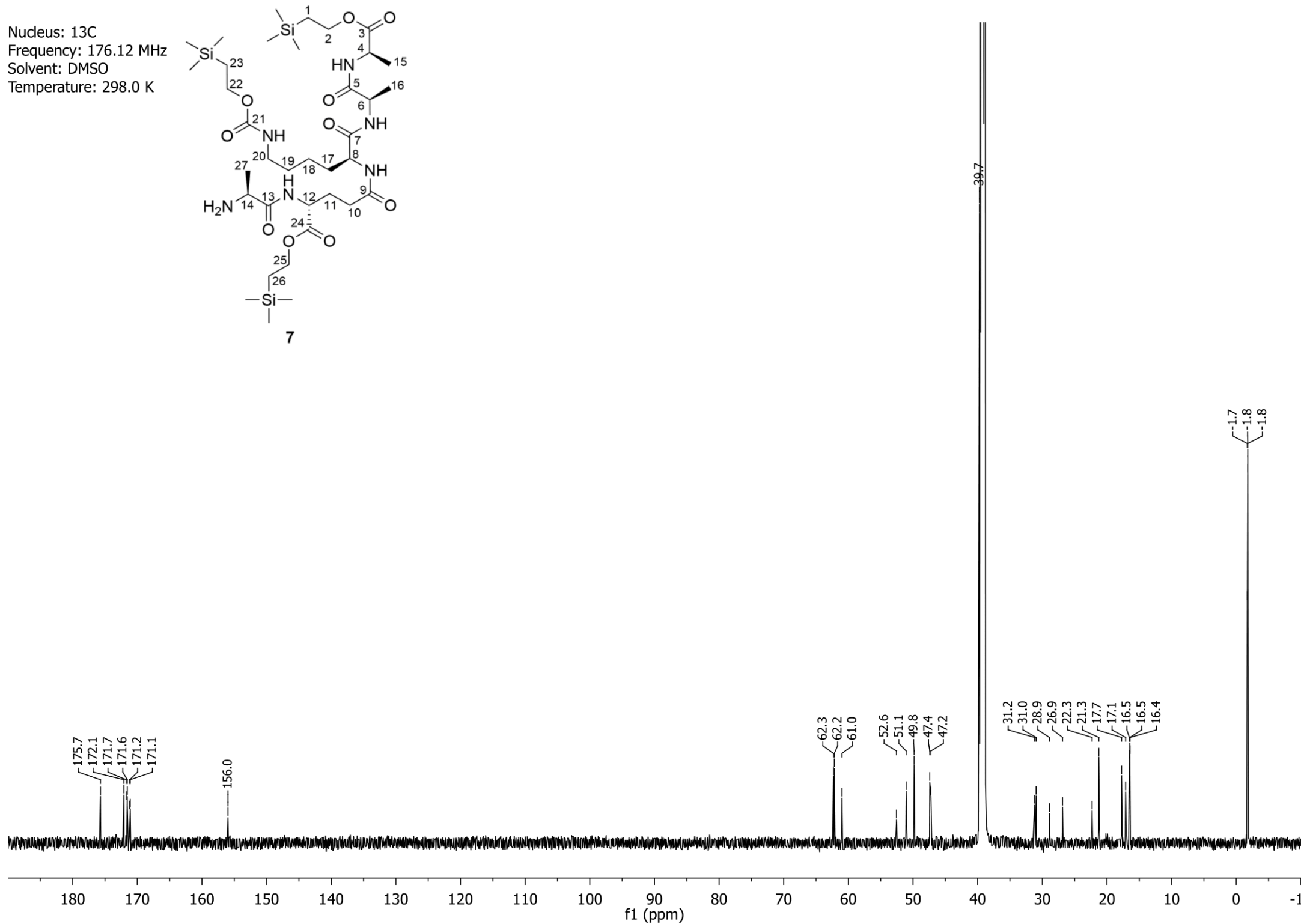
$\begin{aligned} & \text { Nucleus: } 1 \mathrm{H} \\ & \text { Frequency: } 500.07 \mathrm{MHz} \\ & \text { Solvent: } \mathrm{MeOD}\end{aligned}$
Temperature: $298.0 \mathrm{~K}$

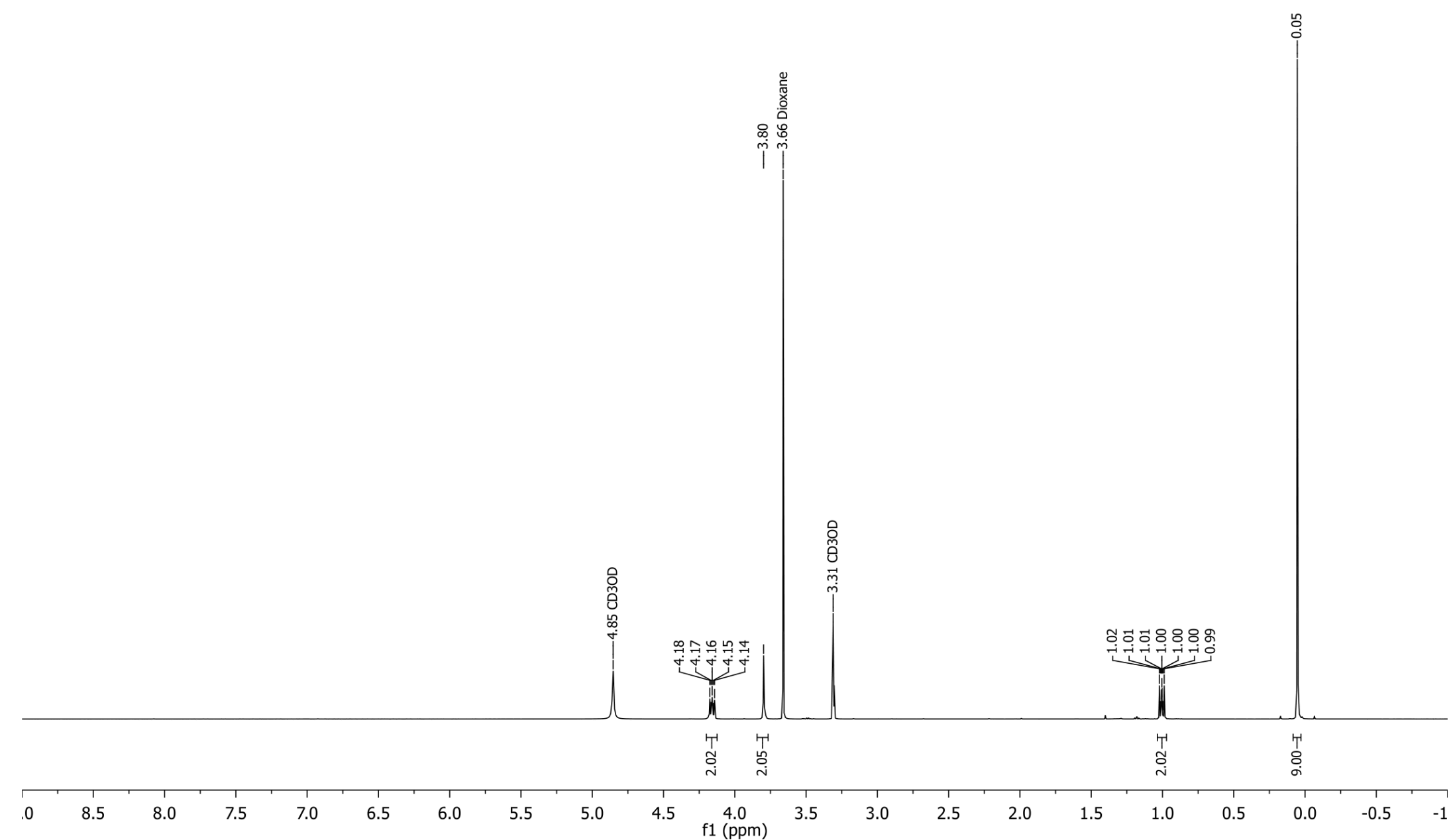


$\begin{aligned} & \text { Nucleus: } 13 \mathrm{C} \\ & \text { Frequency: } 125.76 \mathrm{MHz} \\ & \text { Solvent: MeOD } \\ & \text { Temperature: } 298.0 \mathrm{~K}\end{aligned}$

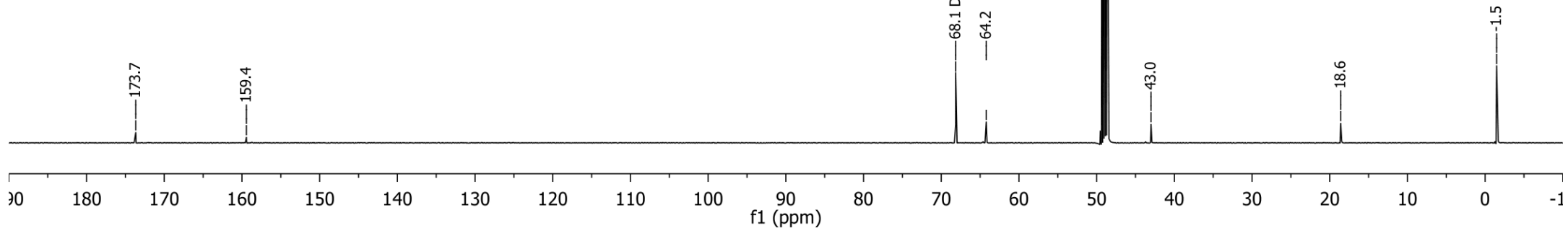



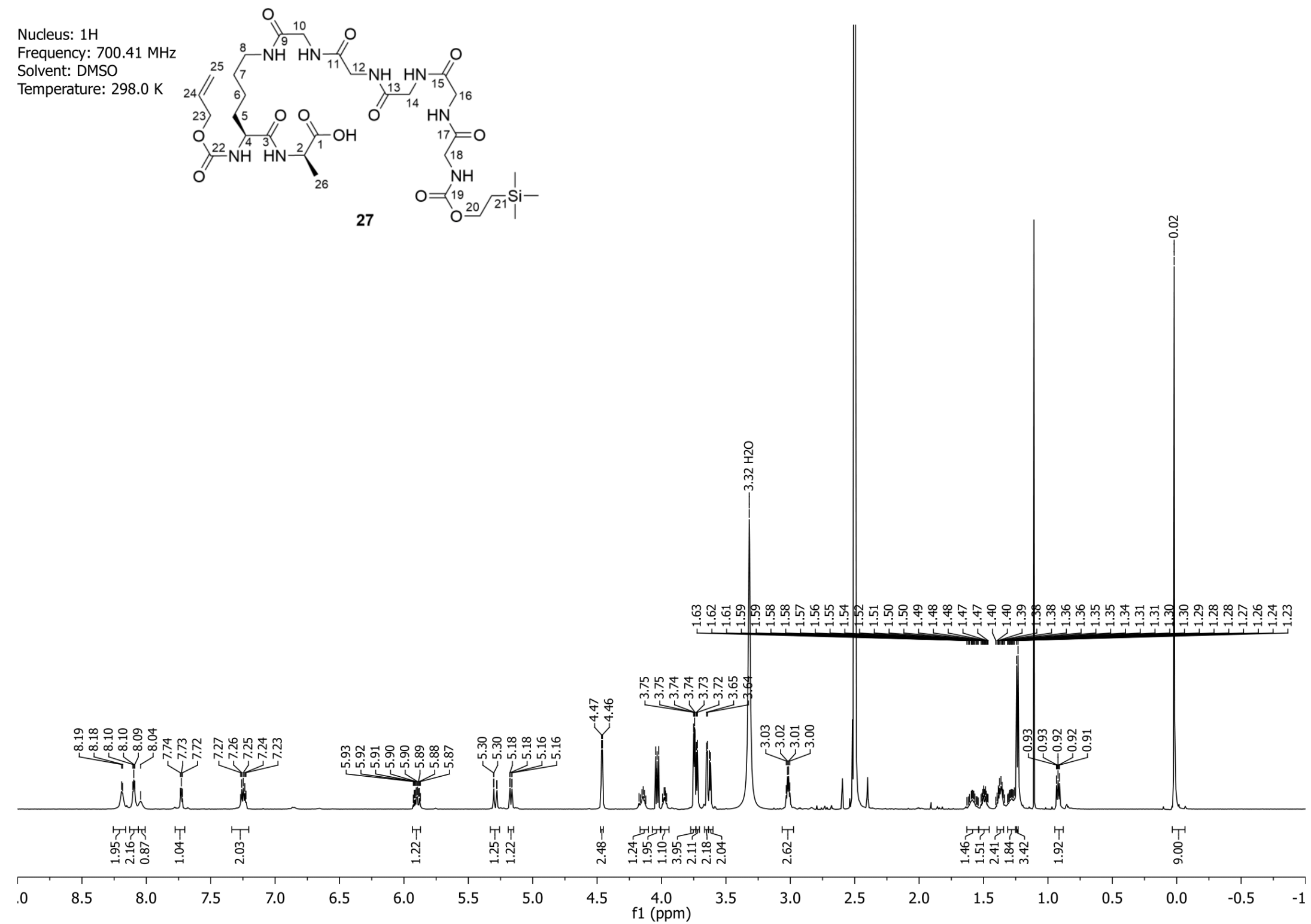

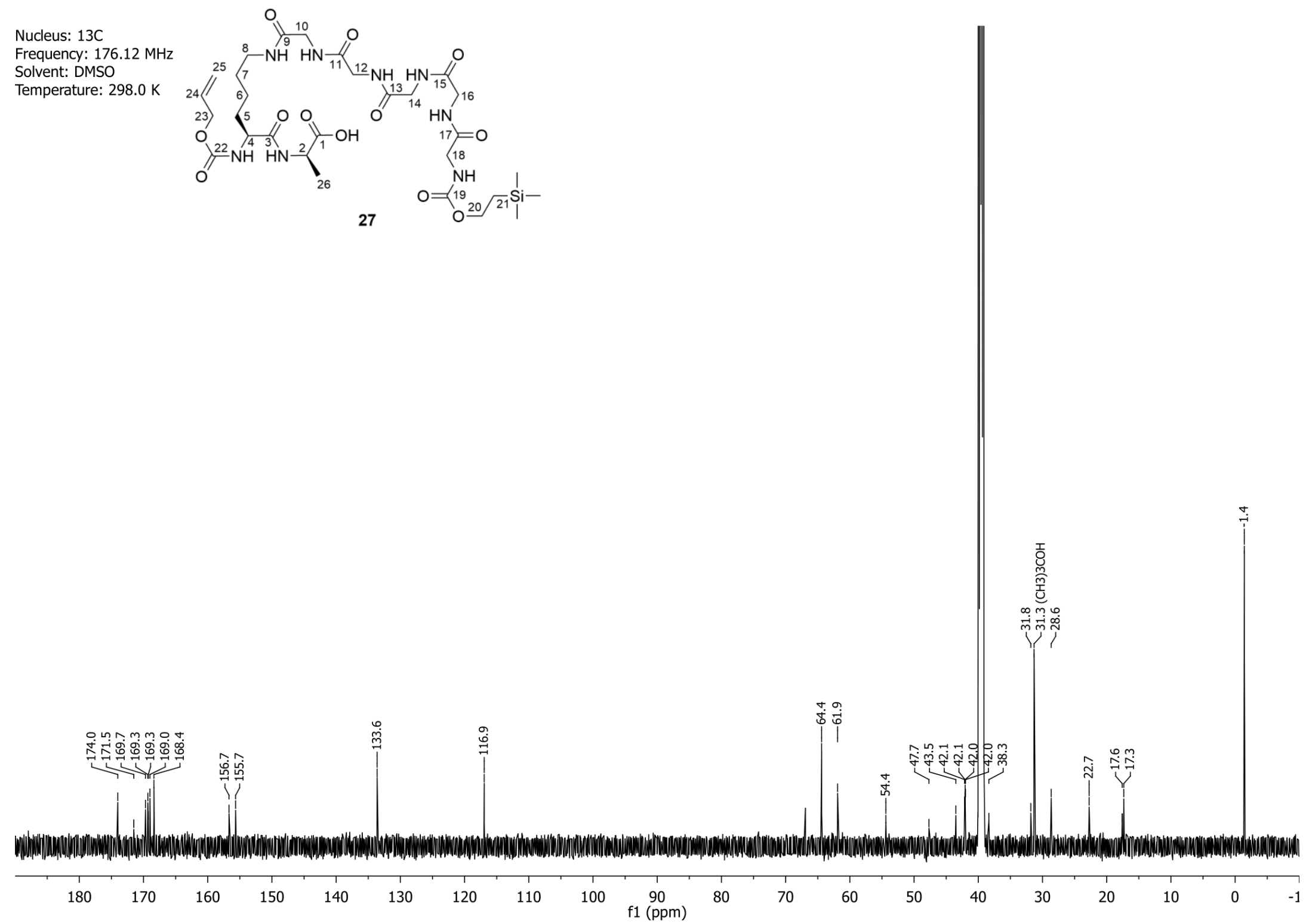
Nucleus: $1 \mathrm{H}$

Frequency: $700.41 \mathrm{MHz}$

Solvent: DMSO

Temperature: $298.0 \mathrm{~K}$

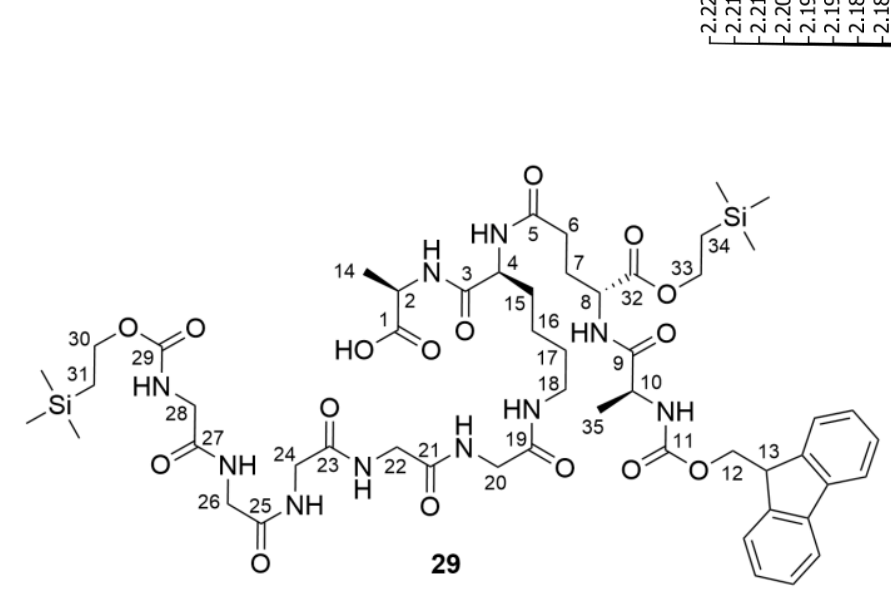

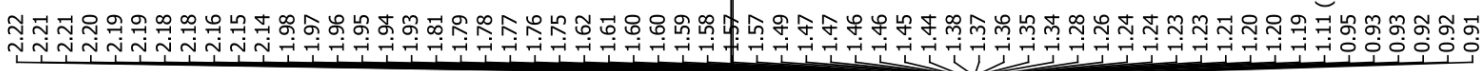

공
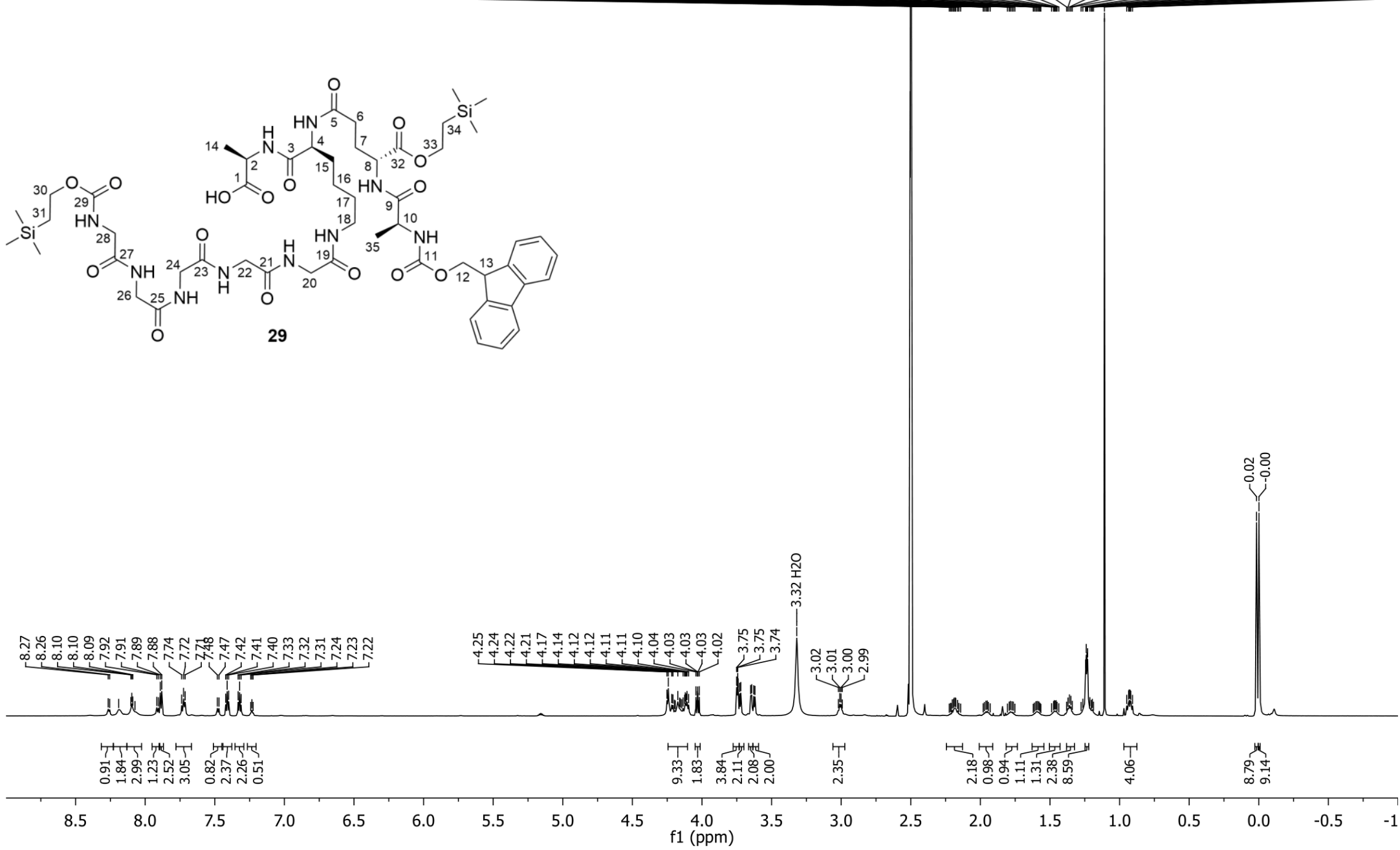

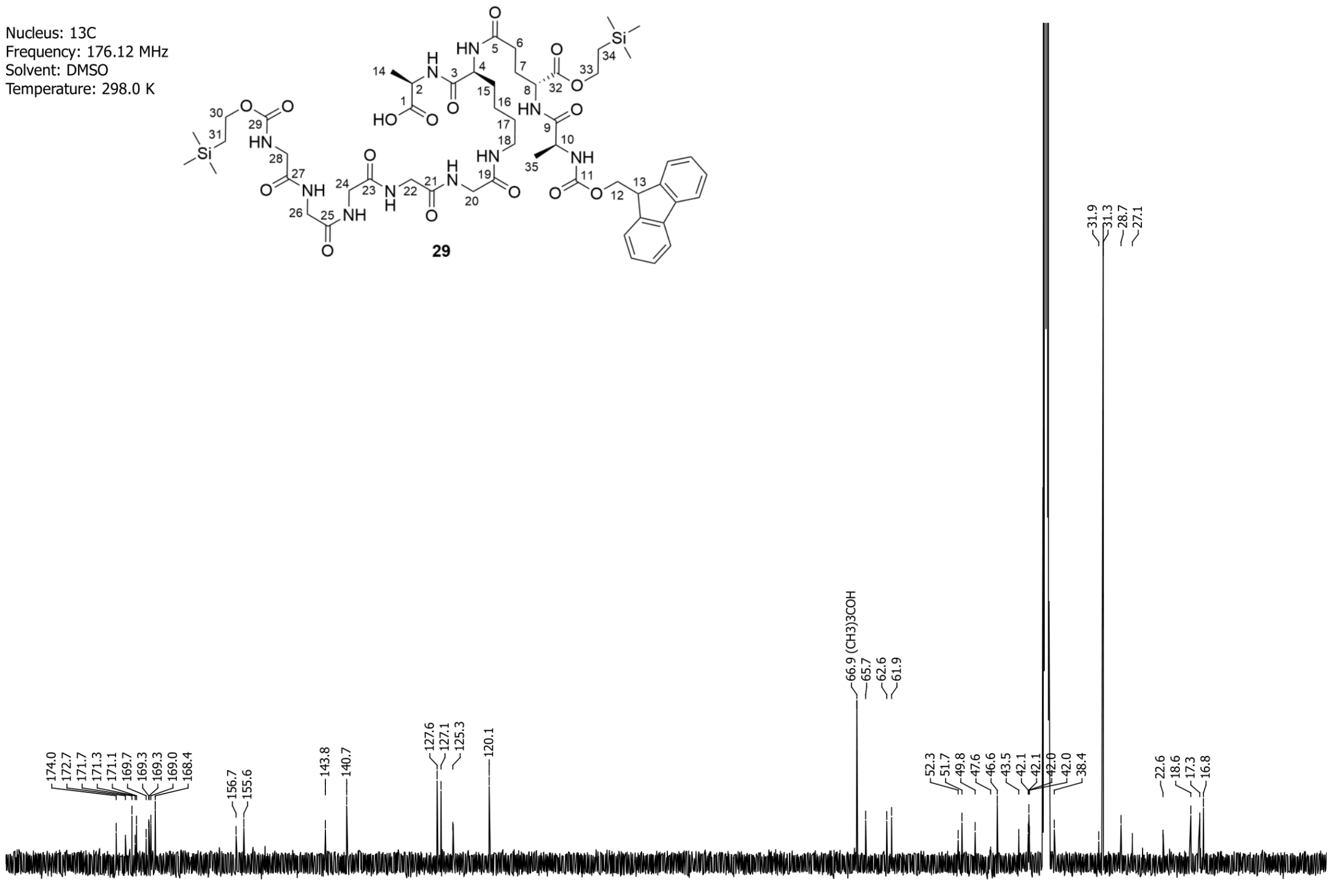

180

$\begin{array}{ll}170 & 160\end{array}$

150

140

120
$30 \quad 1$

110

100 f1 (ppm)

80

70

60

50

$40 \quad 30$

20

10 


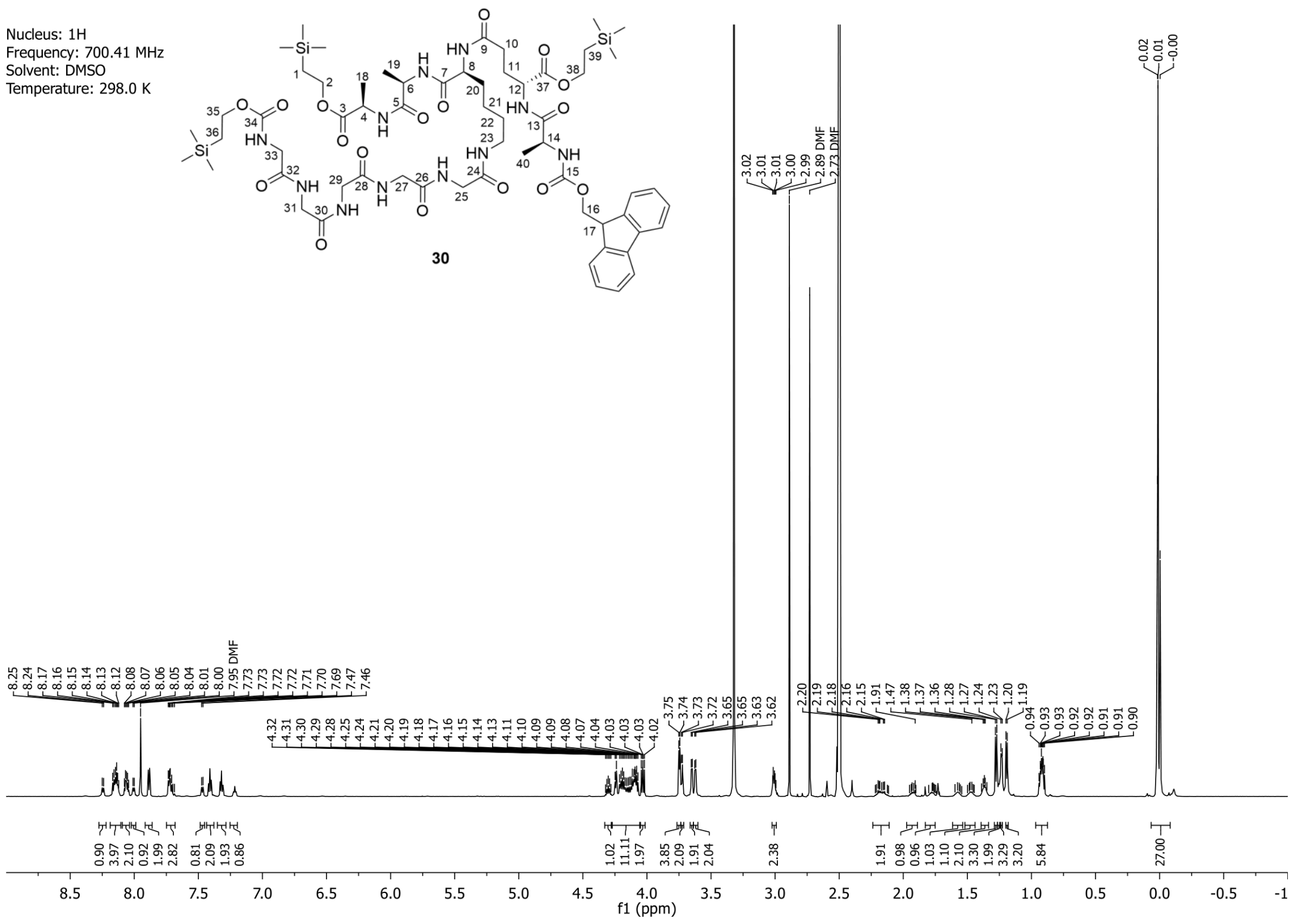



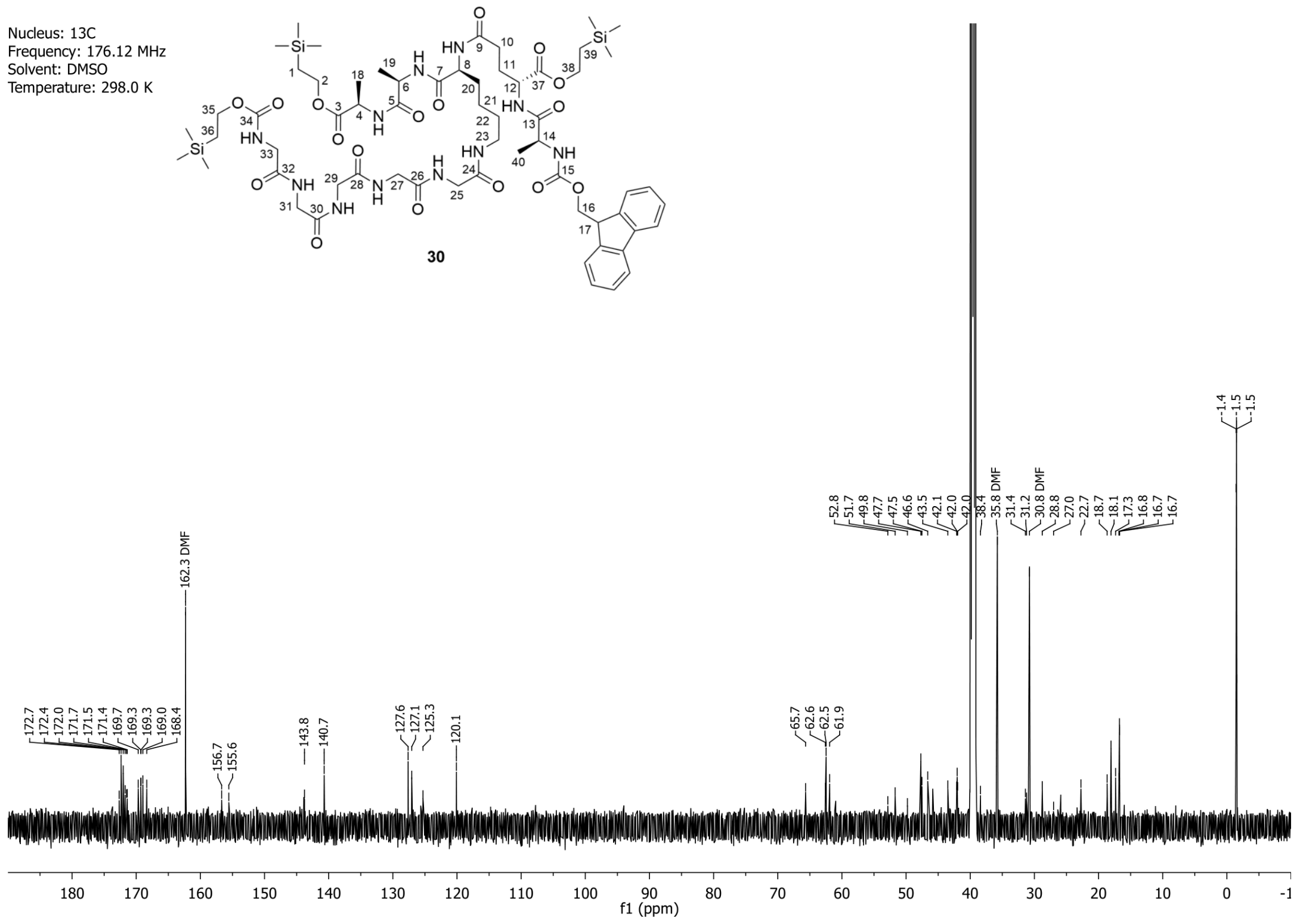


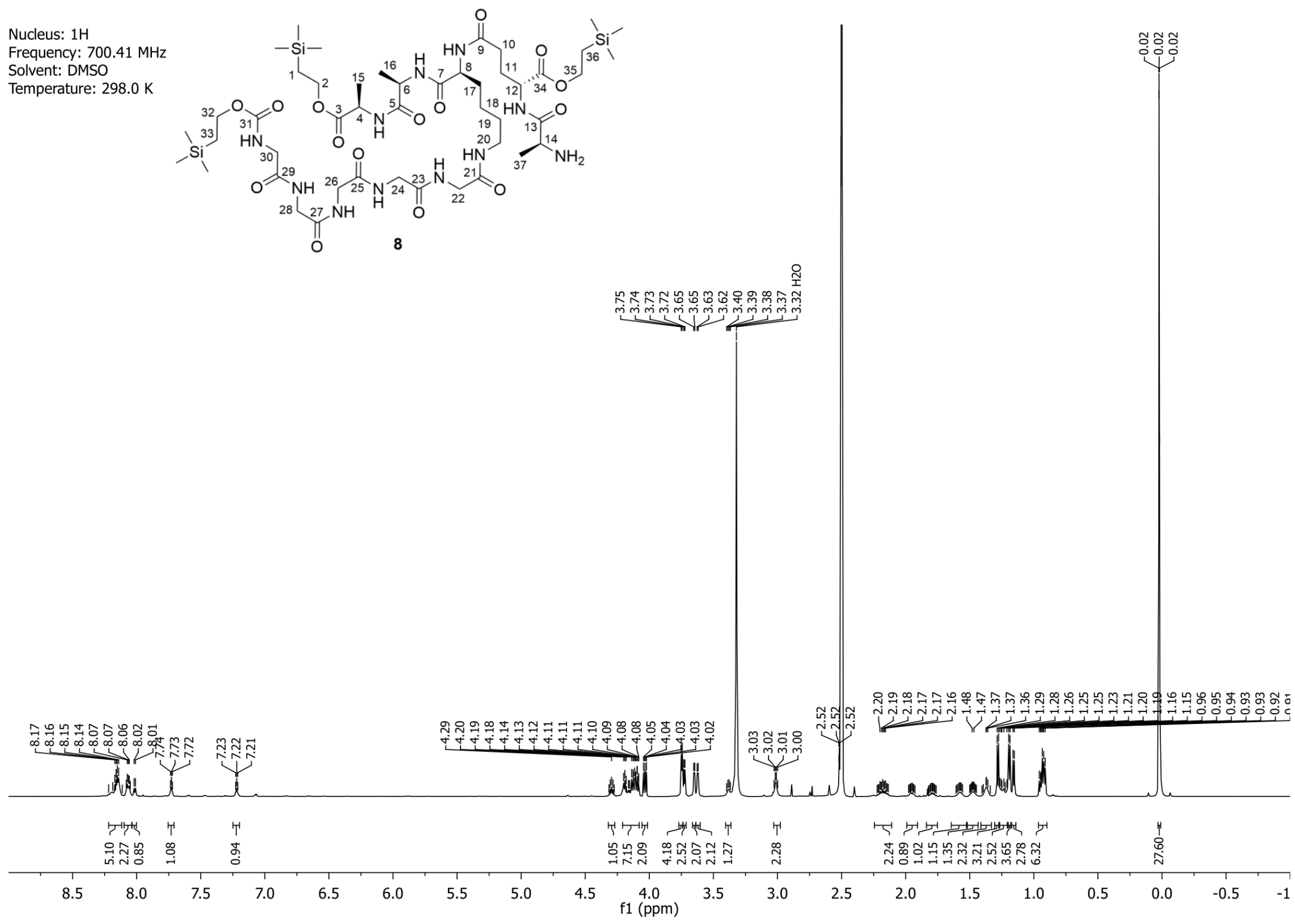



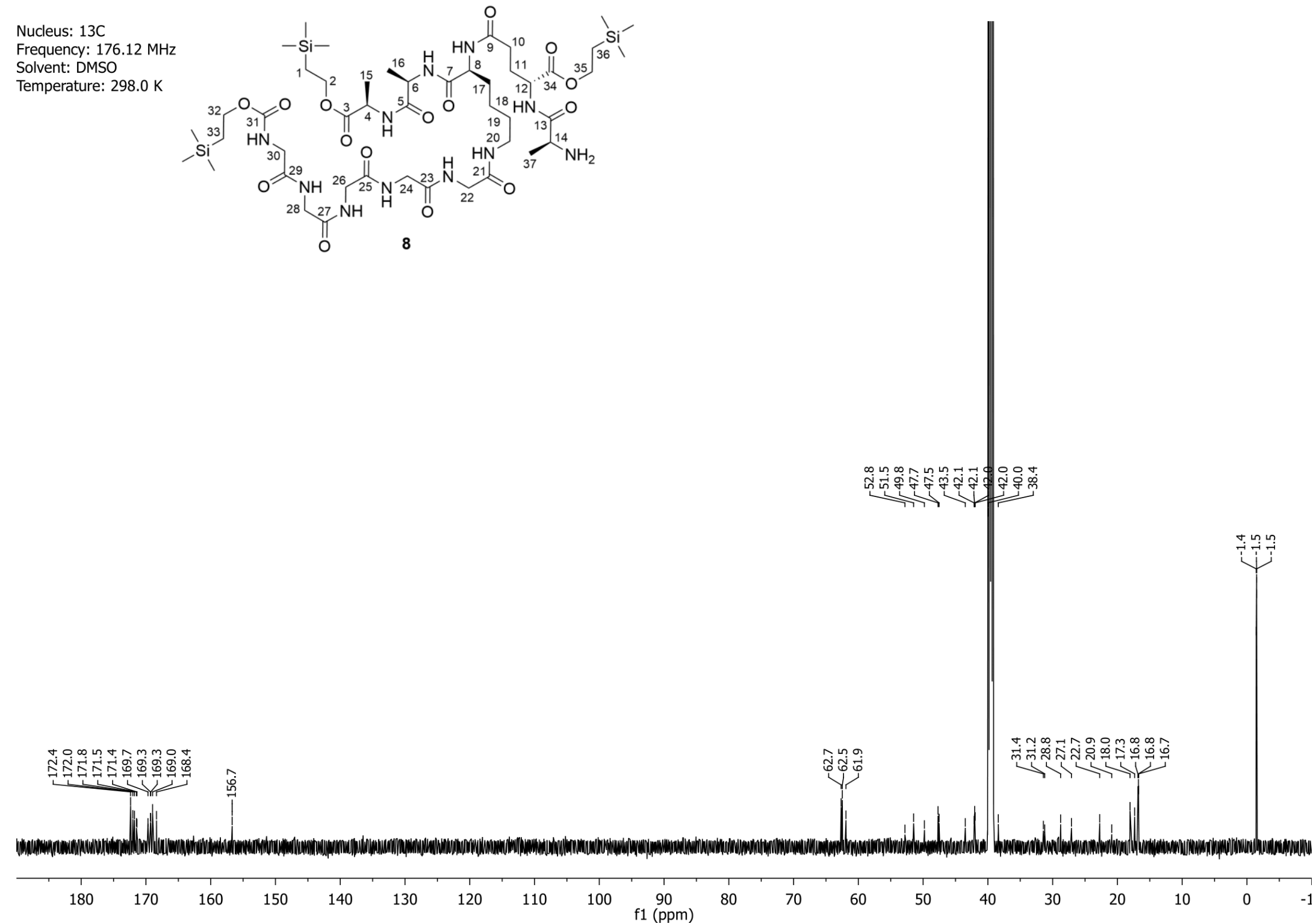

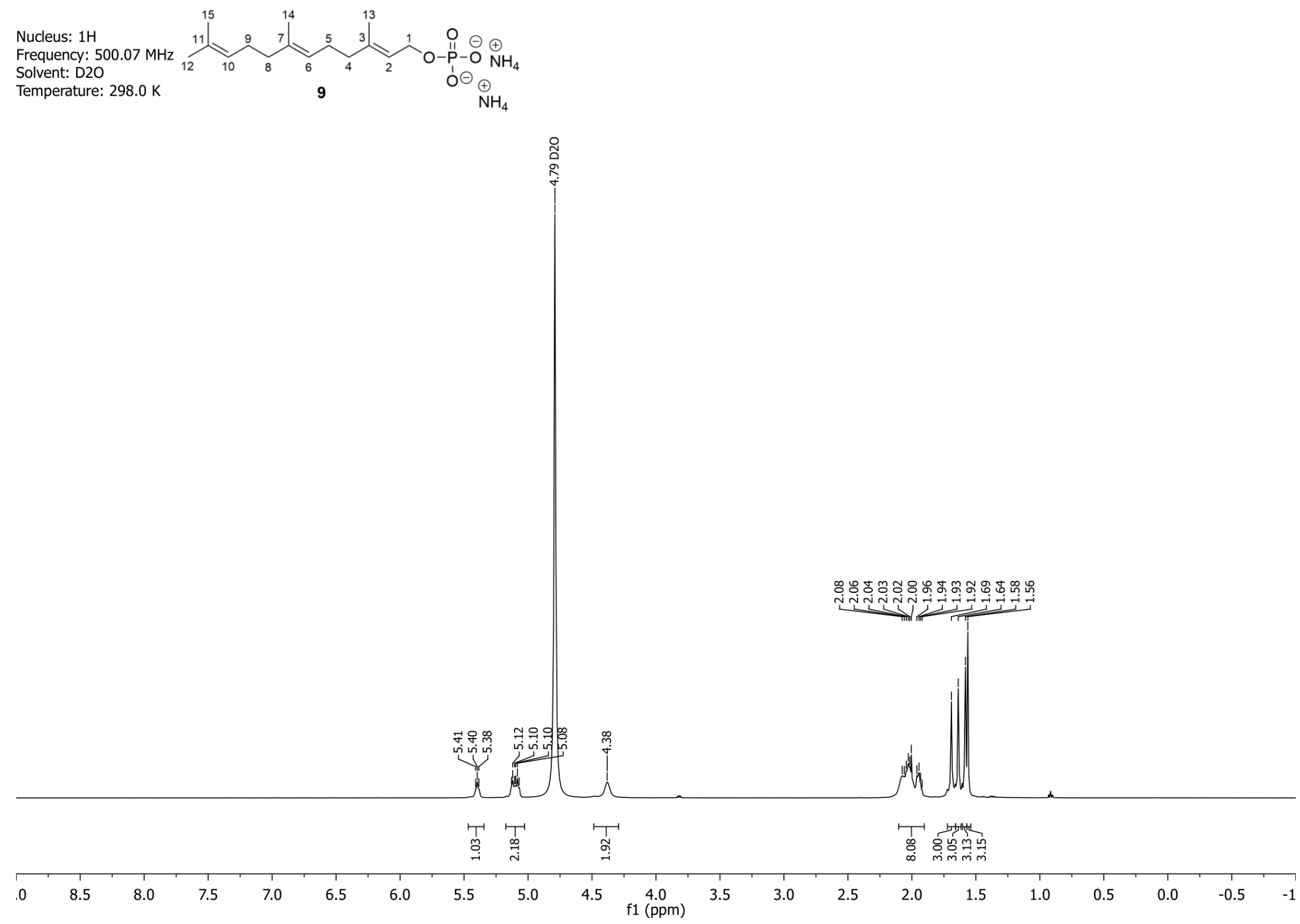

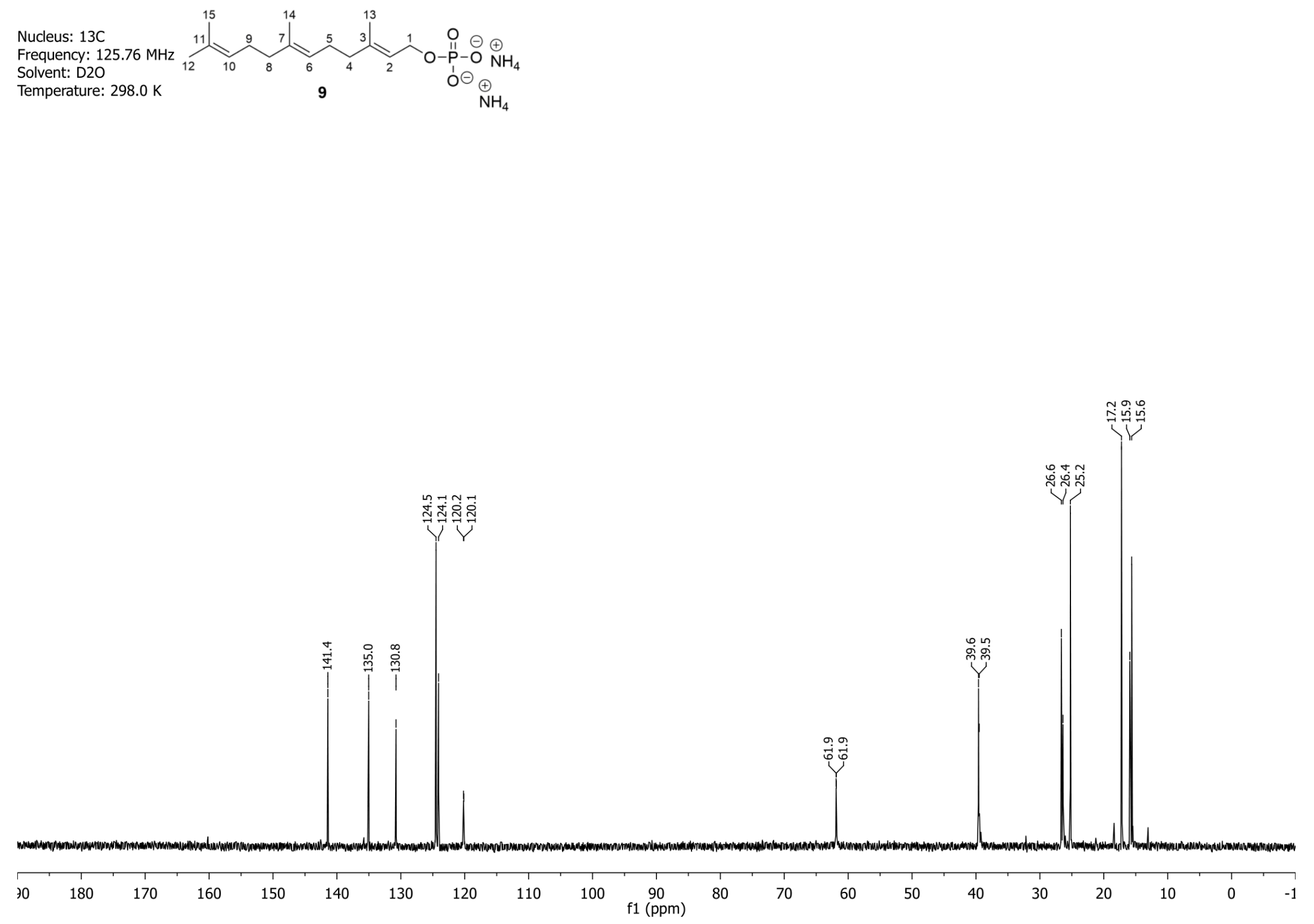

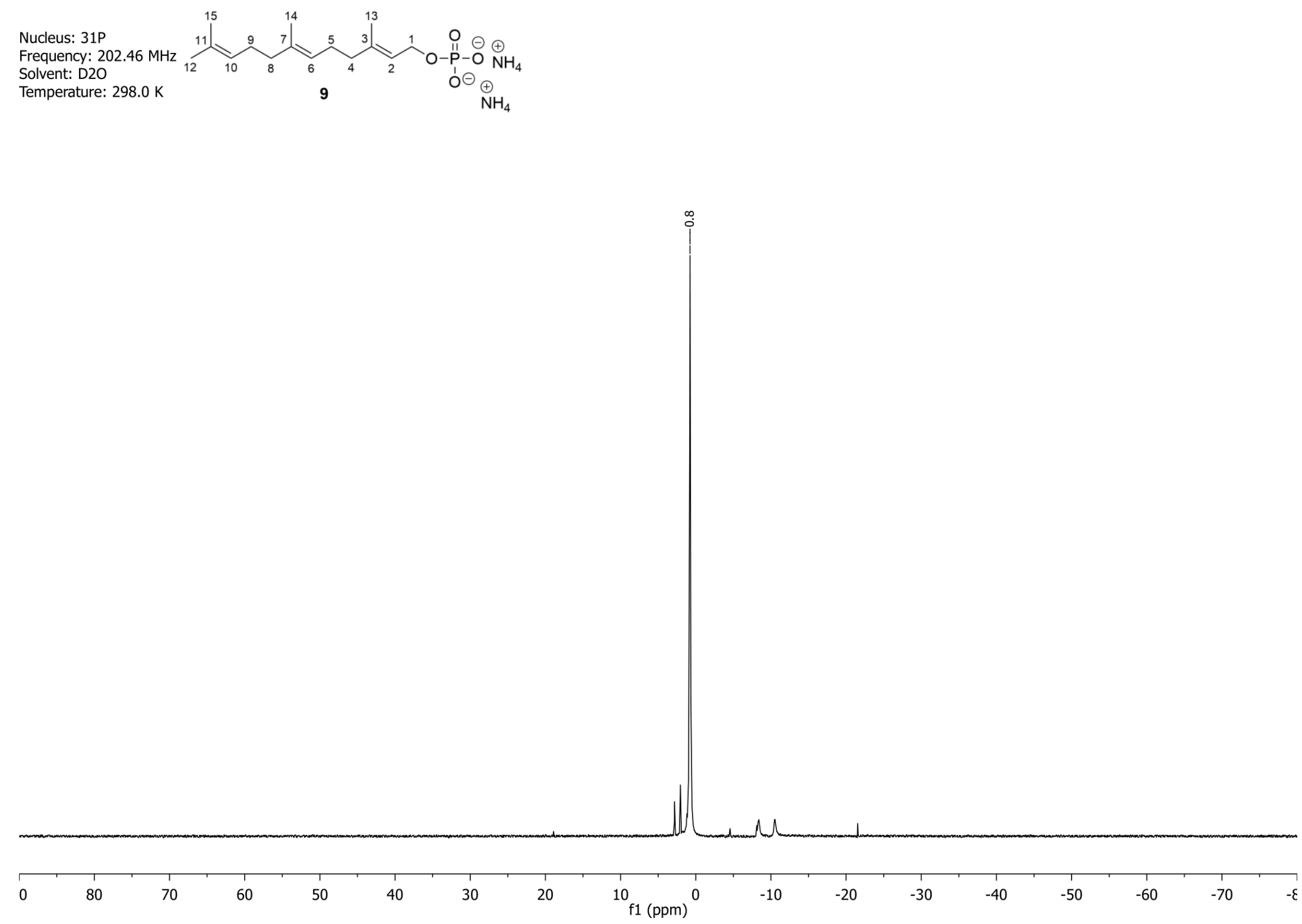
Nucleus: $1 \mathrm{H}$

Frequency: $700.41 \mathrm{MHz}$

Solvent: MeOD

Temperature: $298.0 \mathrm{~K}$

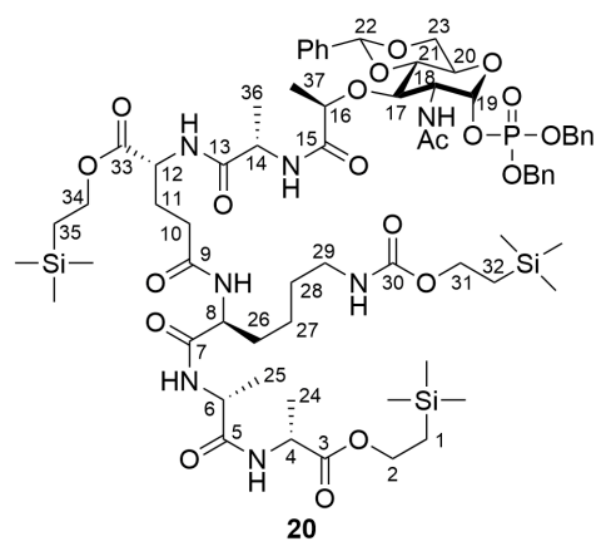

20

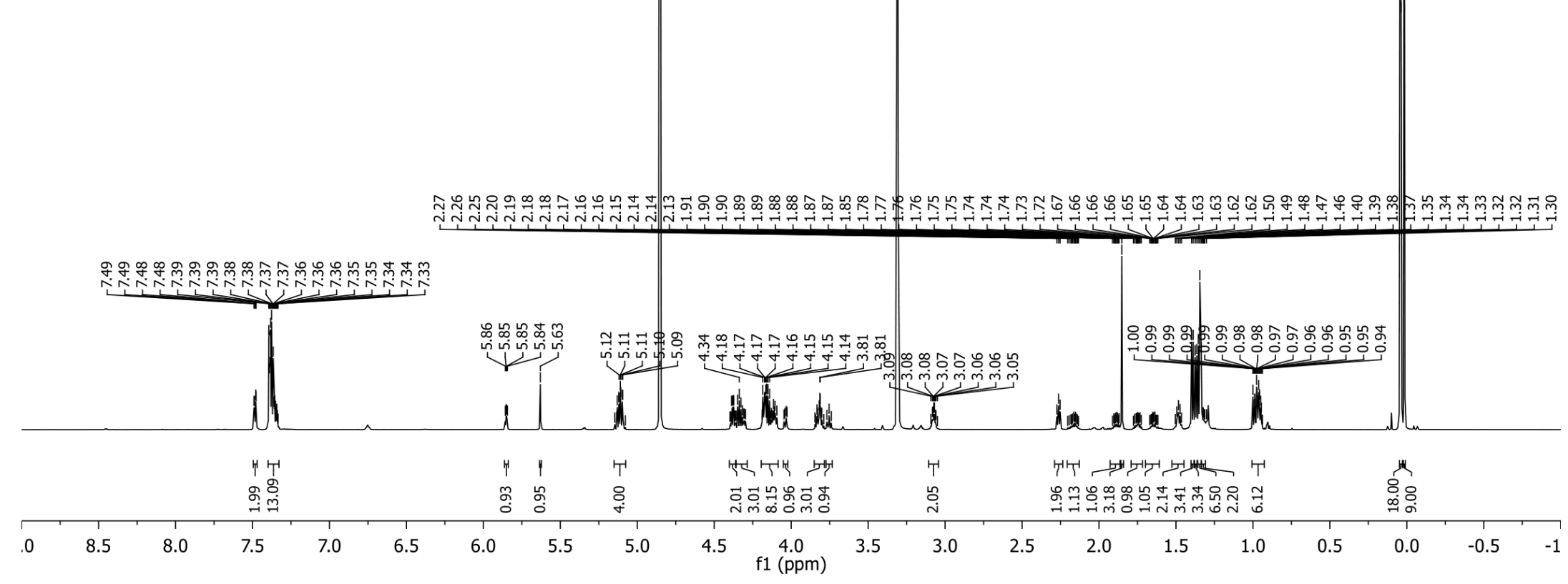



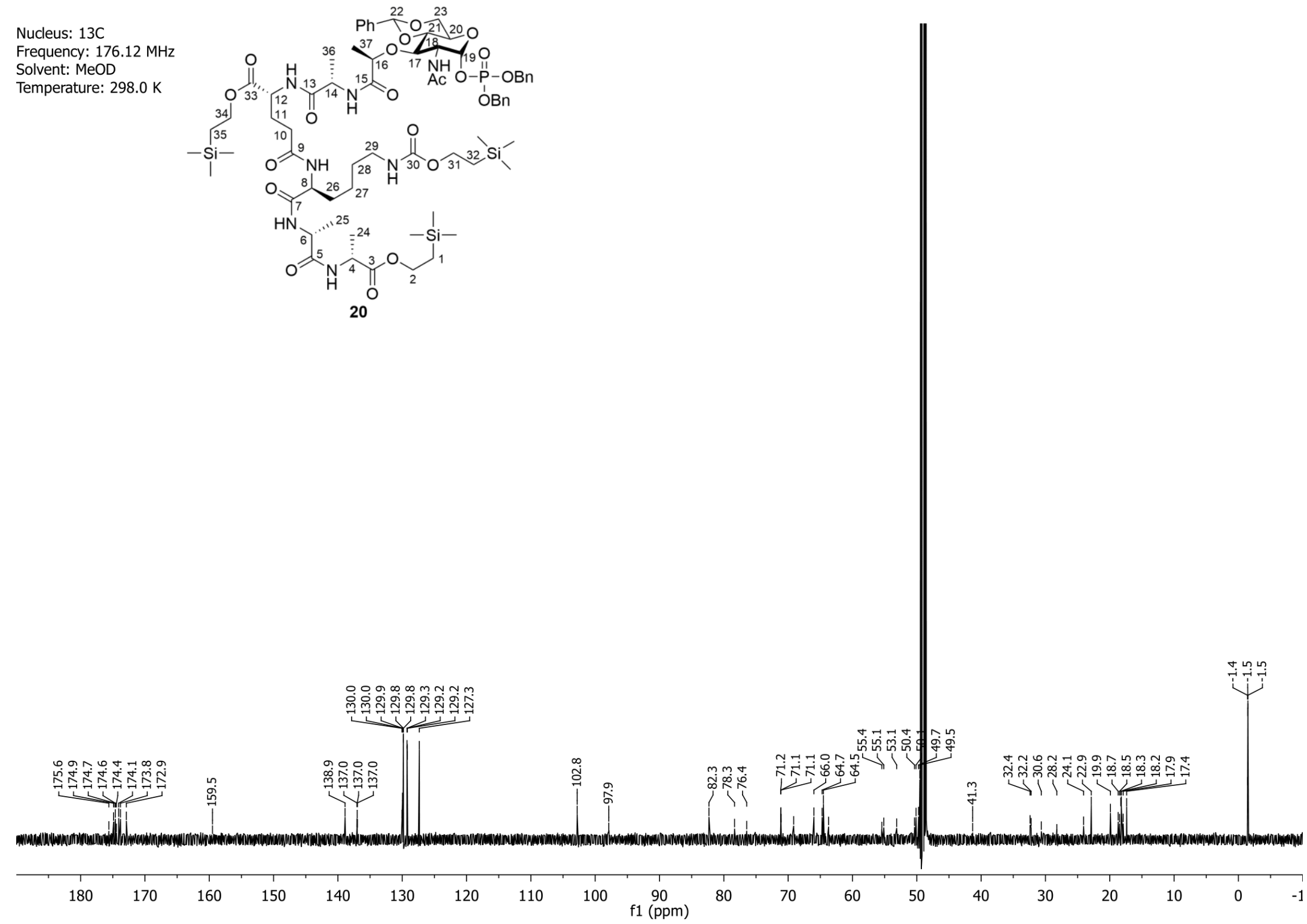

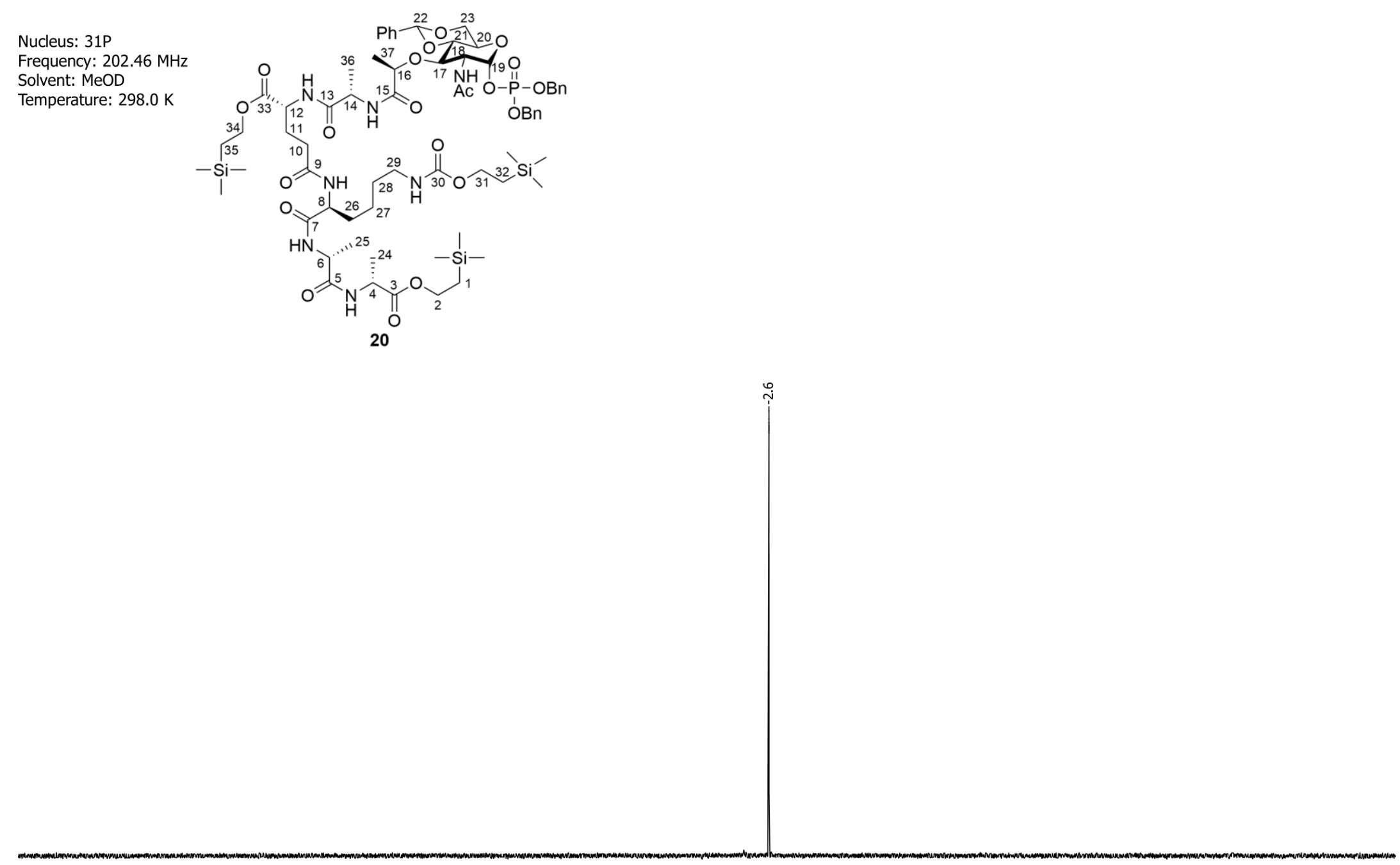

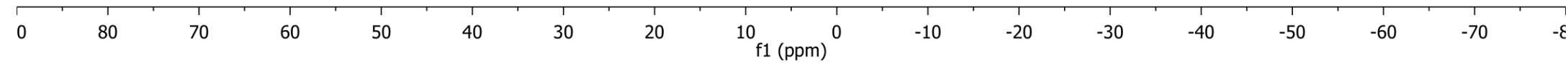




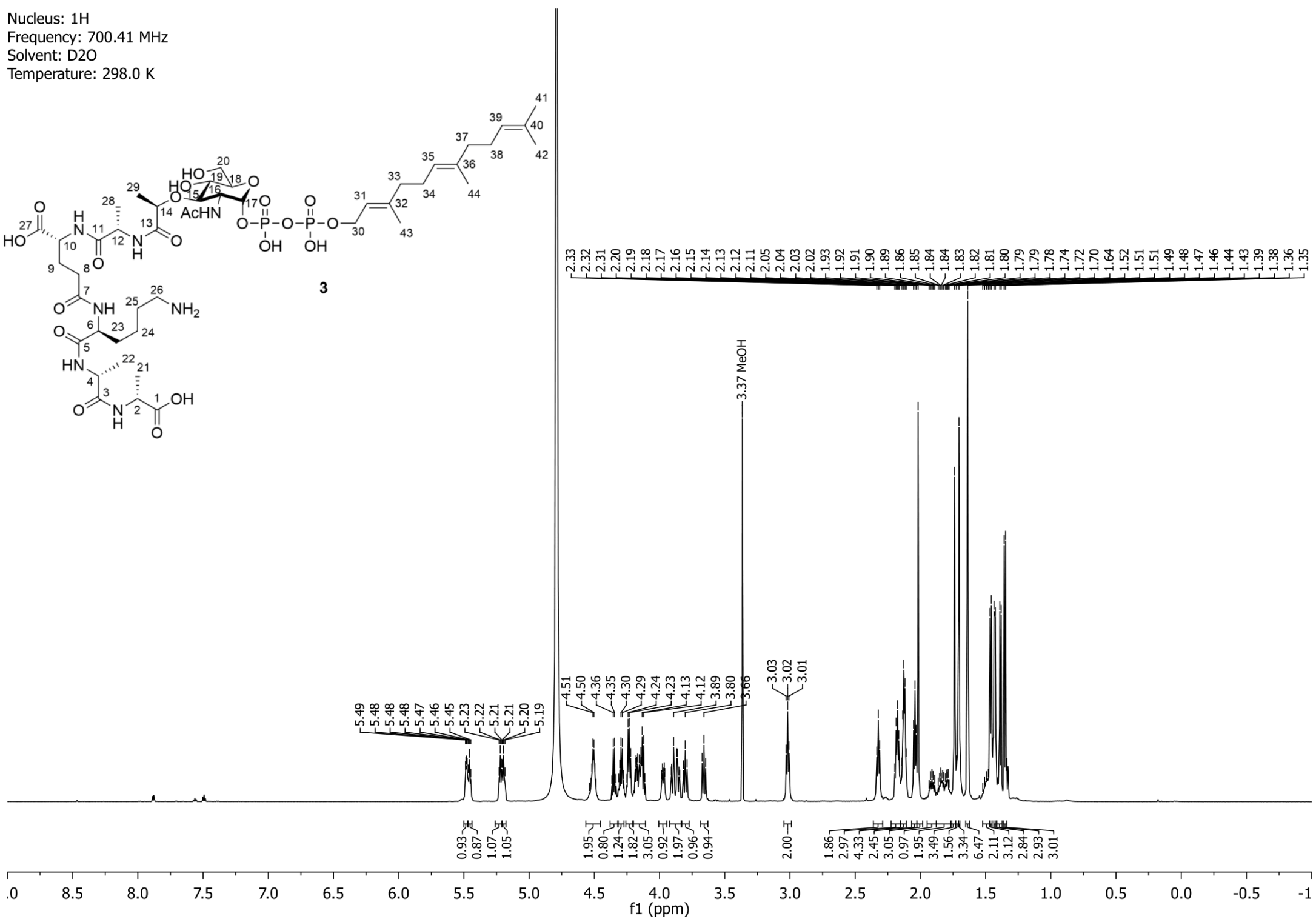


Nucleus: $13 \mathrm{C}$

Frequency: $176.12 \mathrm{MHz}$

Solvent: D2O

Temperature: $298.0 \mathrm{~K}$
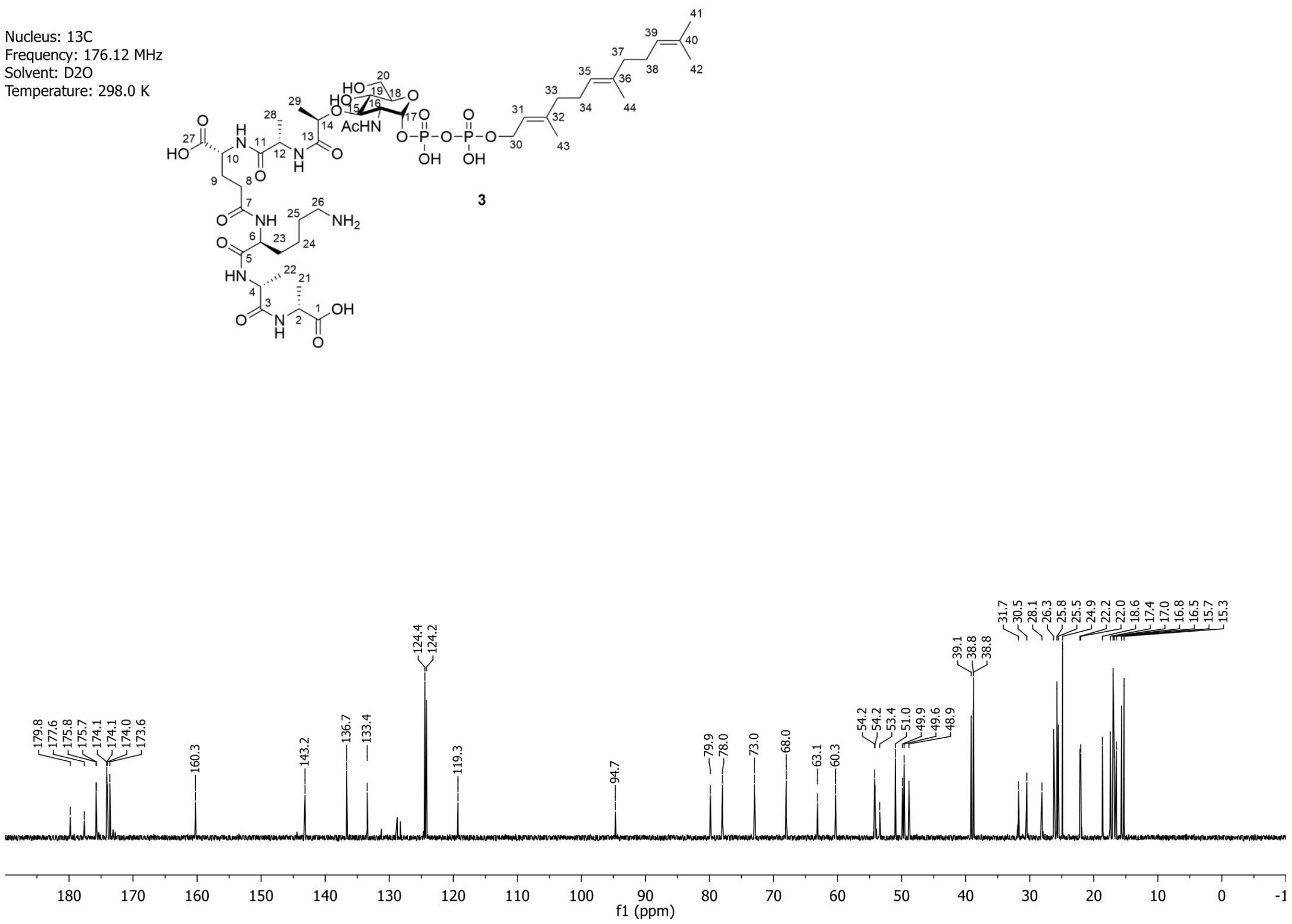

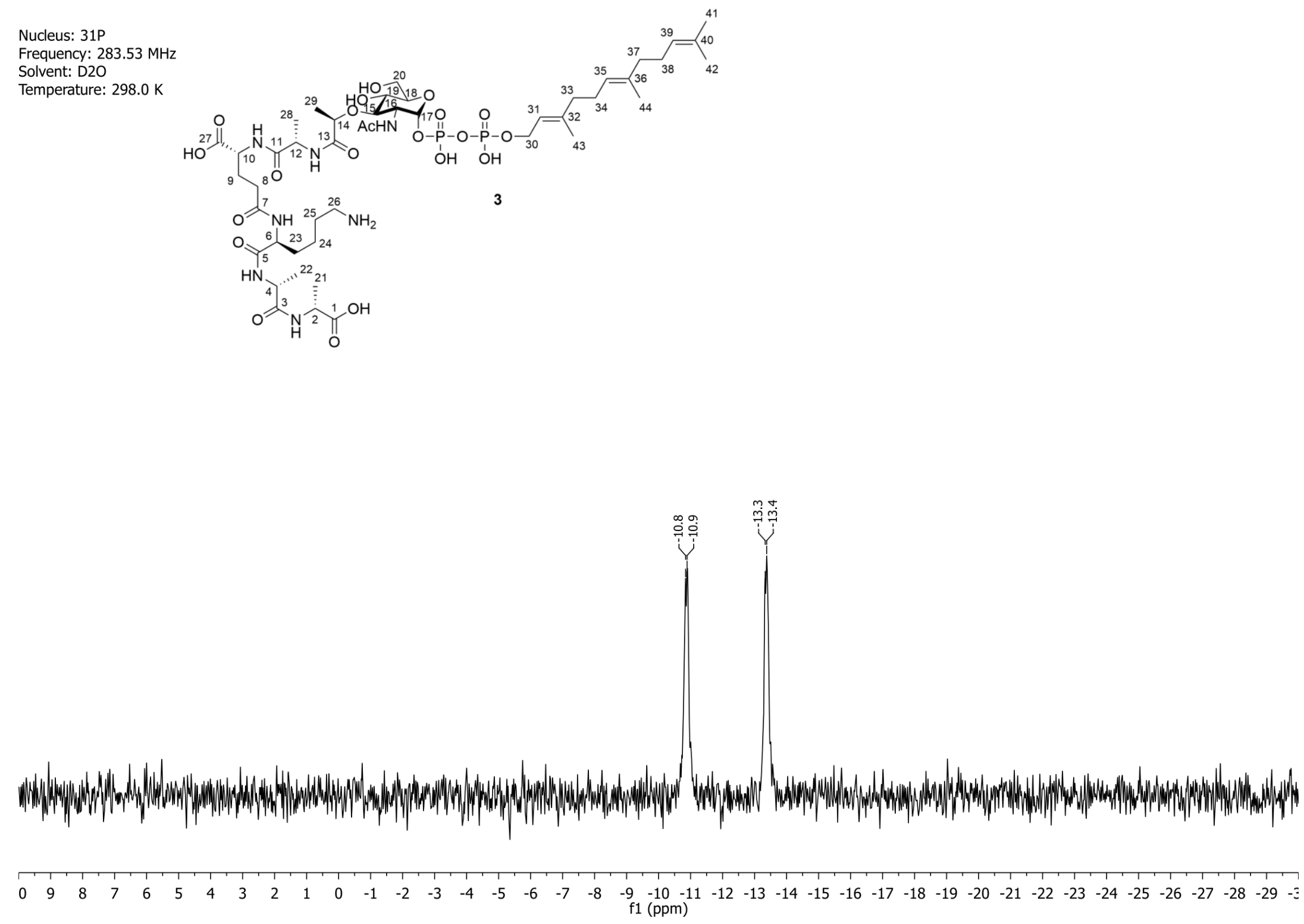


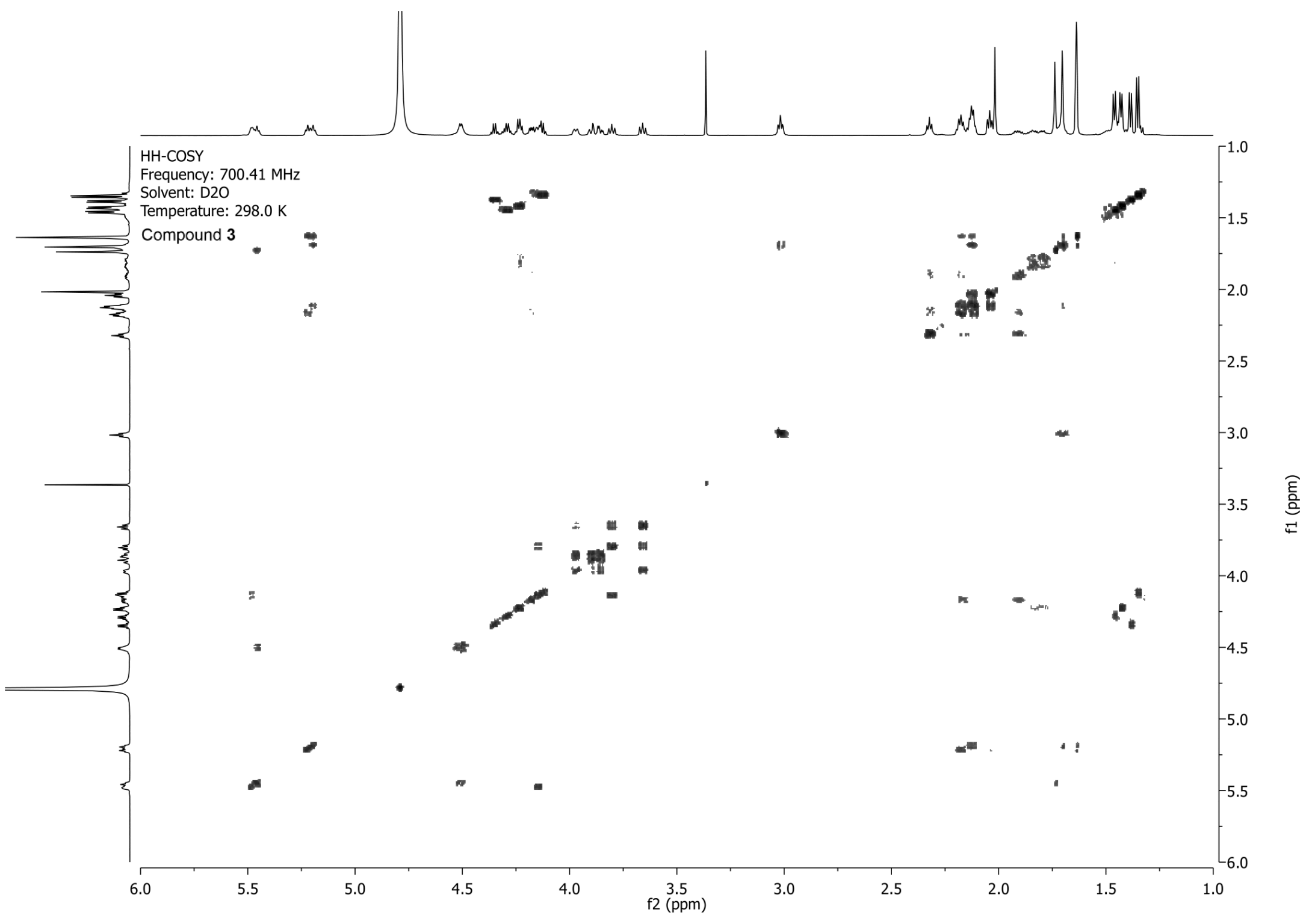




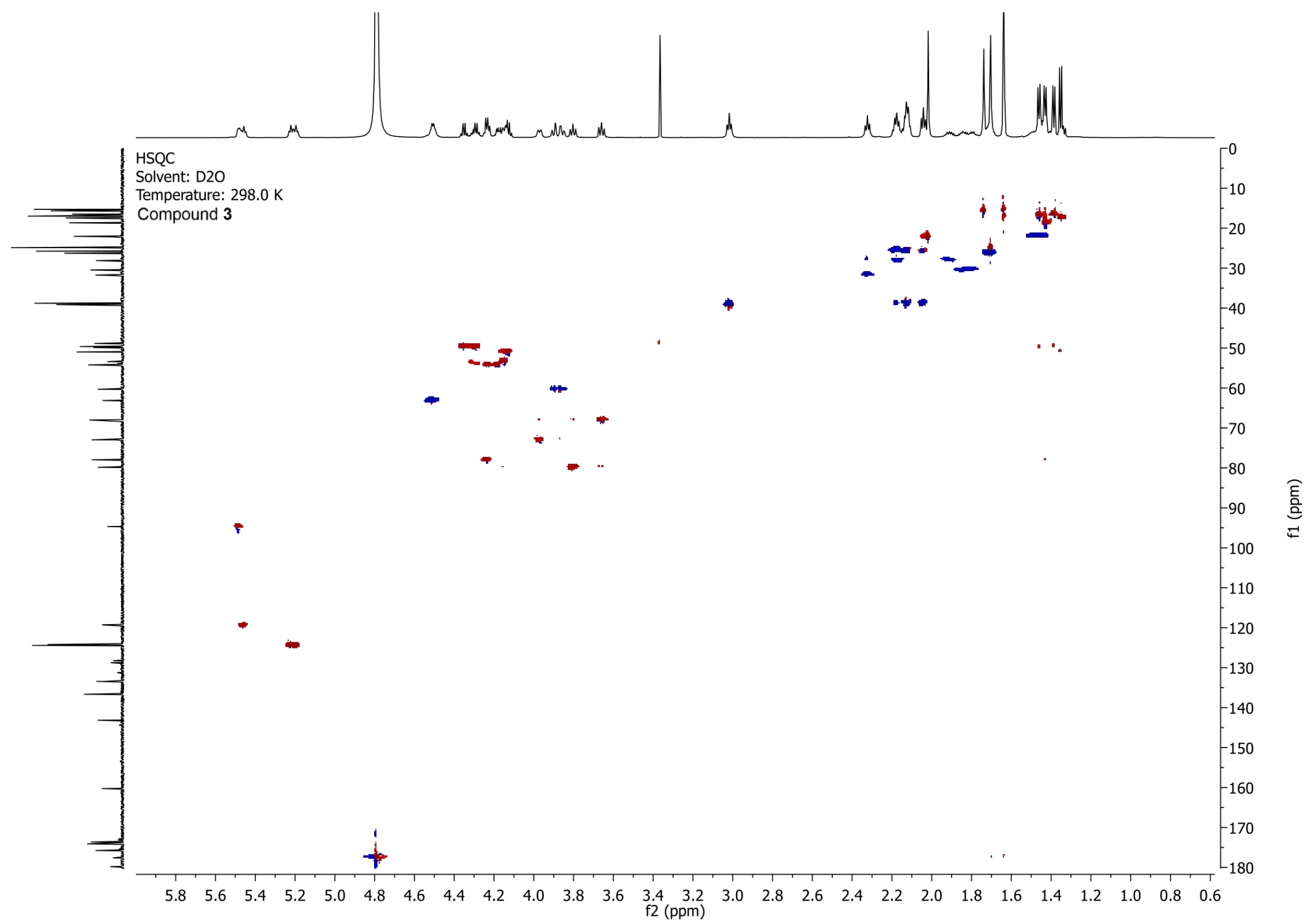




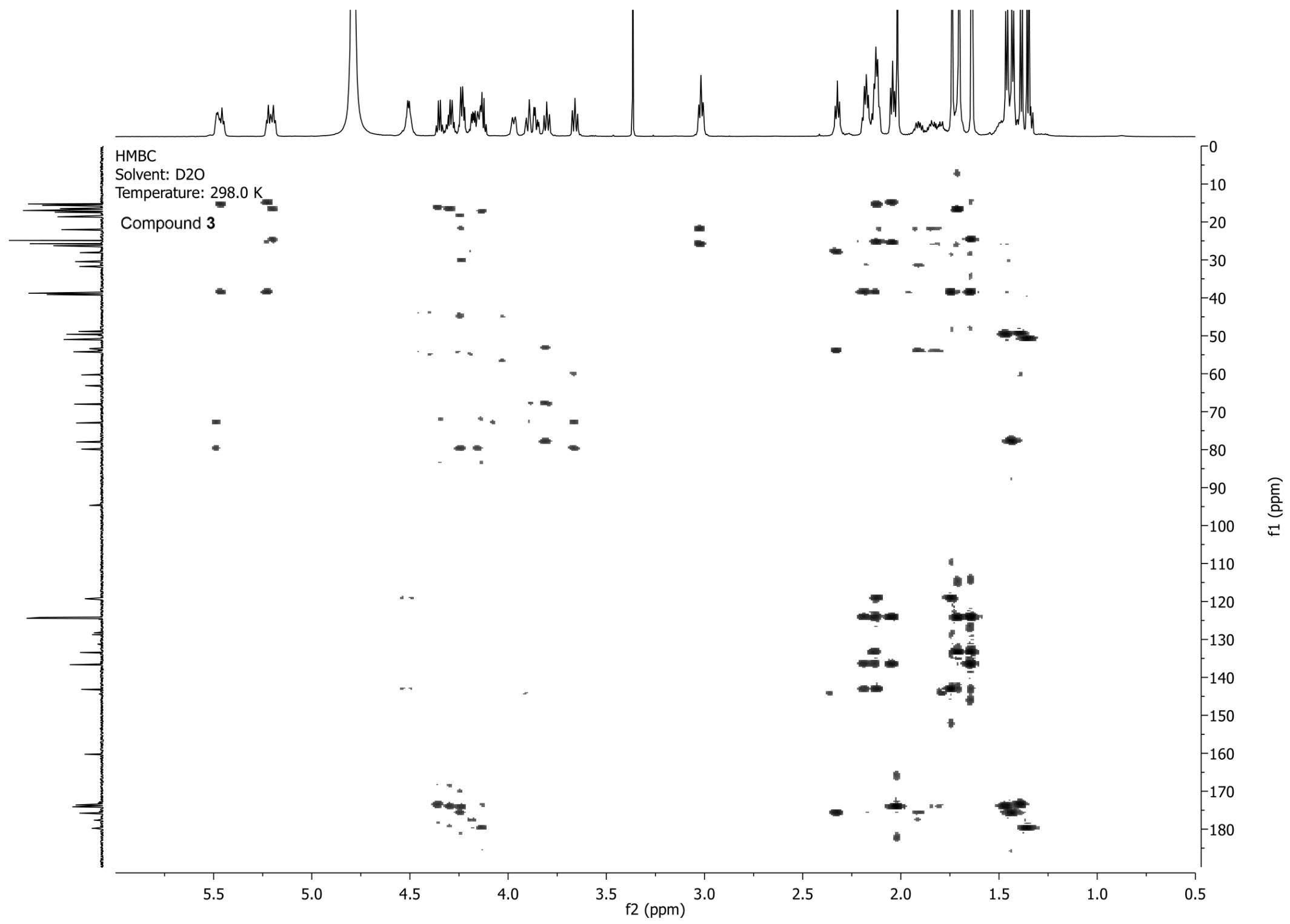




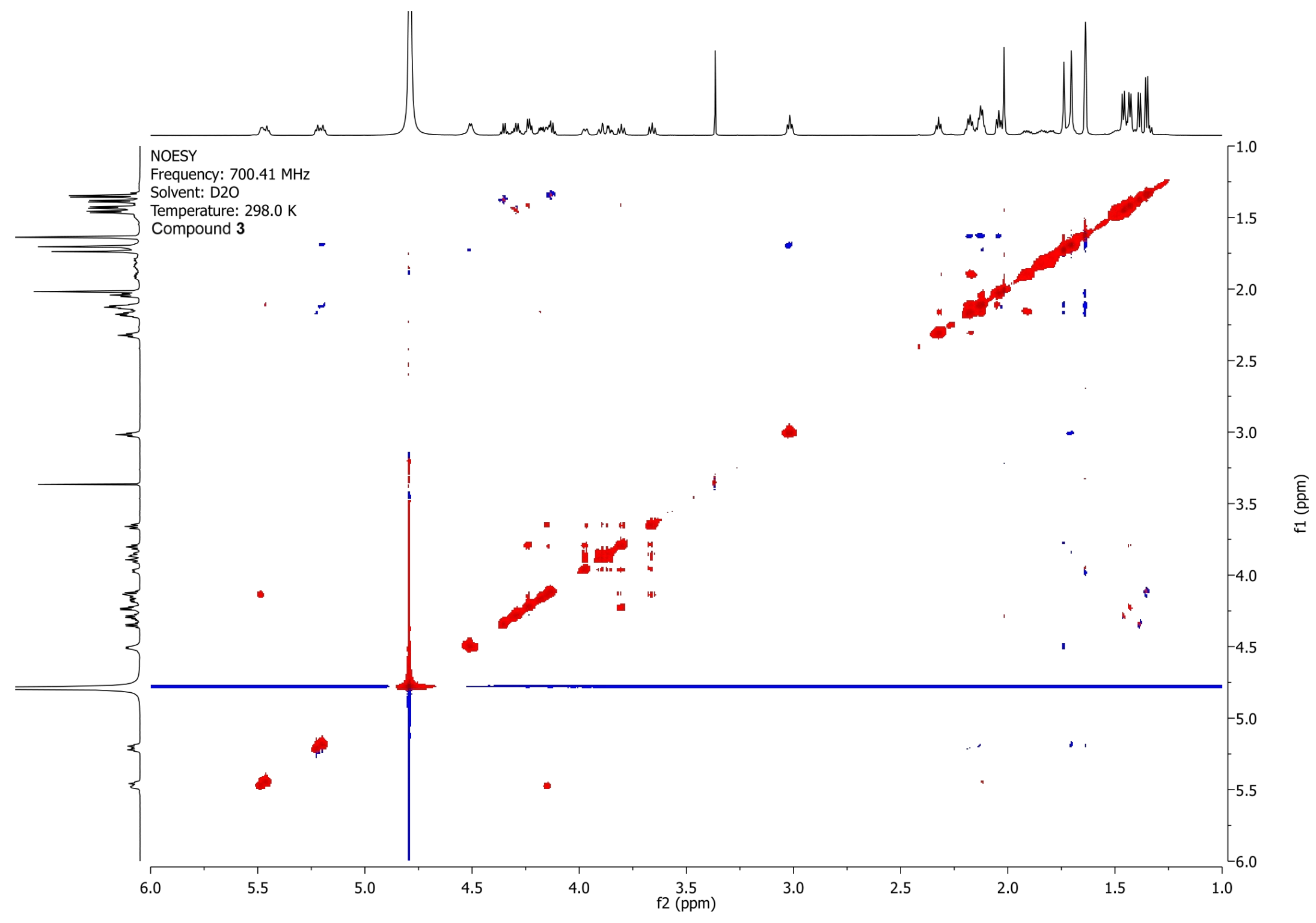




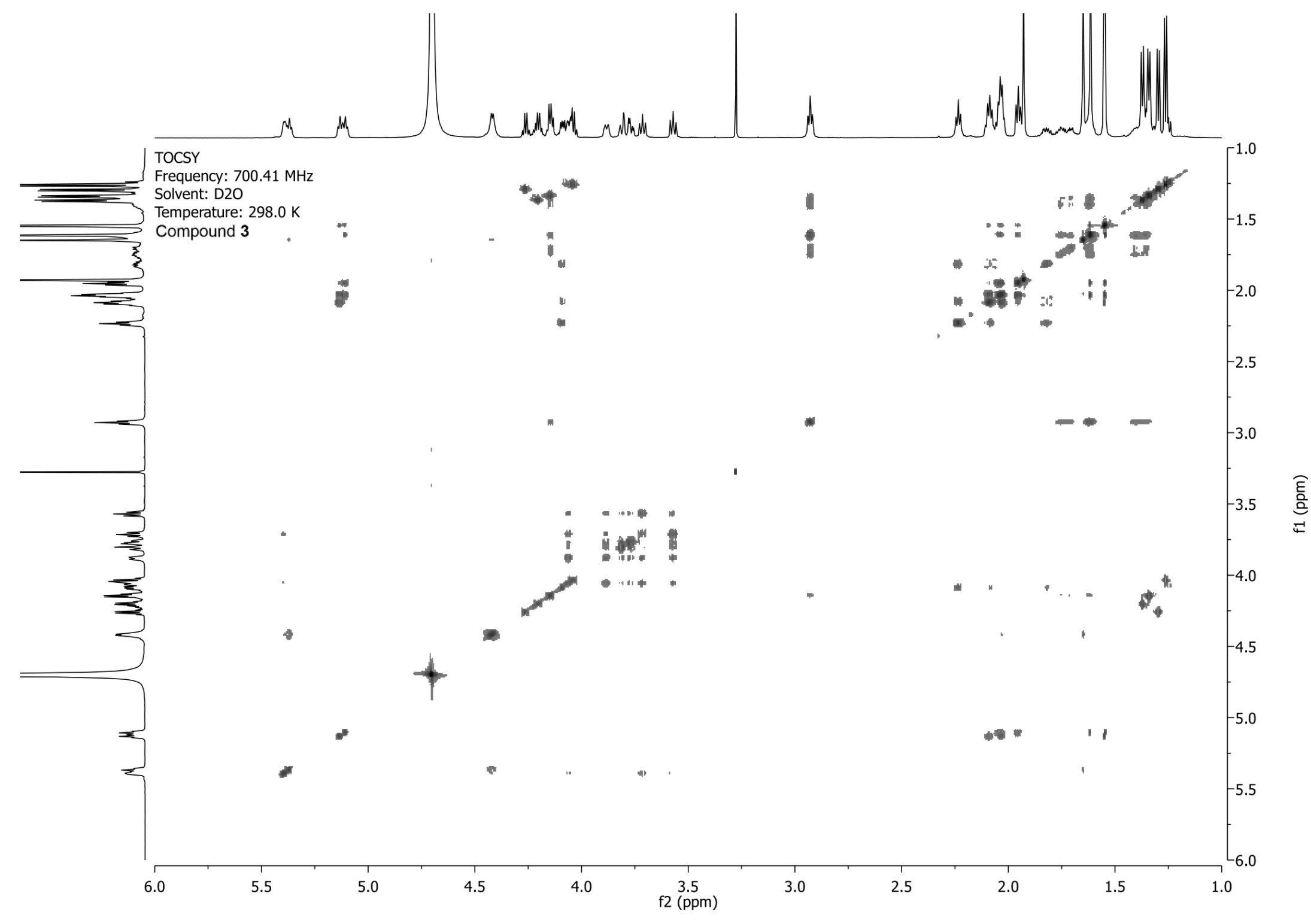




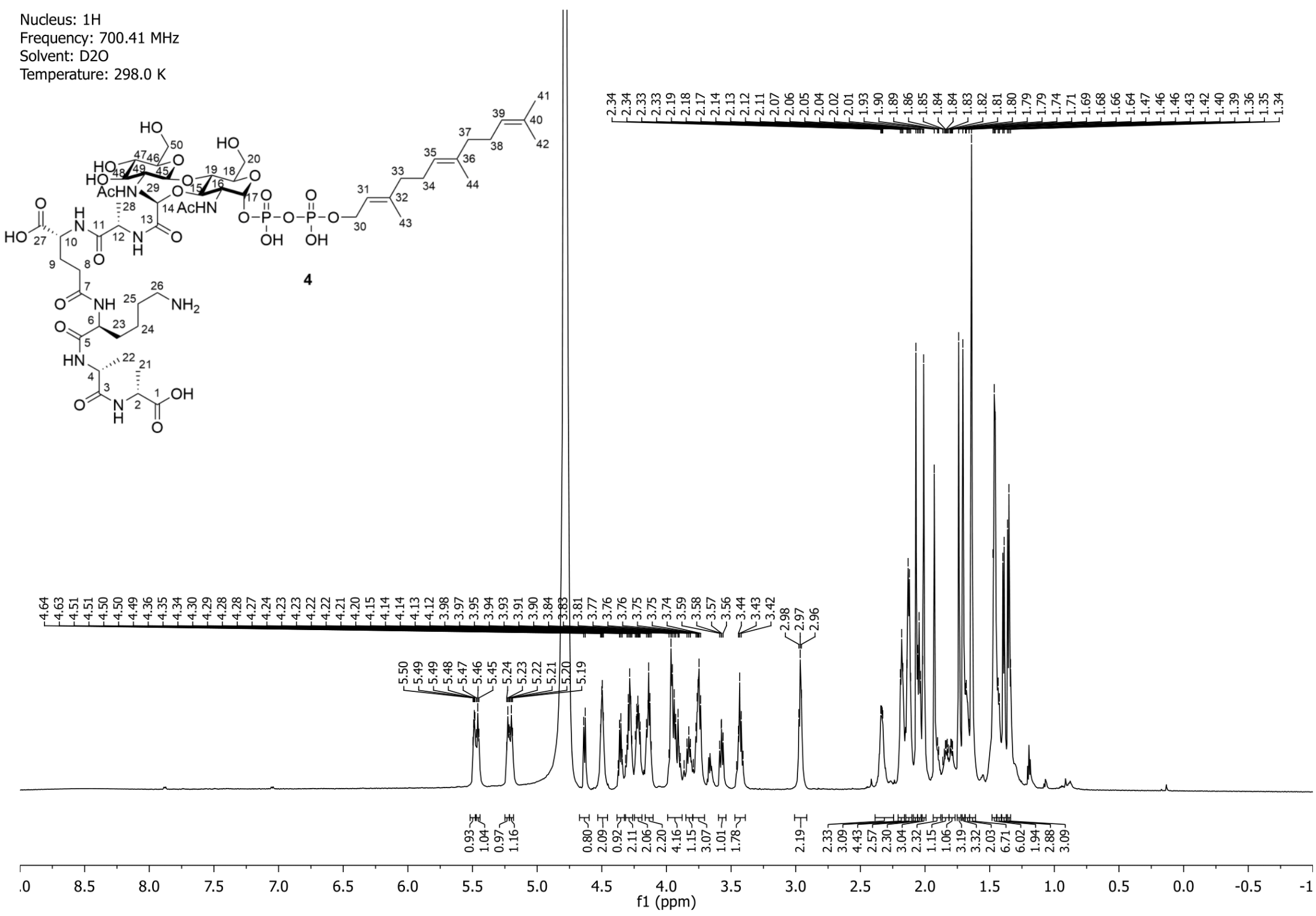



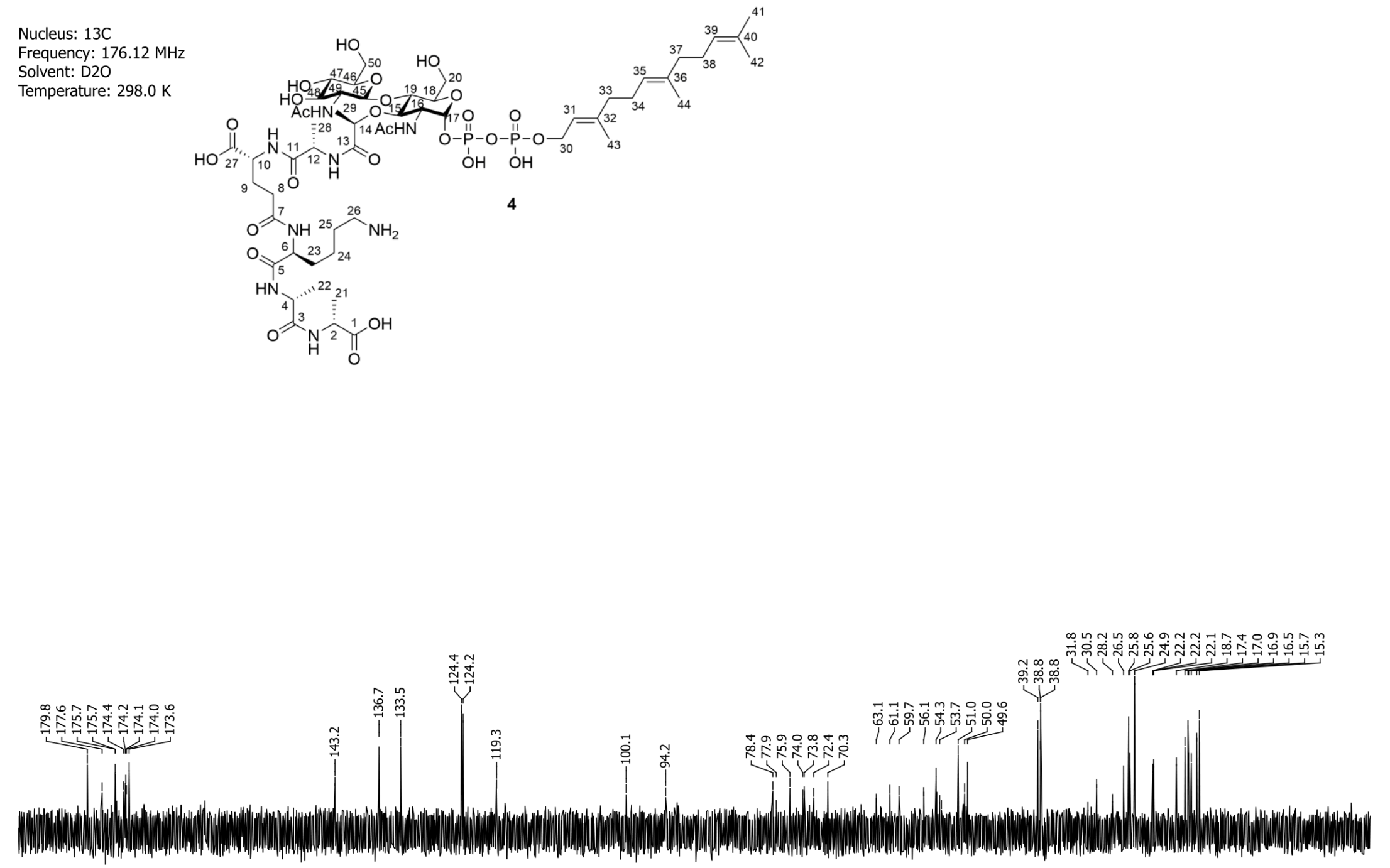

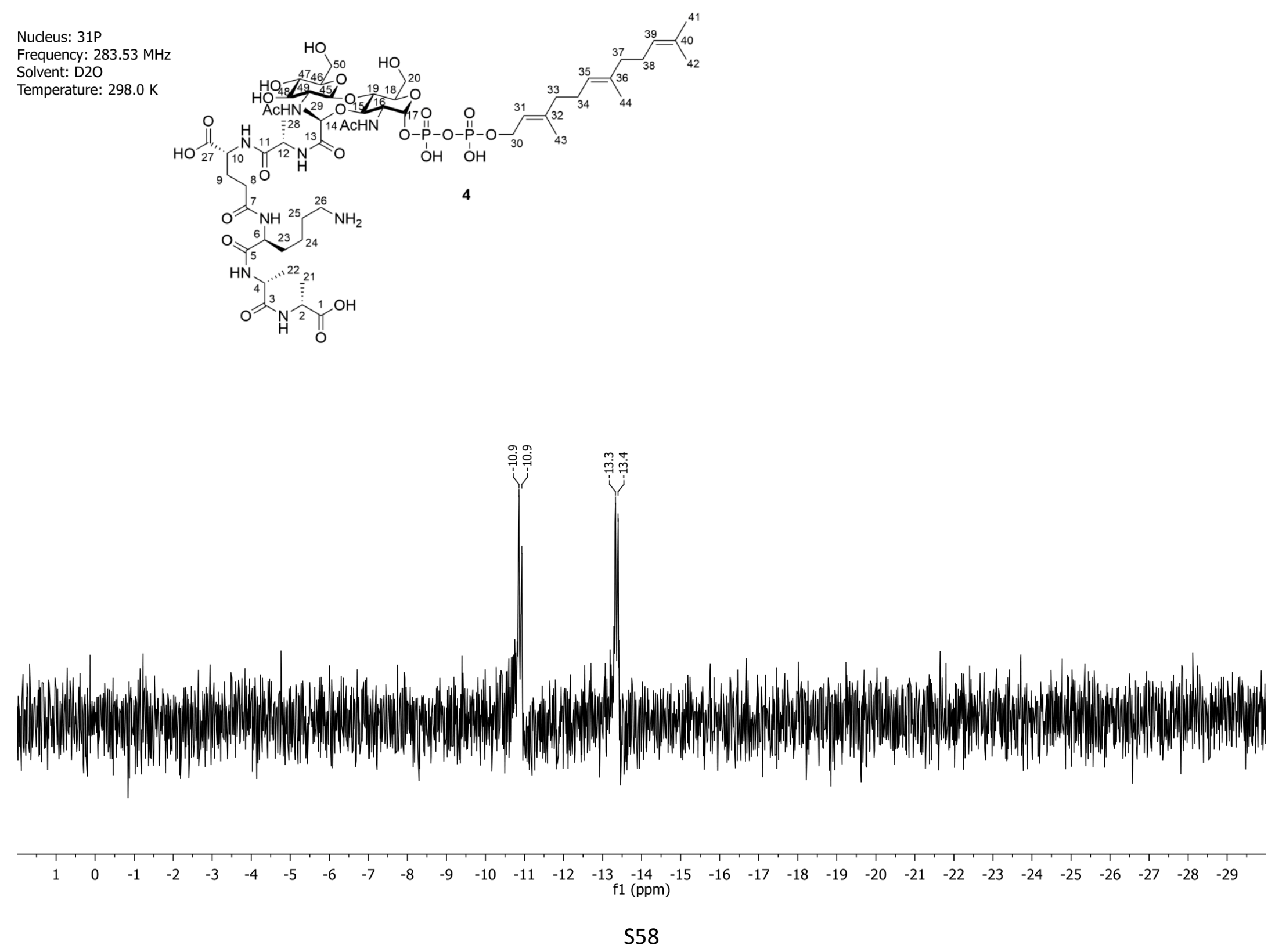


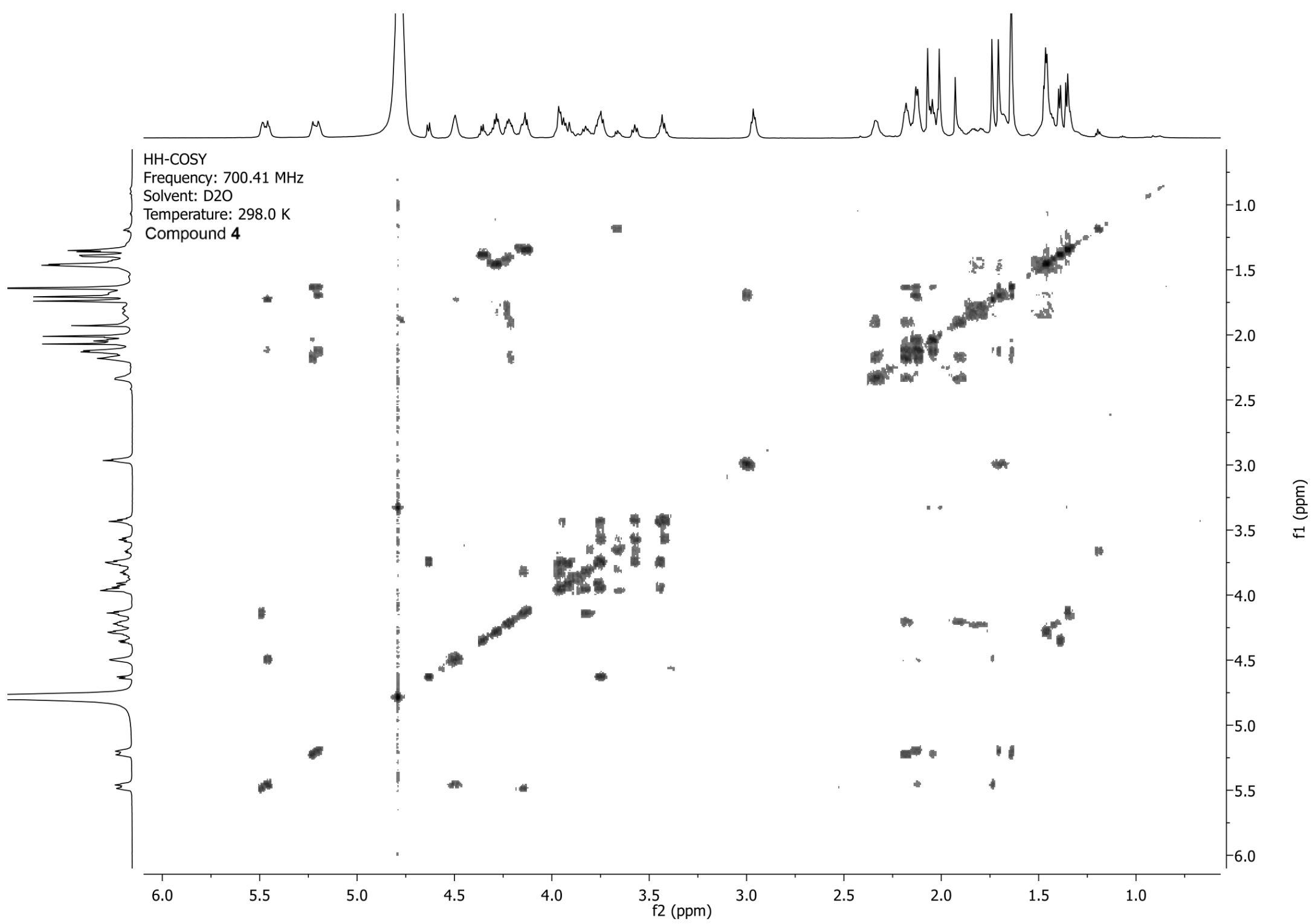




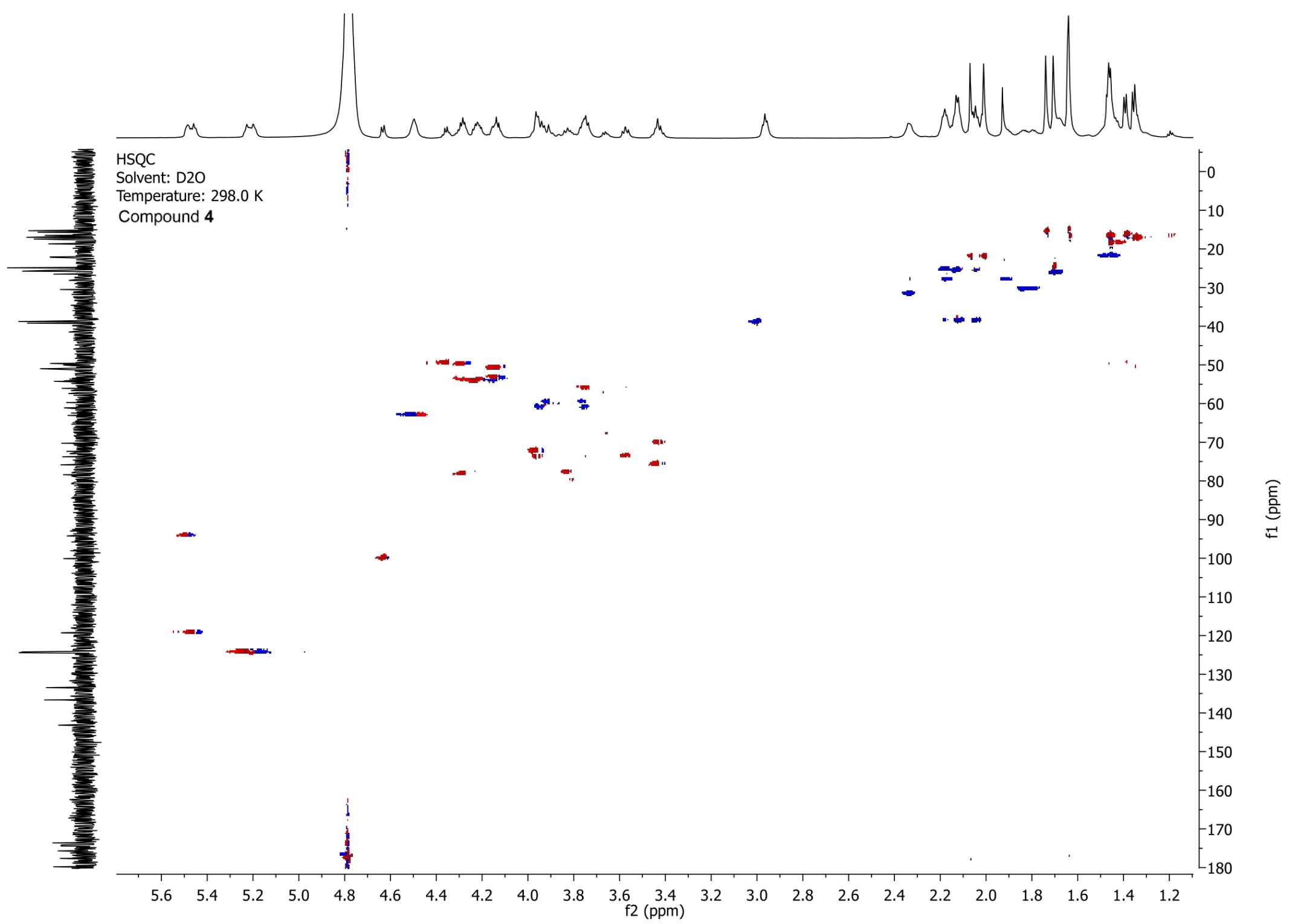




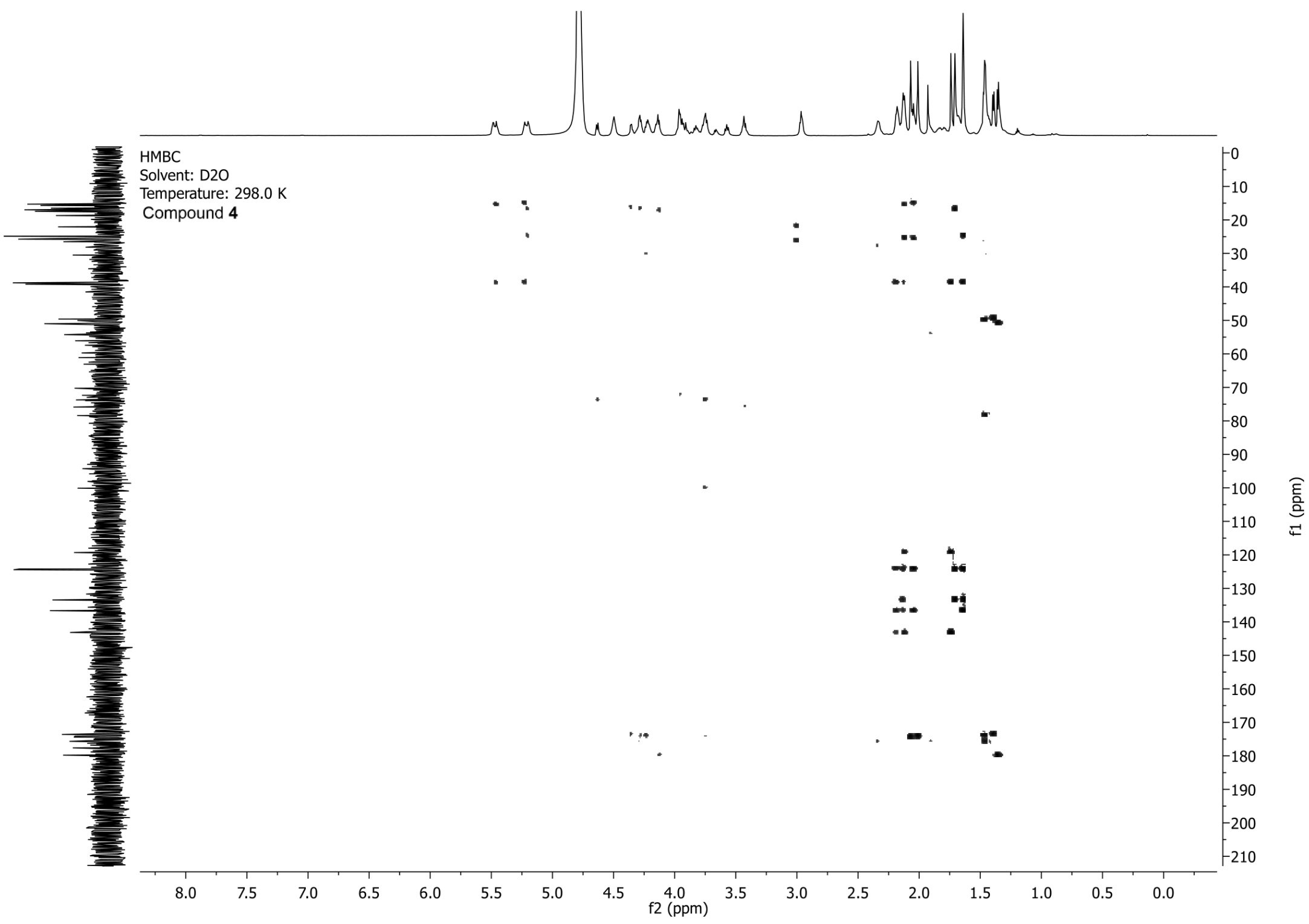




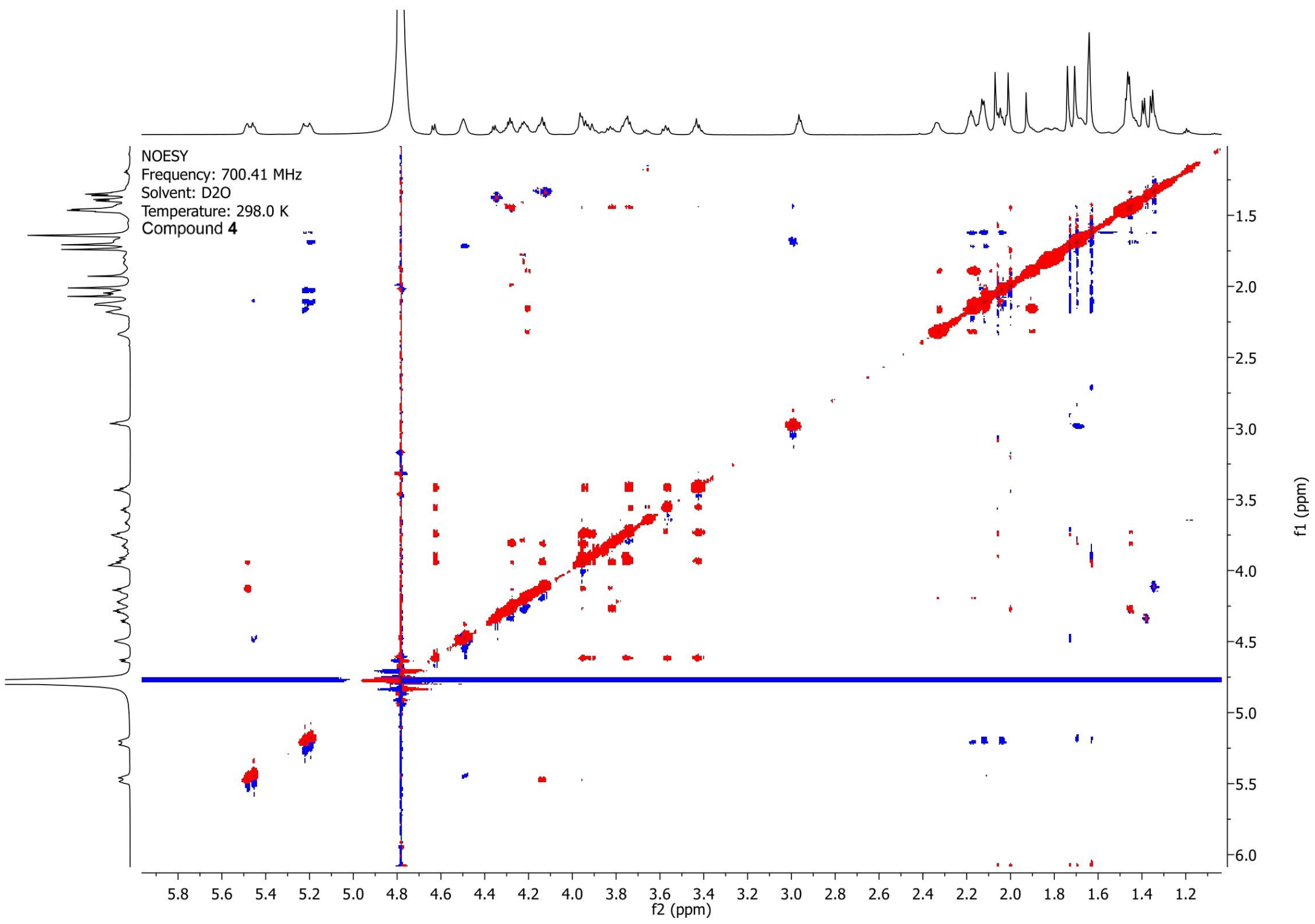




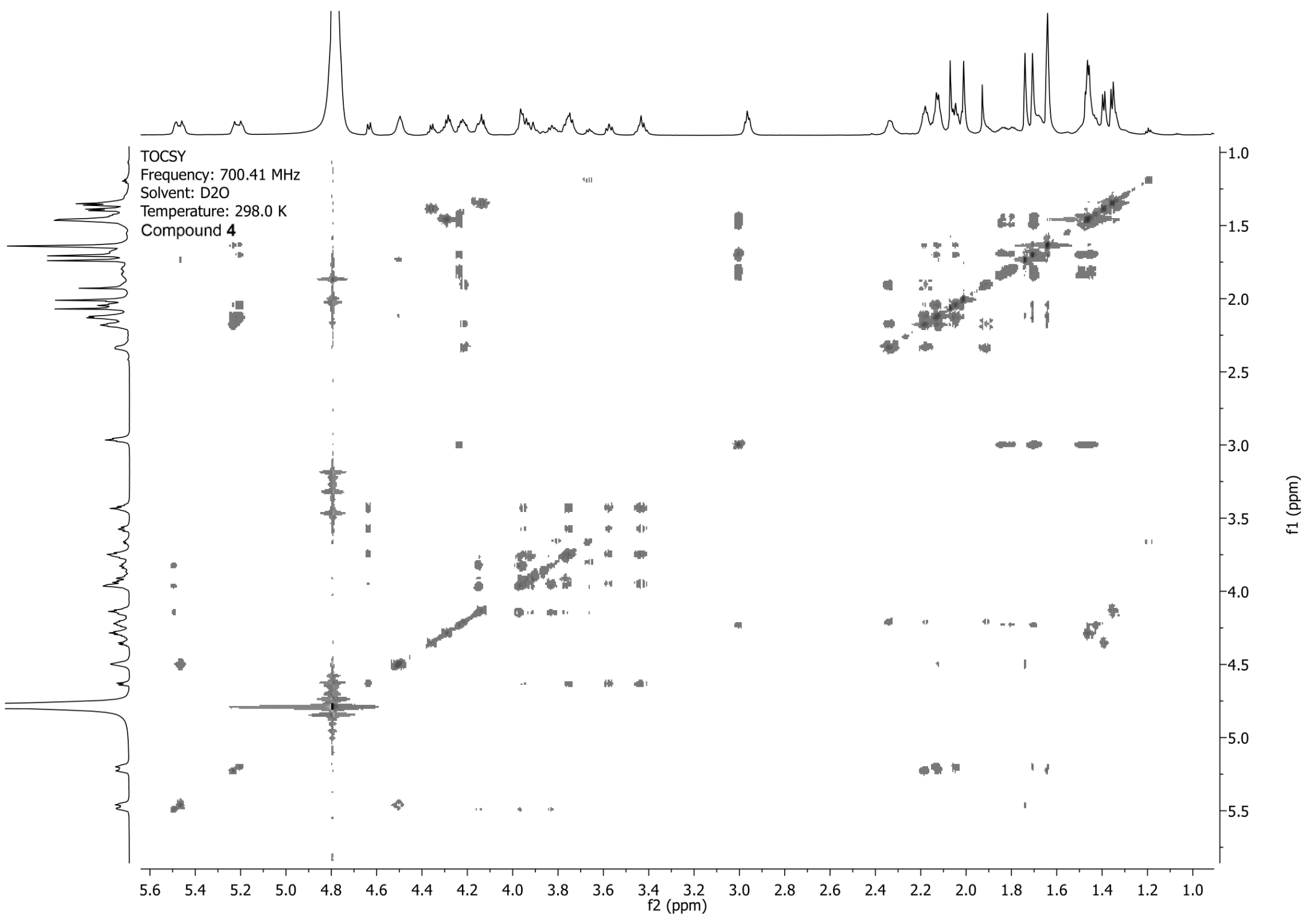




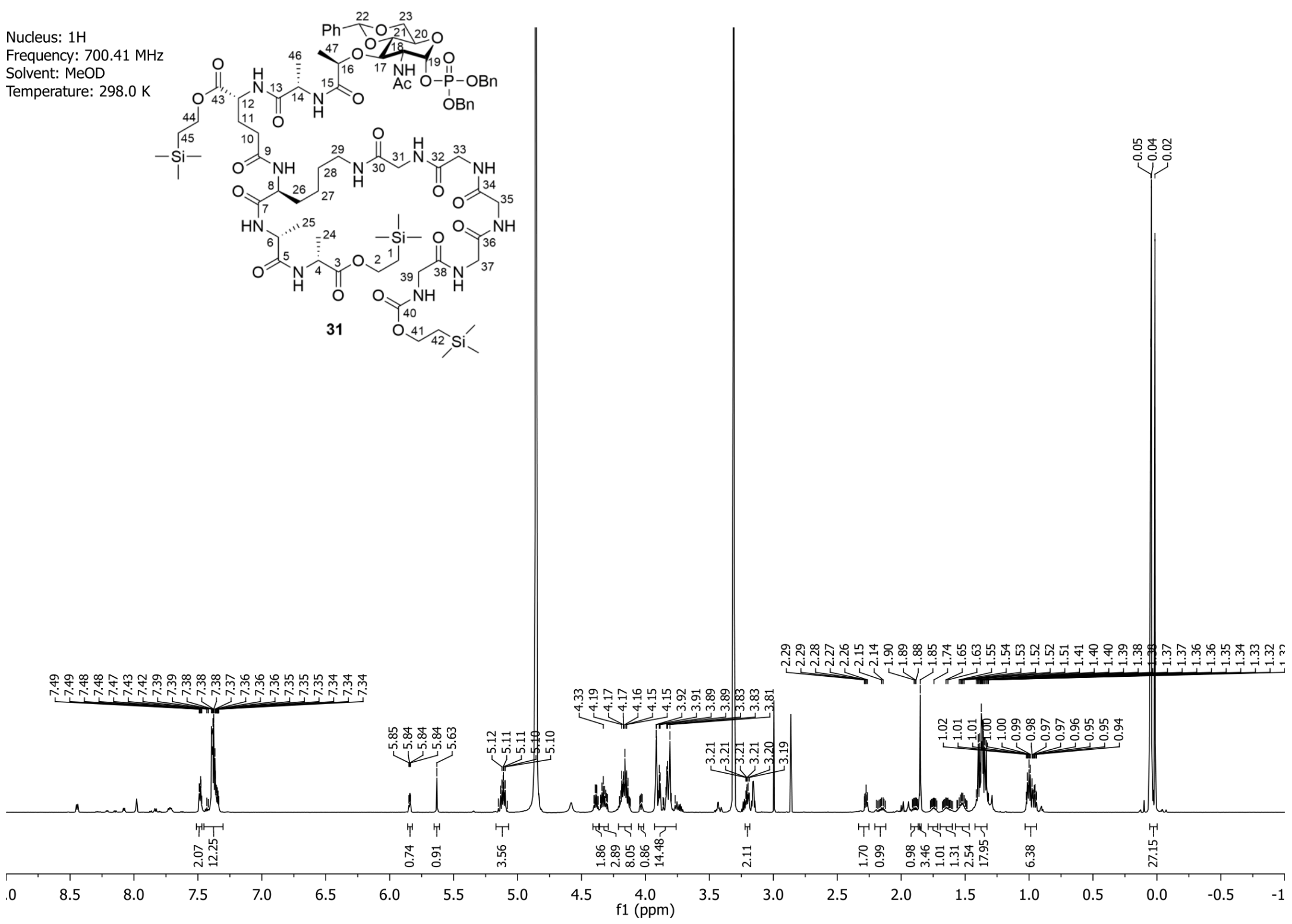



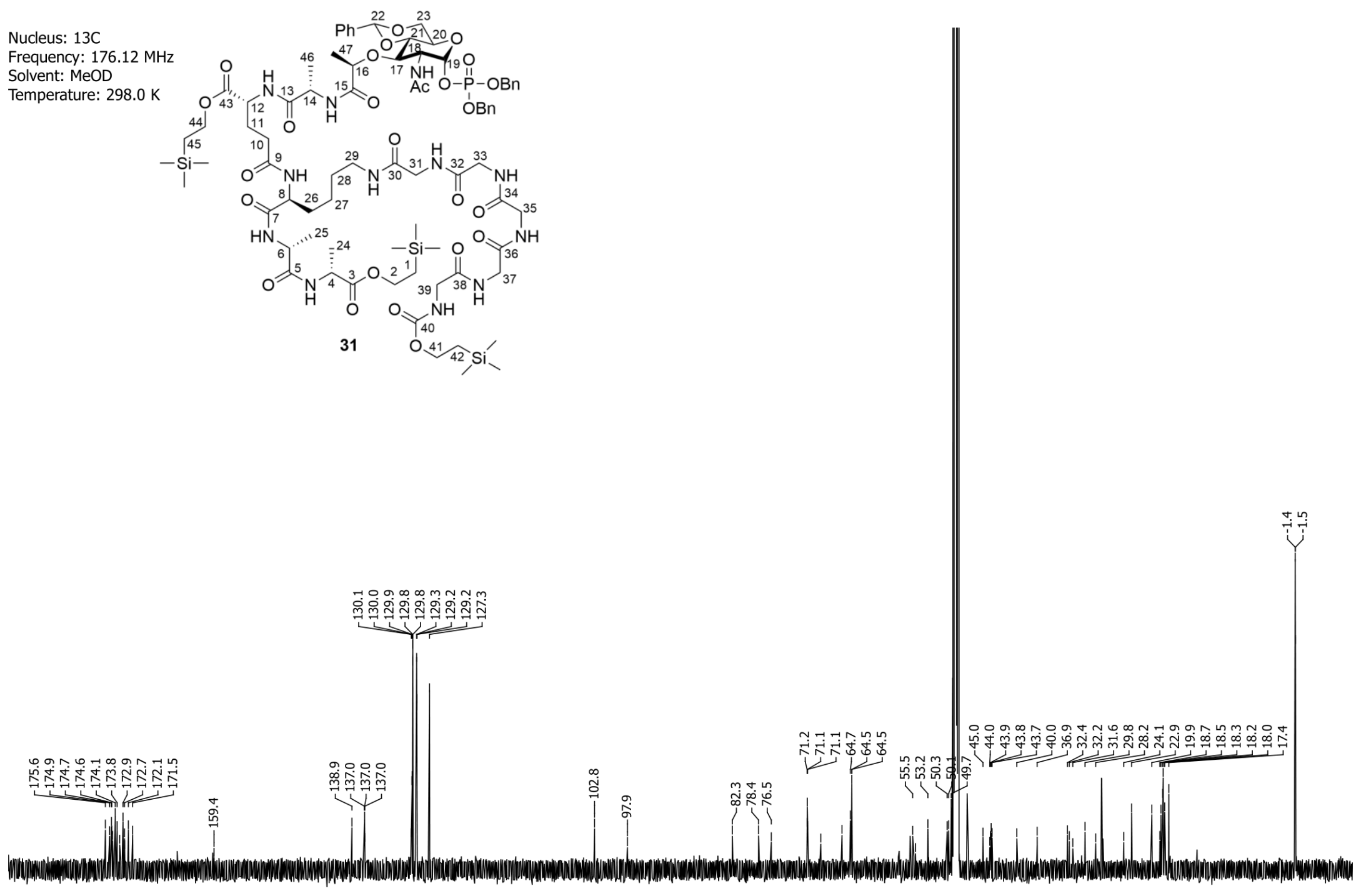


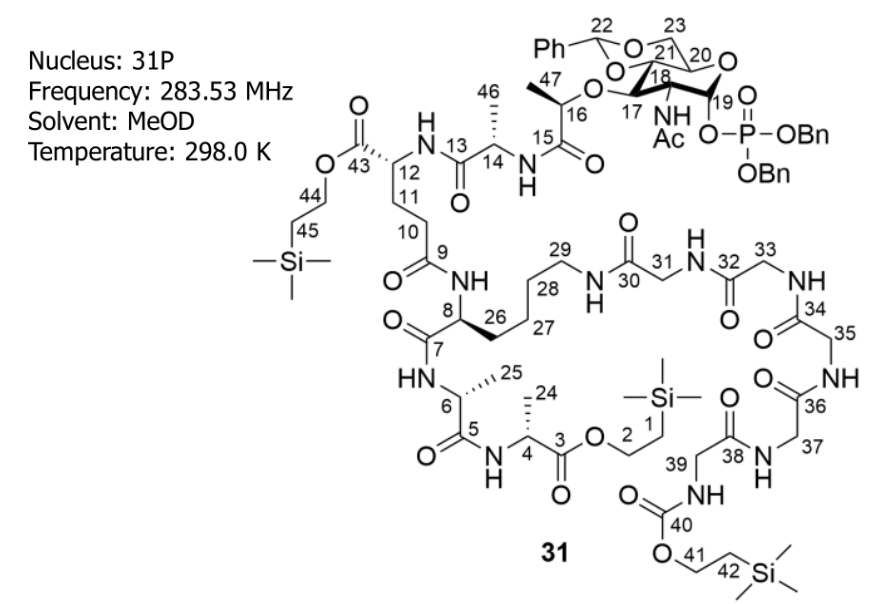

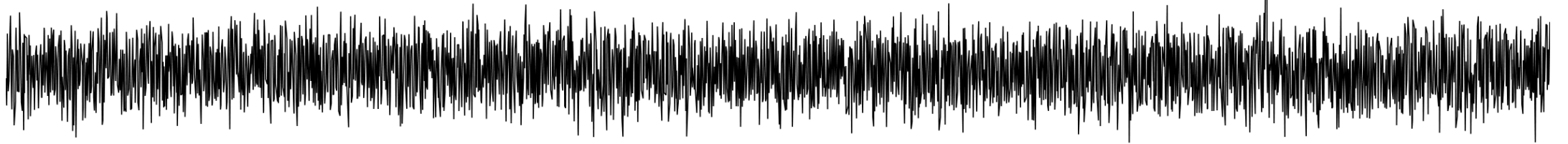

$\begin{array}{lllllllllllllllllllllllllllllllllllllllllllllllllllllll}29 & 28 & 27 & 26 & 25 & 24 & 23 & 22 & 21 & 20 & 19 & 18 & 17 & 16 & 15 & 14 & 13 & 12 & 11 & 10 & 9 & 8 & 7 & 6 & 5 & 4 & 3 & 2 & 1 & 0 & -1 & -2 & -3 & -4 & -5 & -6 & -7 & -8 & -9 & -1\end{array}$ 
Nucleus: $1 \mathrm{H}$

Frequency: $700.41 \mathrm{MHz}$
Solvent: $\mathrm{D} 2 \mathrm{O}$
Temperature: $298.0 \mathrm{~K}$

Frequency: $700.41 \mathrm{MHz}$
Solvent: D2O
Temperature: $298.0 \mathrm{~K}$

Frequency: $700.41 \mathrm{MHz}$
Solvent: D2O
Temperature: $298.0 \mathrm{~K}$

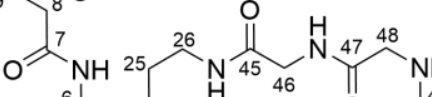

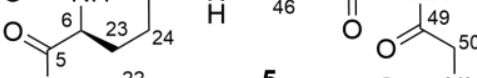

$\mathrm{HN}_{4} \ldots \mathrm{N}^{22}=\mathrm{O}^{\mathrm{O}} \mathrm{Y}_{51} \mathrm{NH}$

$\mathrm{O}_{\mathrm{H}} \mathrm{N}^{2}$

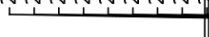

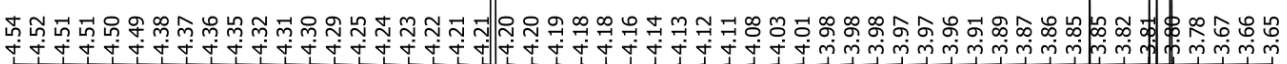

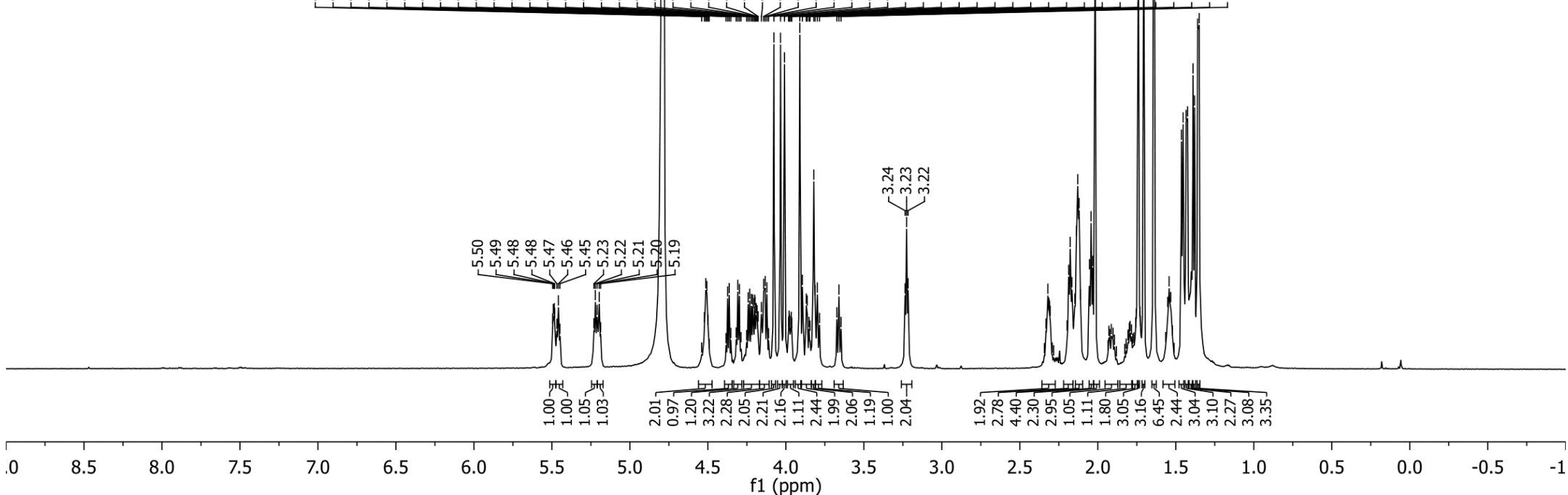



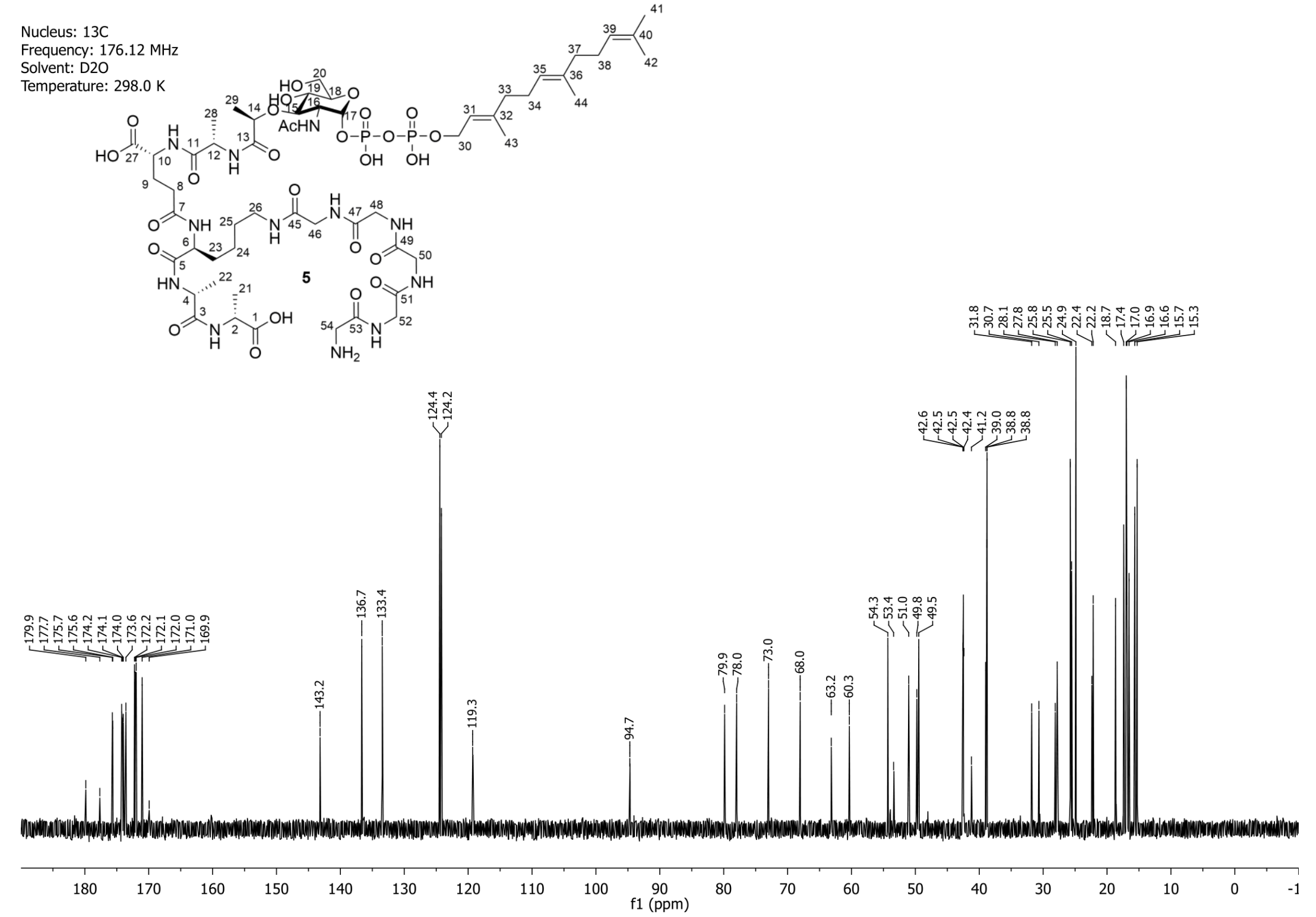


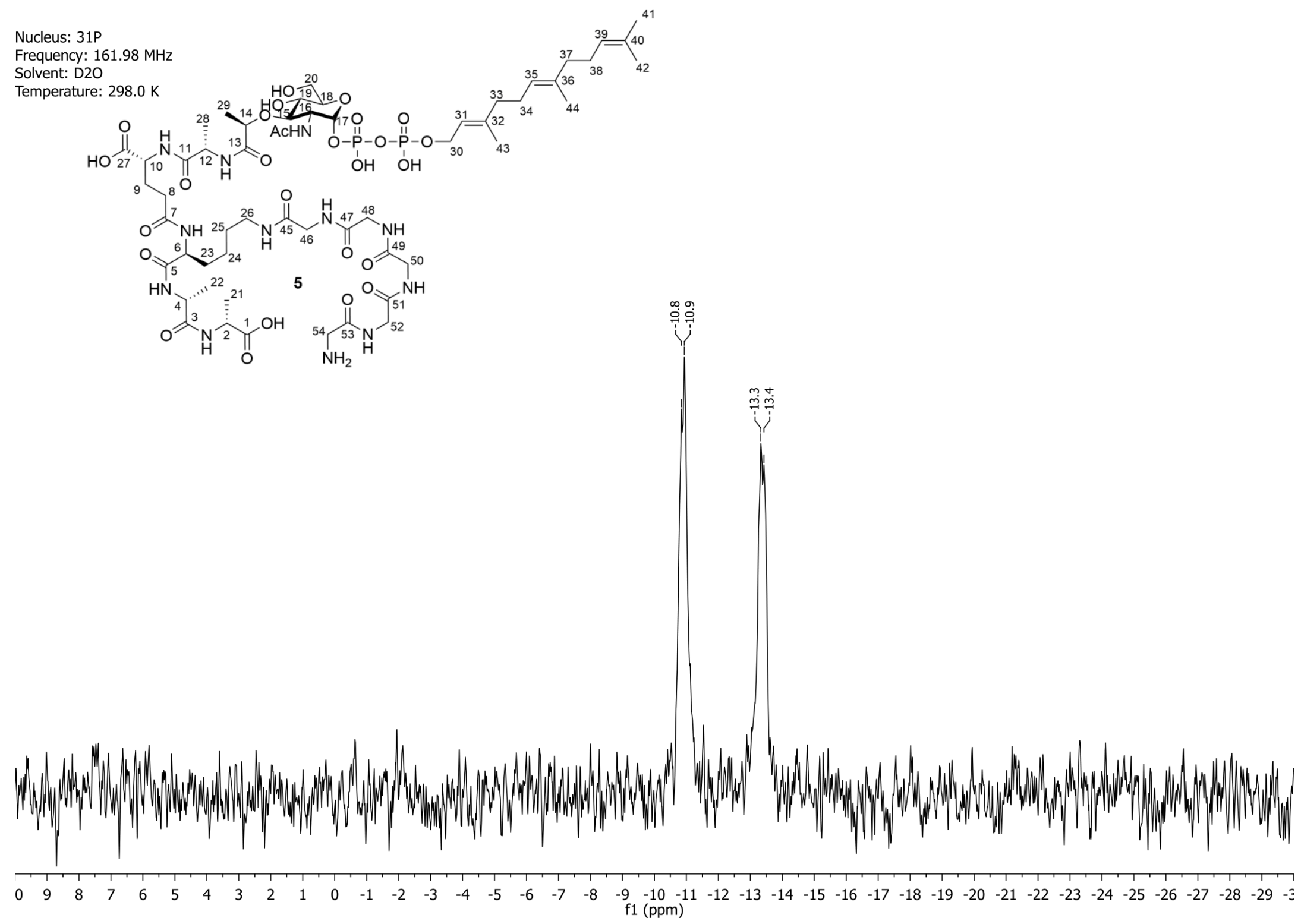




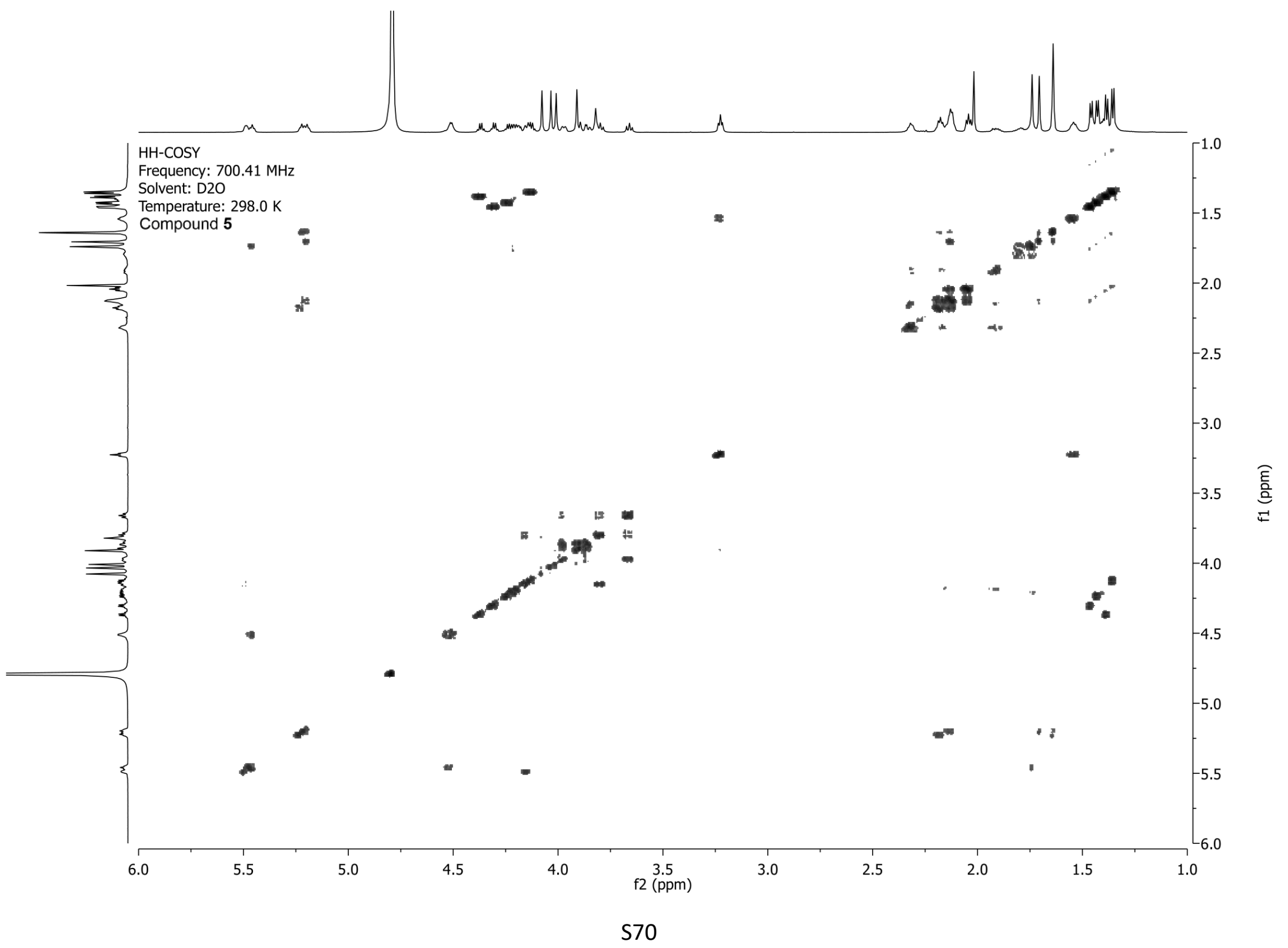




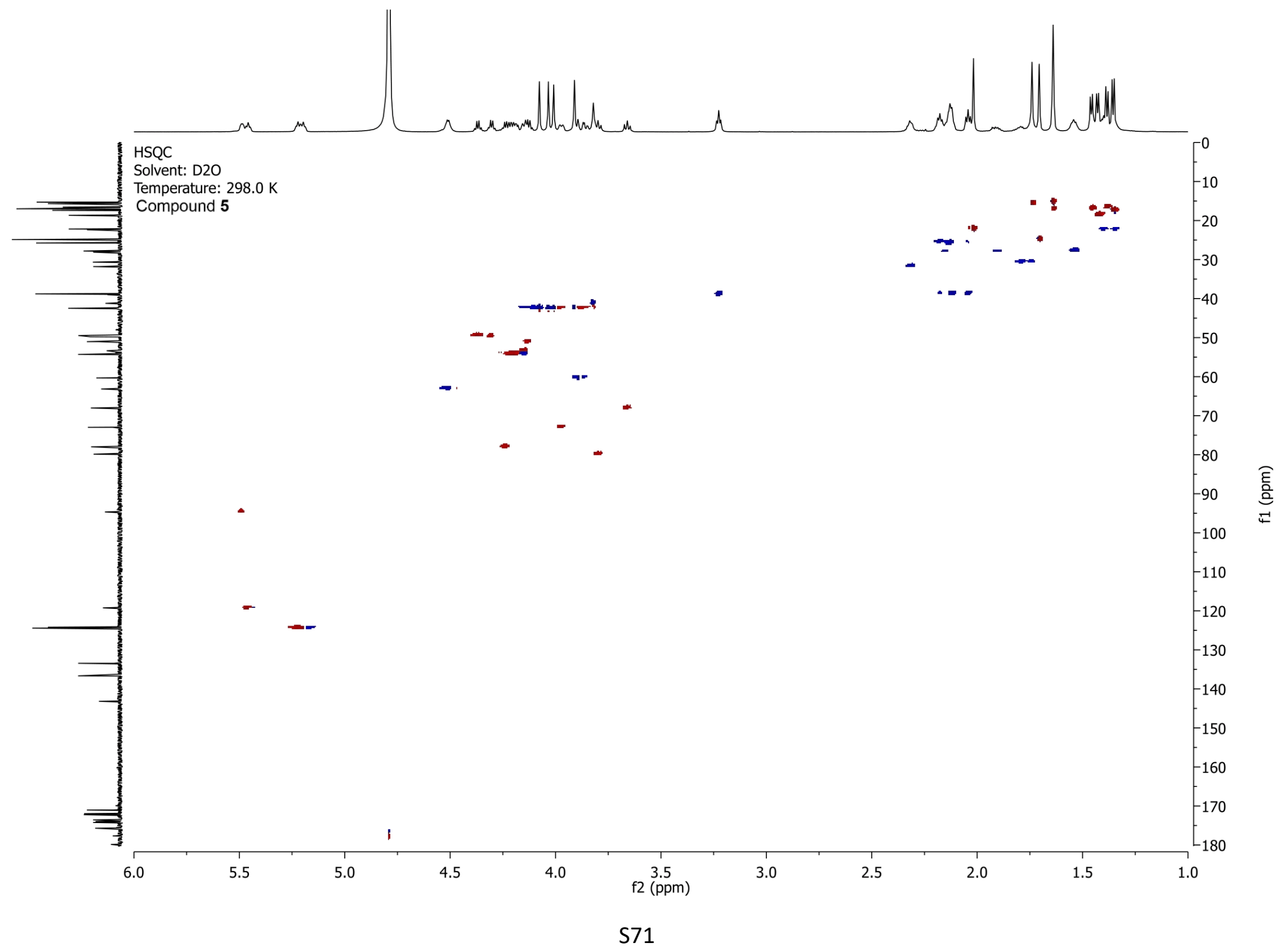




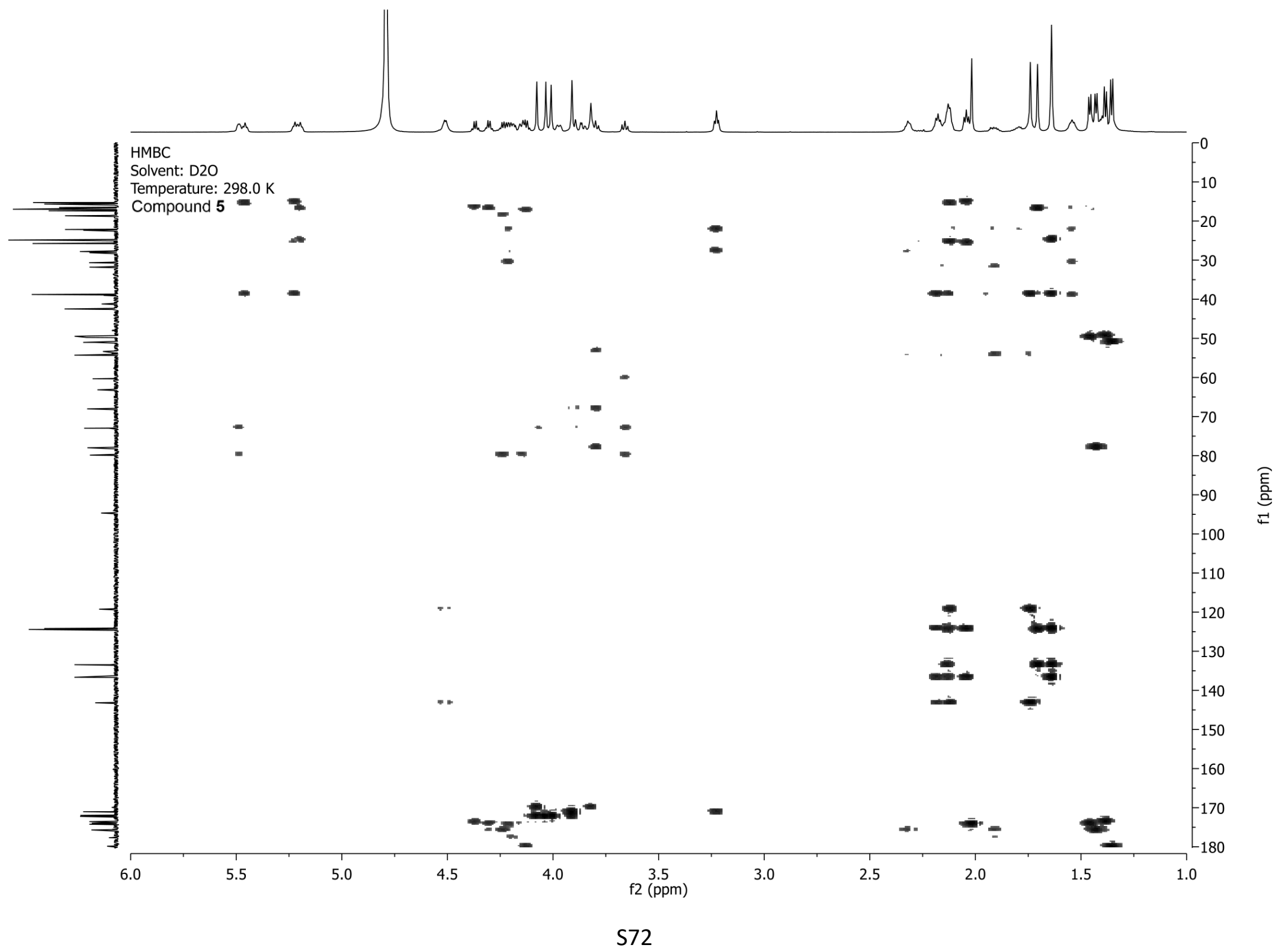




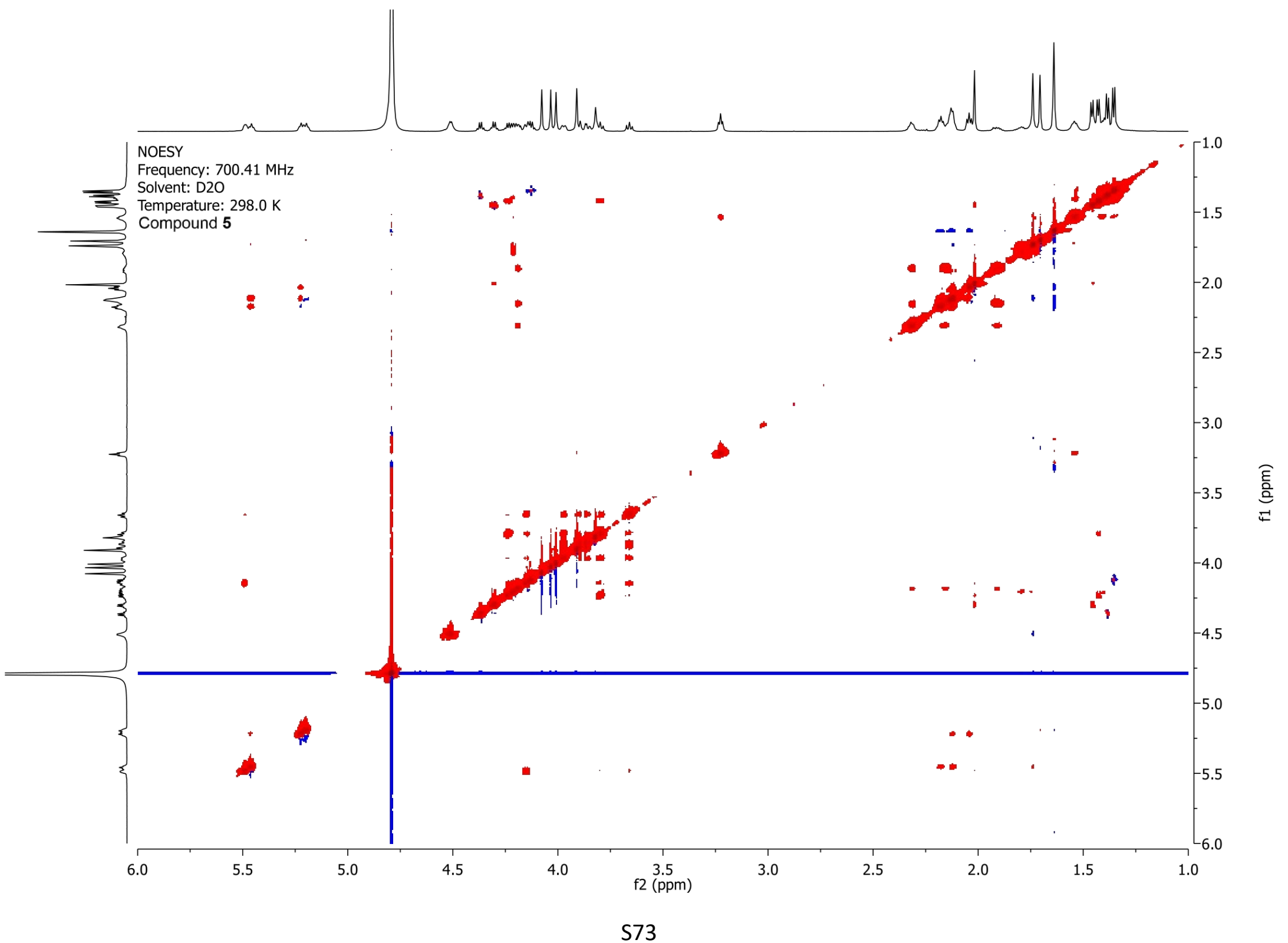




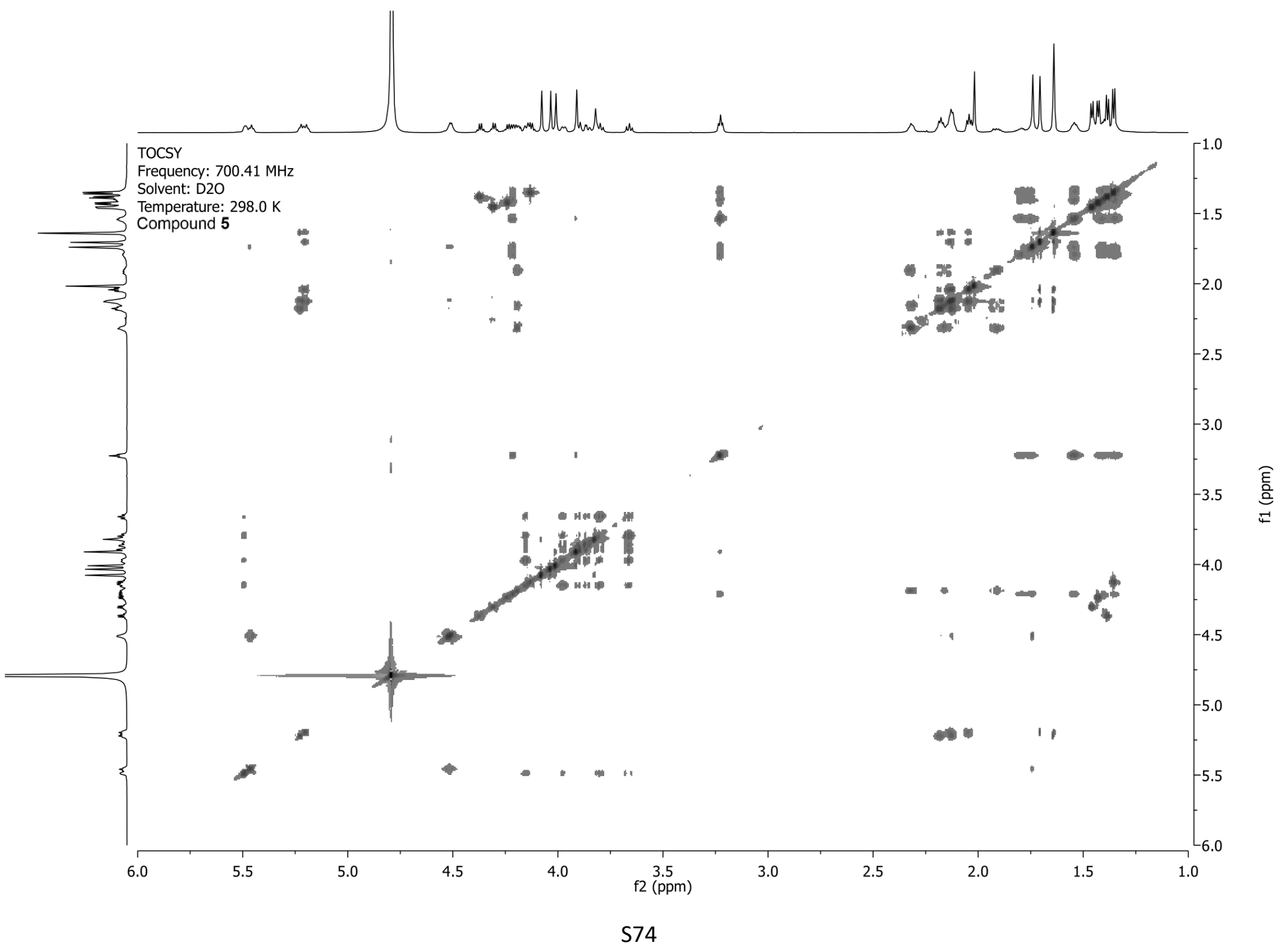


